Environmental Quality Technology Research and Development Program

\title{
Documentation of a One-Dimensional, Time- Varying Contaminant Transport and Fate Model for Streams
}

Scott Fant and Mark S. Dortch

January 2007 


\title{
Documentation of a One-Dimensional, Time- Varying Contaminant Transport and Fate Model for Streams
}

\author{
Scott Fant \\ SpecPro, Inc. \\ 122 Apache Court \\ Clinton, MS 39056-3149 \\ Mark S. Dortch \\ Environmental Laboratory \\ U.S. Army Engineer Research and Development Center \\ 3909 Halls Ferry Road \\ Vicksburg, MS 39180-6199
}

Final report

Approved for public release; distribution is unlimited.

Prepared for U.S. Army Corps of Engineers

Washington, DC 20314-1000 


\begin{abstract}
The Contaminant Model for Streams (CMS) was developed for studies where data and resources for model application are limited. CMS can be relatively easily and quickly applied, yet it is a versatile model that can be used for a variety of conditions ranging from short-term spill modeling to multi-year simulations of contaminant fate in stream water and bottom sediments. CMS was developed to fill a gap in the Adaptive Risk Assessment Modeling System (ARAMS). Before the addition of CMS, ARAMS did not have a one-dimensional contaminant transport and fate model for streams that could simulate interactions between the water column and sediment bed.
\end{abstract}

CMS was developed such that it can be applied within the ARAMS framework and also can be run as a stand-alone application outside of ARAMS. The model can be used to simulate a wide range of conditions from spill simulations with time steps in seconds to long-term simulations with time steps of about a year. A variable time step is used with user options. It can be applied for both organic and inorganic contaminants, and the available fate and transport processes include advection and diffusion along the stream reach, settling, resuspension, burial, volatilization, decay or degradation, and diffusion between the water column and the sediment pore water. Suspended solids can be transported or a steady-state concentration may be input. However, the ARAMS version does not currently include solids transport. Steady-state, uniform hydraulic conditions are assumed within the modeled reach. Time-varying upstream loadings and flows can be applied, but flows are updated instantaneously throughout the reach, i.e., there is no hydraulic routing feature, thus greatly reducing model complexity.

The model user interface provides an easy-to-use method for quickly setting up the model and examining results. The interface also allows the user to select the methods and parameters used for the numerical solutions. The solution methods were selected to result in very short computer execution time for most applications. The model was verified against results from two other models developed by ERDC, RECOVERY, and PREWet, the latter of which uses an analytical solution method. This report describes the model and its verification.

DISCLAIMER: The contents of this report are not to be used for advertising, publication, or promotional purposes. Citation of trade names does not constitute an official endorsement or approval of the use of such commercial products. All product names and trademarks cited are the property of their respective owners. The findings of this report are not to be construed as an official Department of the Army position unless so designated by other authorized documents.

DESTROY THIS REPORT WHEN NO LONGER NEEDED. DO NOT RETURN IT TO THE ORIGINATOR. 


\section{Contents}

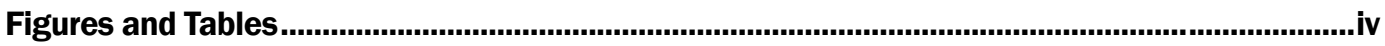

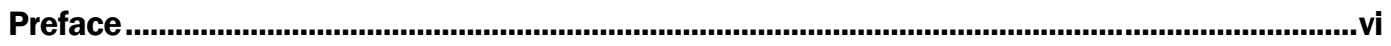

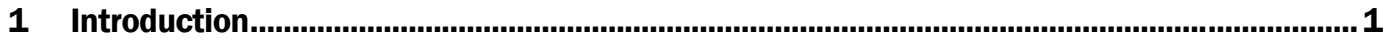

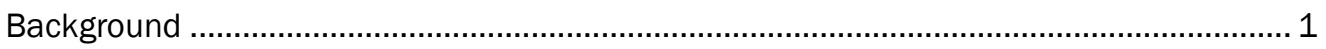

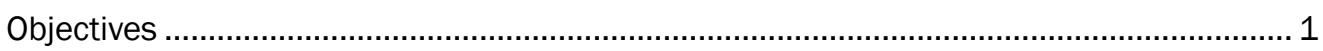

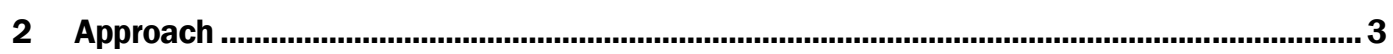

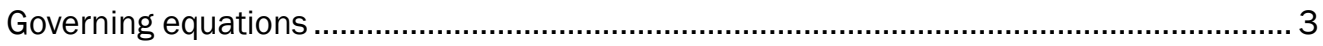

Water column contaminants ............................................................................................. 3

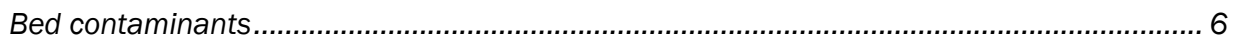

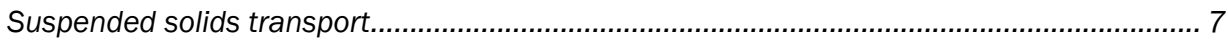

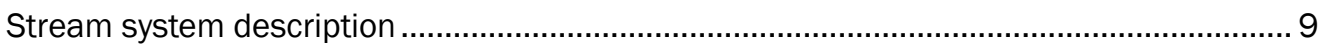

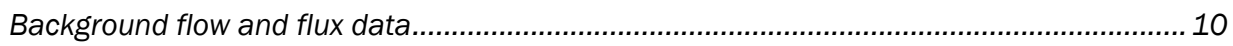

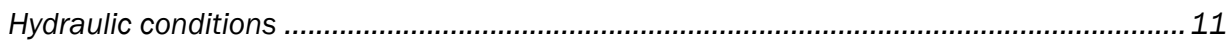

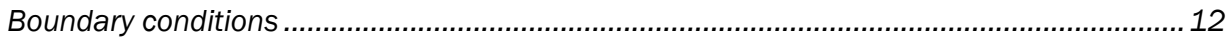

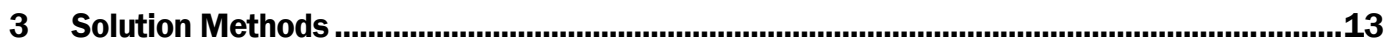

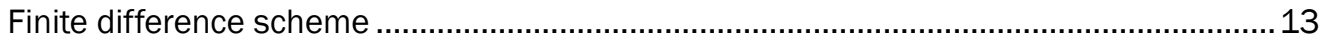

Ordinary differential equation solution ......................................................................... 17

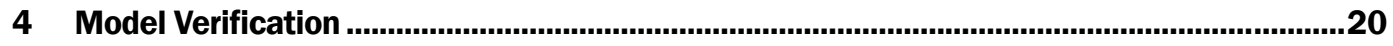

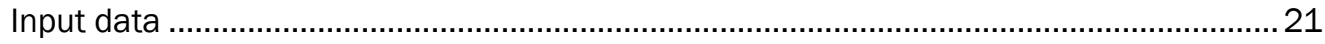

Chemical specific inputs..........................................................................................21

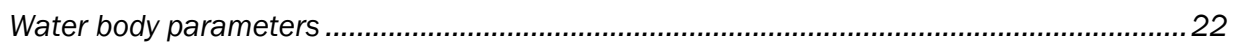

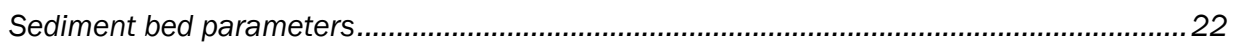

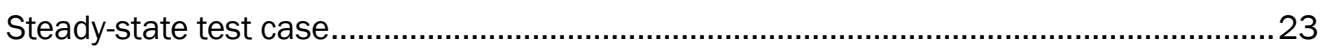

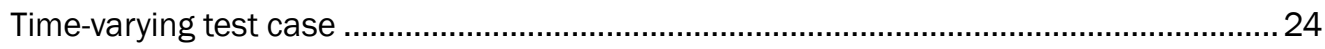

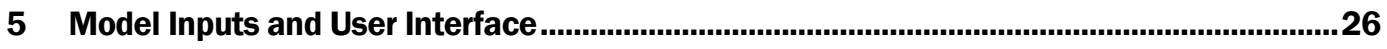

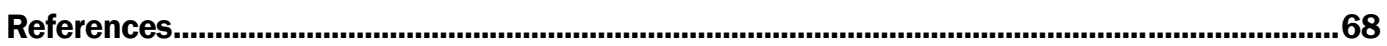

Appendix A: Calculation of Volatilization Rate ..................................................................

Appendix B: Calculation of Mass Transfer Rate for Sediment-Water Interface ........................73

\section{Report Documentation Page}




\section{Figures and Tables}

\section{Figures}

Figure 1. Sediment bed and water interactions for solids. ......................................................... 8

Figure 2. Flows and concentrations entering the reach......................................................... 10

Figure 3. Boundary condition assumptions for the model reach. ................................................... 12

Figure 4. Computational molecule or stencil for the Crank-Nicolson method using a centered difference approximation for the advective term.................................................................. 13

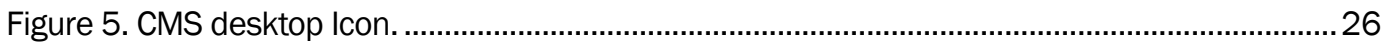

Figure 6. CMS Start Menu Item............................................................................................ 26

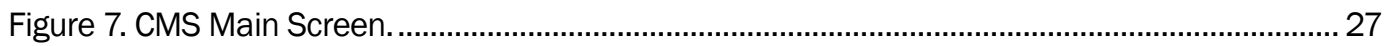

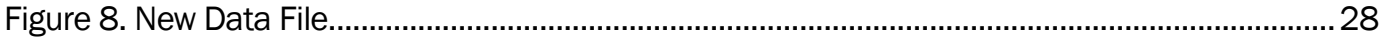

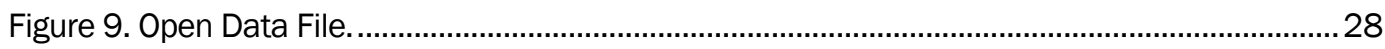

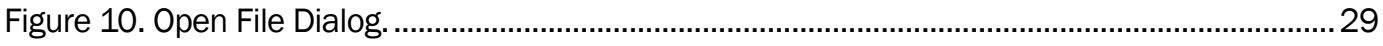

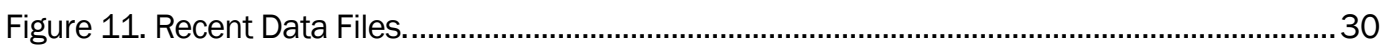

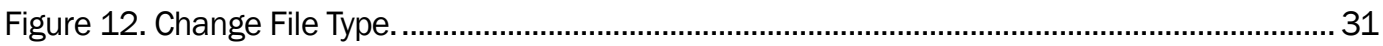

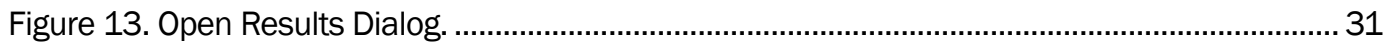

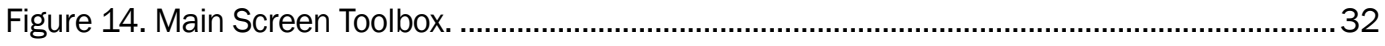

Figure 15. Model Parameters Screen. ....................................................................................... 33

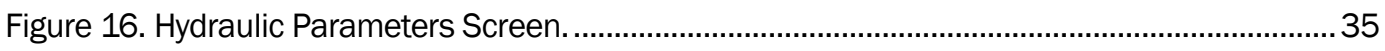

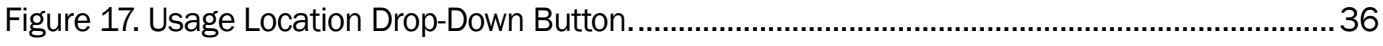

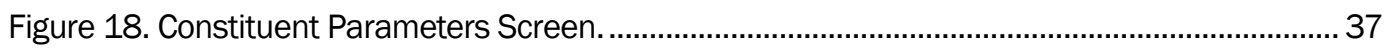

Figure 19. Constituent Drop-Down Button........................................................................................38

Figure 20. Sedimentation Parameters Screen............................................................................ 40

Figure 21. Sedimentation Parameters Grid Context Menu........................................................ 42

Figure 22. Sedimentation Parameters Screen with Steady-State Solids Balance. ........................... 43

Figure 23. Loading Data Screen (Water Flow Grid).................................................................. 44

Figure 24. Loading Data Screen (Suspended Solids Concentration Grid)...................................... 45

Figure 25. Loading Data Screen (Constituent Flux Grid)............................................................. 46

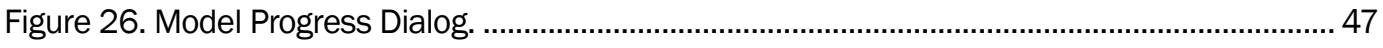

Figure 27. Execution Options Dialog........................................................................................ 48

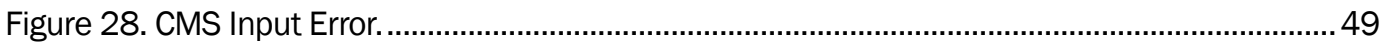

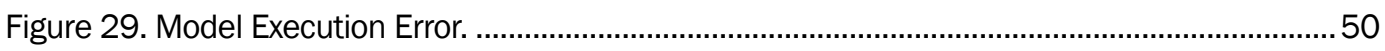

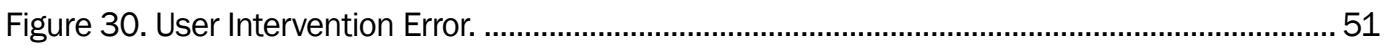

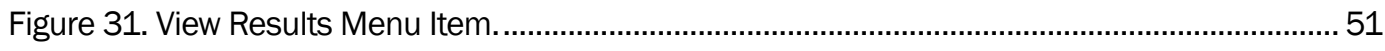

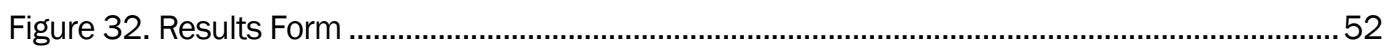

Figure 33. Plot Dialog for a Single Distance. ............................................................................... 54

Figure 34. Plot Dialog for Multiple Distance Values.......................................................................55 


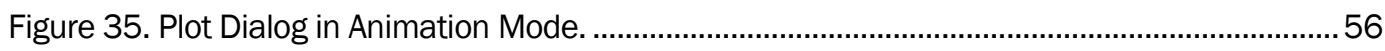

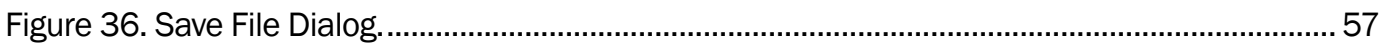

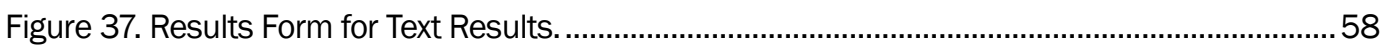

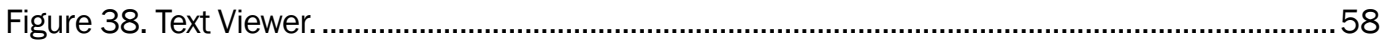

Figure 39. Reference Number Indicator............................................................................. 59

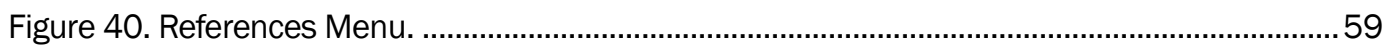

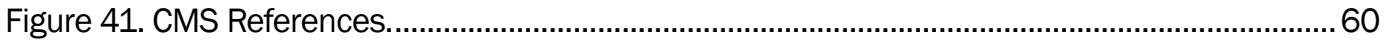

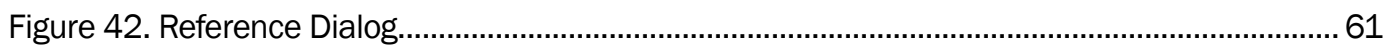

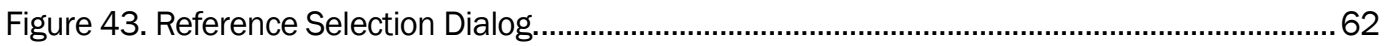

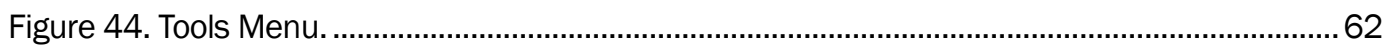

Figure 45. Default Numerical Solution Settings Dialog................................................................ 63

Figure 46. Project Numerical Solution Settings Dialog...................................................................6

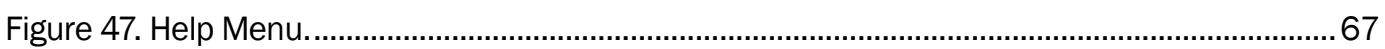

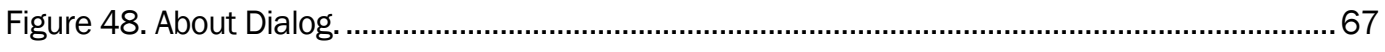

Figure A-1. Representation of Whitman's two-film theory of gas transfer. .......................................70

\section{Tables}

Table 1. Steady-state test results.. 23

Table 2. Steady-state solutions for RECOVERY and PREWet using modified suspended solids concentration of $135 \mathrm{mg} / \mathrm{L}$............................................................................................. 24

Table 3. Constituent inflow concentrations for step function test case............................................. 24

Table 4. Final results for RECOVERY and CMS models for the step function test case. ....................25 


\section{Preface}

This report documents a one-dimensional, time-varying contaminant transport and fate model for streams, referred to as the Contaminant Model for Streams (CMS). CMS was developed by Scott Fant of SpecPro, Inc., and Dr. Mark Dortch of the Water Quality and Contaminant Modeling Branch (WQCMB), Environmental Processes and Engineering Division (EPED), Environmental Laboratory (EL), U.S. Army Engineer Research and Development Center (ERDC). This report was prepared by Fant and Dr. Dortch.

This work was conducted as part of the Hazard/Risk Focus area of the U.S. Army Environmental Quality Technology (EQT) Research and Development Program. Dr. John Cullinane is the EQT Program Manager. This work was conducted under the general supervision of Dr. Barry Bunch, Chief, WQCMB, and Dr. Richard E. Price, Chief, EPED.

Dr. Michael Passmore was Acting Director, EL, and Dr. Elizabeth Fleming, was Director, EL.

COL Richard B. Jenkins was Commander and Executive Director of ERDC. Dr. James R. Houston was Director. 


\section{Introduction}

\section{Background}

Although there are many water quality models for streams, there was not a versatile, yet easy-to-use, model for contaminant transport and fate in streams prior to the development of the Contaminant Model for Streams (CMS). Such a model was needed for studies involving health risk assessment, which are often characterized by limited data and time to produce results. An easy-to-use, yet flexible, model was needed for predicting short- and long-term concentrations of contaminants in the water column and bottom sediments.

The Adaptive Risk Assessment Modeling System (ARAMS) (http://el.erdc.usace army.mil/arams/) was developed for the Army by ERDC and the U.S. Army Center for Health Promotion and Preventive Medicine (USACHPPM) to provide a reliable platform for conducting human and ecological health risk assessment. ARAMS integrates multimedia fate/transport and multipathway exposure and uptake with effects assessment to characterize risk. Although many models are available in ARAMS for fate/transport in water, there were not any models for predicting fate of contaminants in streams with sediment interactions. There are many riverine water quality models available that were considered for use in ARAMS, however, none of these models met the requirements without introducing excessive complexity.

\section{Objectives}

The overall objective of this study was to develop a flexible, but easy-touse, one-dimensional (1-D), numerical contaminant model for streams and rivers. Other objectives were:

- to be able to predict time-varying contaminant concentrations in the water column and sediment bed and include the effects of sediment processes and interactions;

- to be able to simulate short-term spill concentrations, as well as longterm fate; 
- to provide some degree of freedom over the numerical solution settings, but still be easy to set up and run and quickly provide useful results; and

- to provide a user interface to facilitate ease of use for model setup and quickly viewing results.

- The report presents the theoretical basis for the model, the model verification results, and a description of model inputs. 


\section{Approach}

The fundamental law utilized in the development of the CMS is conservation of mass along the longitudinal axis (flow direction) of a surface water body, such as streams and rivers. The stream surface water is represented by a $1 \mathrm{D}$ (longitudinal) discretization for mass balance, where mass concentrations are assumed to be uniform across the width and depth of the stream. Constituent mass balance is performed for the water column and sediment bed. The bed is treated as a single active layer. The bed layer for each longitudinal segment is independent of other longitudinal bed segments, i.e., there is no longitudinal transport or transfer within the bed. Each bed layer interacts with only the water column immediately above the bed segment. Numerical solution schemes are used to provide flexibility for simulating variable inputs and a variety of processes.

\section{Governing equations}

There are 3 unknowns: contaminant concentration in the water column and in the bed and suspended solids concentration, if the solids transport option is chosen. For contaminants, the 2 unknowns require 2 equations, a mass balance equation for the water column and for the bed. For suspended solids, a mass balance equation for the water column is required. Each of these equations is presented along with assumptions and supporting equations.

\section{Water column contaminants}

The dependent, state variable for contaminants in the water column is concentration of total chemical mass (dissolved and particulate) on a total water volume basis. The governing equation becomes

$$
\begin{aligned}
\frac{\partial c_{w}}{\partial t}+U \frac{\partial c_{w}}{\partial x} & =D_{x} \frac{\partial^{2} c_{w}}{\partial x^{2}}-\left(k_{d w}+\frac{k_{v}}{H}\right) F_{d w} c_{w}-k_{p w} F_{p w} c_{w} \\
& -\frac{V_{s}}{H} F_{p w} c_{w}+\frac{V_{r}}{H} c_{b}-\frac{V_{d}}{H}\left(F_{d w} c_{w}-F_{d b} c_{b}\right)
\end{aligned}
$$


where

$$
\begin{aligned}
U= & \text { mean velocity }(\mathrm{L} / \mathrm{T}) \\
D_{x}= & \text { longitudinal diffusion coefficient }\left(\mathrm{L}^{2} / \mathrm{T}\right) \\
k_{v}= & \text { volatilization rate of the constituent }(\mathrm{L} / \mathrm{T}) \\
\mathrm{x}= & \text { downstream distance }(\mathrm{L}) \\
c_{b}= & \text { concentration of the constituent in the sediment bed }\left(\mathrm{M} / \mathrm{L}^{3}\right), \\
& \text { total mass on a total volume basis } \\
k_{d w}= & \text { decay rate of dissolved constituent in the water column }\left(\mathrm{T}^{-1}\right) \\
k_{p w}= & \text { decay rate of particulate constituent in the water column }\left(\mathrm{T}^{-1}\right) \\
V_{d}= & \text { mass transfer rate across the sediment-water interface } \\
& \text { resulting from diffusion of the dissolved constituent }(\mathrm{L} / \mathrm{T}) \\
V_{s}= & \text { suspended solids settling rate }(\mathrm{L} / \mathrm{T}) \\
H= & \text { hydraulic depth of the stream }(\mathrm{L}) \\
F_{d b}= & \text { fraction of the constituent dissolved in the sediment bed pore } \\
& \text { water } \\
F_{p w}= & \text { fraction of the constituent dissolved in sediment pore water } \\
& \text { (M/L3) } \\
F_{d w}= & \text { fraction of the constituent dissolved in the water column } \\
C_{w}= & \text { concentration of the constituent in the water column }(\mathrm{M} / \mathrm{L} 3), \\
& \text { total mass on a total volume basis } \\
V_{r}= & \text { active sediment layer resuspension rate }(\mathrm{L} / \mathrm{T}) .
\end{aligned}
$$

Equation 1 assumes reversible, equilibrium partitioning between sediment solids and water. In addition to the 1-D assumption, uniform velocity and dispersion is assumed along the modeled stream reach.

The processes included in the water column mass balance for contaminants are advection, diffusion, settling of particulate mass, resuspension of sediment bed mass, dissolved mass transfer across the sediment-water interface, degradation/decay, and volatilization. The mass transfer across the sediment-water interface is actually a diffusive flow that is dependent upon the concentration gradient of the dissolved mass between the water column and the sediment bed. The volatilization rate is multiplied by the fraction dissolved in the water column because only this fraction is assumed to volatilize. The resuspension velocity is not multiplied by either the fraction dissolved or fraction particulate because both phases are assumed to be introduced into the water column during resuspension. However, settling involves only the particulate fraction that is in the water column. 
The terms for the fraction dissolved and fraction particulate in both the water column and sediment bed were derived using the water column and sediment bed distribution coefficients for reversible, linear, equilibrium partitioning between dissolved and sorbed phases and are shown in equations $2-5$ below.

$$
\begin{gathered}
F_{d w}=\frac{1}{1+K_{d w} S} \\
F_{p w}=\frac{K_{d w} S}{1+K_{d w} S} \\
F_{d b}=\frac{1}{\phi+K_{d s}(1-\phi) \rho_{s}} \\
F_{p b}=\frac{K_{d s}(1-\phi) \rho_{s}}{\phi+K_{d s}(1-\phi) \rho_{s}}
\end{gathered}
$$

where

$$
\begin{aligned}
K_{d w}= & \text { distribution coefficient for the constituent in the water column } \\
& (\mathrm{L} / \mathrm{g}) \\
S= & \text { solids concentration }\left(\mathrm{M} / \mathrm{L}^{3}\right) \\
\phi= & \text { porosity of bed sediments } \\
\rho_{s}= & \text { dry sediment density }(\mathrm{M} / \mathrm{L} 3) \\
K_{d s}= & \text { distribution coefficient for the constituent in the sediment bed } \\
& (\mathrm{L} / \mathrm{g}) .
\end{aligned}
$$

The last fraction, $F_{p b}$, is the fraction of constituent in particulate form on a total volume basis in the bed and is used for the bed mass balance equation.

Options are built into the model to either input the volatilization rate or calculation of it based upon Henry's Law and Whitman's two-film theory (Chapra 1997) as modified for the influence of water flow and wind as described in Appendix A. Mass transfer rate of dissolved constituents across the sediment-water interface is calculated based upon flow conditions, molecular diffusivity, and other factors as described in Appendix B. Calculation of $V_{s}$ and $V_{r}$ is discussed in the section on suspended solids 
transport. Other independent variables in Equation 1 are input by the user as discussed in Chapter 5 .

The terms in Equation 1 can be grouped to form a simplified version of the advection/diffusion/reaction equation:

$$
\frac{\partial c_{w}}{\partial t}=-U \frac{\partial c_{w}}{\partial x}+D_{x} \frac{\partial^{2} c_{w}}{\partial x^{2}}-k c_{w}+q
$$

where

$$
\begin{gathered}
k=\left(k_{d w}+\frac{k_{v}}{H}+\frac{V_{d}}{H}\right) F_{d w}+\left(k_{p w}+\frac{V_{s}}{H}\right) F_{p w} \\
q=\frac{V_{r}}{H} C_{b}+\frac{V_{d}}{H} F_{d b} c_{b} .
\end{gathered}
$$

The term $k$ includes all of the loss terms for the constituent in the water column that depend on the water column concentration. Since the terms for resuspension and mass transfer from the sediment bed do not involve the water column concentration, they are grouped together and treated as a source term, $q$.

\section{Bed contaminants}

The mass balance for total (dissolved and particulate) contaminant mass in the sediment bed for each stream segment is stated as

$$
\begin{aligned}
\frac{d c_{b}}{d t}= & -\left(k_{d b} F_{d b}+k_{p b} F_{p b}\right) c_{b}+\frac{V_{d}}{h}\left(F_{d w} c_{w}-F_{d b} c_{b}\right) \\
& -\frac{V_{r}}{h} c_{b}+\frac{V_{s}}{h} F_{p w} c_{w}-\frac{V_{b}}{h} c_{b}
\end{aligned}
$$

where

$k_{d b}=$ decay rate of dissolved constituent in bed pore water $\left(\mathrm{T}^{-1}\right)$

$k_{p b}=$ decay rate of particulate constituent in the bed $\left(\mathrm{T}^{-1}\right)$

$V_{b}=$ active sediment layer burial rate $(\mathrm{L} / \mathrm{T})$

$h=$ active sediment layer thickness (L). 
Equation 9 includes the following processes for the bed: decay or degradation, mass transfer of dissolved constituents across the sediment-water interface, resuspension to the water column, settling of particulate constituents from the water column, and burial to lower sediment layers. Longitudinal exchange between adjacent bed segments, such as pore water flow or diffusion along the stream flow axis, is assumed to be negligible.

\section{Suspended solids transport}

If suspended solids in the water column are transported, then they are treated similar to a contaminant constituent that does not decay or volatilize. The solids are advected and dispersed along the length of the stream reach in the same manner as the constituents but do not have all of the same loss mechanisms. The only loss mechanism for suspended solids in the water column is settling. In the same manner there will be an influx of solids to the water column from any sediment resuspension that occurs. The suspended solids mass balance in the water column is stated as

$$
\frac{\partial S}{\partial t}+U \frac{\partial S}{\partial x}=D_{x} \frac{\partial^{2} S}{\partial x^{2}}-\frac{V_{s}}{H} S+\frac{V_{r}}{H} S_{b}
$$

where $S_{b}$ is the concentration of solids in the sediment bed (M/L3), which is the same as the sediment bulk density, $\rho_{b}=(1-\phi) \rho_{\mathrm{s}}$. The remaining variables are the same as those defined previously.

The CMS can also be run with a steady-state solids concentration. In this case, solids will not be modeled in the water column, and the background solids concentration will be held constant for the entire simulation period. This is the only option currently available in the ARAMS version of CMS.

The modeled suspended solids include both inorganic and organic solids. The approach taken here is generally applicable to both types. However, total suspended solids concentration is the state variable of interest since a total solids balance is necessary to perform analyses for other water quality constituents.

A single active sediment layer is modeled. The active bed layer is assumed to have constant properties, thus, the thickness, volume, porosity, bulk density, and solids mass are constant over time (i.e., steady-state) and assumed to be uniform over the stream reach. Solids and contaminant mass that is buried to deep sediments is assumed to be lost. Performing a 
steady-state solids balance for the bed layer results in the following relationship:

$$
V_{b}=\frac{V_{s} S}{S_{b}}-V_{r}
$$

where all variables have been previously defined. With the settling and resuspension rates specified, the burial rate, which is required for the bed contaminant mass balance (Equation 9), can be determined. Alternatively, any two of the three rates in Equation 11 could be specified and the unknown rate solved. The relationship of water column and bed solids and the three process rates are shown schematically in Figure 1. The three process rates of Equation 11 are applied throughout the modeled stream reach for the steady-state solids option.

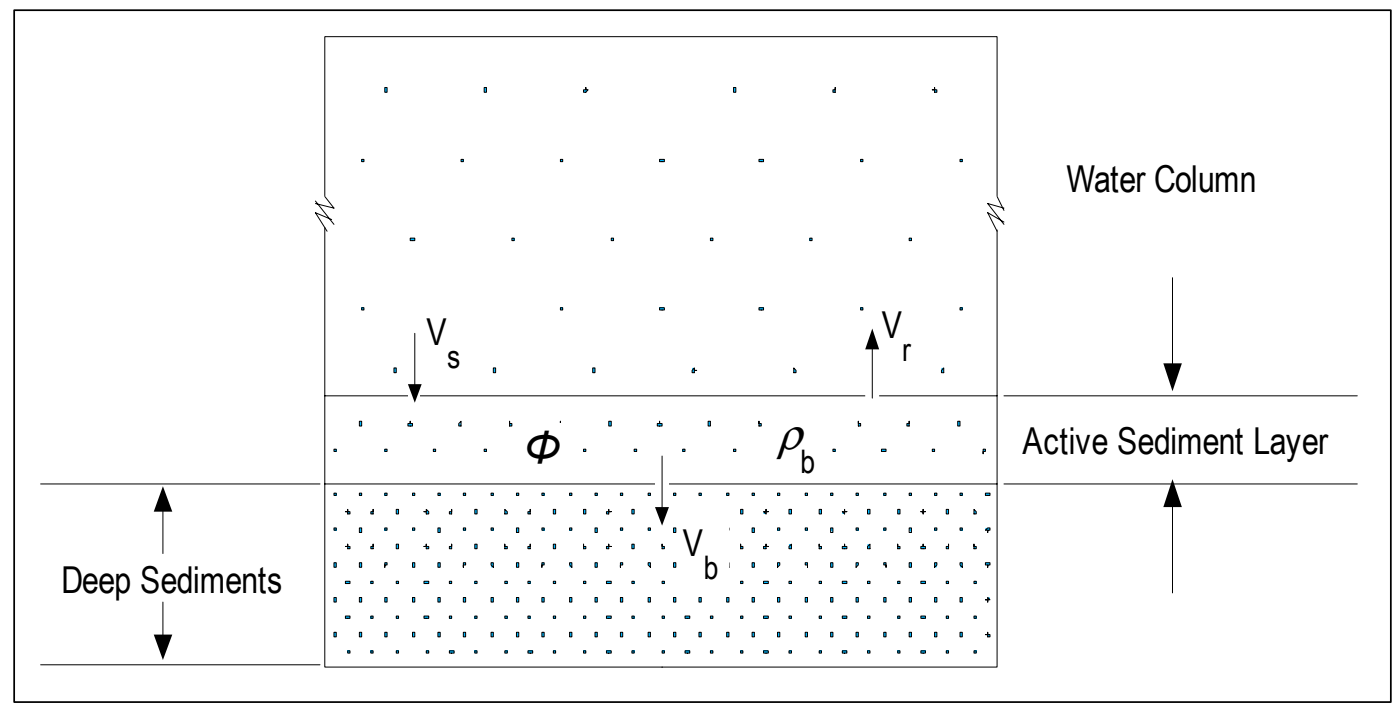

Figure 1. Sediment bed and water interactions for solids.

Settling rate can be determined based on particle size from Stokes law. The resuspension formula of Ariathurai, MacArthur, and Krone (1977) is used to estimate bed surface erosion rate

$$
E=P\left(\frac{\tau}{\tau_{c}}-1\right)
$$


where

$$
\begin{aligned}
E & =\text { rate of surface erosion, } \mathrm{g} / \mathrm{cm}^{2} / \mathrm{sec} \\
P & =\text { erosion rate constant, } \mathrm{g} / \mathrm{cm}^{2} / \mathrm{sec} \\
\tau & =\text { bottom shear stress, dynes } / \mathrm{cm}^{2} \\
\tau_{c} & =\text { critical shear stress, dynes } / \mathrm{cm}^{2} .
\end{aligned}
$$

The bottom shear stress must be larger than the critical shear stress for erosion to occur, otherwise, $E$ is o.o. Values for $P$ and $\tau_{c}$ must be input by the user, and values for $P$ typically range between $1.3 \mathrm{E}-5$ and $4.7 \mathrm{E}-5$. The critical shear stress can be determined from flume studies or modeling experience. The bottom shear stress can be computed from $\tau=\gamma H s$, where $\gamma$ is the specific weight of water (approximately 1.0 dyne $/ \mathrm{cm}^{3}$ ) and $s$ is the water surface slope, which is equal to the stream bed slope for steady, uniform flow. Although $P$ and $\tau_{c}$ are input as constant over time, the rate of erosion rate can change with time if the flow depth, $H$, changes as a result of flow changes.

The resuspension rate, $V_{r}(\mathrm{~cm} / \mathrm{sec})$, is computed from $V_{r}=E / \rho_{b}$, where $\rho_{b}$ has units of $\mathrm{g} / \mathrm{cm}^{3}$ here. It can be seen from Equation 11 that large values of $V_{r}$ can result in negative burial rates, which means the bed is scouring rather than depositing. When this occurs, it is assumed that deeper clean sediments below the modeled bed layer are entrained into the bed layer and mixed with the remaining contaminated sediments. Thus, the bed sediment mass remains fixed, but contaminant mass is lost to resuspension, and the bed contaminant concentration is diluted.

The stand-alone version of CMS has the option for computing resuspension rates based on flow conditions; however, for the ARAMS version 1.3, a steady-state solids balance is assumed (i.e., no suspended sediment transport). Thus, two of the three sedimentation rates are specified, and the third is solved from Equation 11. Only positive burial rates are allowed for the steady-state solids balance.

\section{Stream system description}

The stream system is a single reach with uniform hydraulic conditions, but this may be expanded in a future version to allow multiple reaches with different hydraulic conditions for each. For the modeled reach, multiple points of interest for output can be defined through user-entered usage 
locations. A usage location is a point at a given downstream distance from the farthest upstream node and may indicate a withdrawal point, a habitat for a species of interest, or any point where the constituent concentration is of interest. The associated distance must be specified for each usage location. The total length of the stream reach that will be modeled is the distance to the farthest usage location. A diagram of an example stream reach is shown in Figure 2.

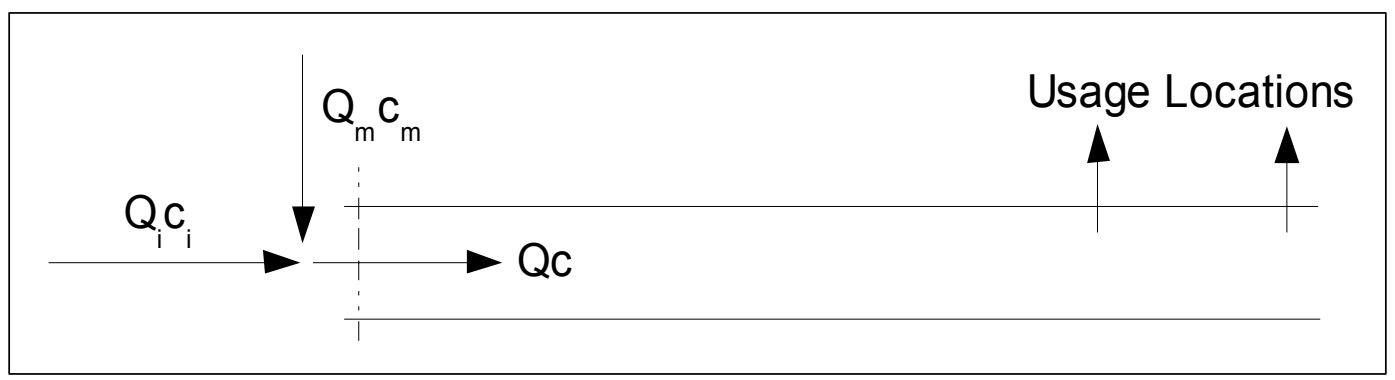

Figure 2. Flows and concentrations entering the reach. The subscript $i$ refers to initial background flows and concentrations, $m$ refers to the loading values, and the total flow rate and concentration entering the reach are denoted as $Q$ and $c$.

\section{Background flow and flux data}

A background flow rate, such as the mean annual flow rate, suspended solids concentration, and constituent concentrations can be specified for the reach being modeled. Background variables are denoted with subscript $i$ in Figure 2. In addition to the constant, steady-state background flow and loadings, time-varying flows and loads can also be specified at the upstream boundary. These variables have the subscript $m$ in Figure 2. Time-varying loading, or flux, data are entered for water, suspended solids, and all modeled contaminant constituents. These inputs may be specified at any time point after time zero, but values for all variables must be specified for time zero, except for suspended solids, which does not need to be entered if a steady-state solids balance is selected in the project settings. In this case, the background concentration is used as the steadystate concentration for the entire stream reach. The background and timevarying loading flows are added together, and a flow weighted balance is performed on the time-varying and background concentrations to set the upstream boundary flows and concentrations. 


\section{Hydraulic conditions}

The hydraulic conditions are not solved, but are specified. Flow conditions are assumed to be steady-state within each loading update interval and uniform over the modeled reach. Flows can change for each loading update interval as a result of changes in $Q_{m}$, but flow rate, depth, and flow area are assumed to change instantaneously over the entire reach, thus, there is no hydraulic or hydrologic routing nor any transient flow features.

Three options are provided for specifying hydraulic conditions:

1. specify stream width and depth as constants throughout the reach;

2. specify stream cross-sectional area and depth as a constant throughout the reach; and

3. calculate the stream cross-sectional area of flow and hydraulic depth as a function of flow in the reach.

The background flow for the stream reach is also specified as a constant. The third option, i.e., calculation of cross-sectional area and depth from flow, uses the following equations:

$$
\begin{aligned}
& A=a Q^{b} \\
& H=c A^{d}
\end{aligned}
$$

where $A$ is the cross-sectional area of flow, and $a, b, c$, and $d$ are functional coefficients. With $A, U$ can be calculated from $U=Q / A$. Most stream rating curves are in the form of $Q=f$ (stage). Thus, there may be some effort involved in generating the relationships described by Equations 13 and 14. Cross-section channel geometry can be used to generate a relationship for $A=f$ (stage) and coupled with the flow-stage relationship leads to development of an area-flow relationship (Equation 13). Also, stream top width $(W)$ is equal to the derivative of $A$ with respect to stage [dA/d (stage)], and $H=A / W$, thus, a relationship for $H$ as a function of area can be developed (Equation 14). It should be noted that computed resuspension rates will be constant over time unless the third hydraulic specification option above is selected. 


\section{Boundary conditions}

Dirichlet boundary conditions are used for the upstream boundary, thus allowing the user to specify concentrations or loading flux at the upstream boundary (Chapra 1997). The upstream boundary also uses a pipe condition where advective flow is allowed into the first segment, but diffusion is not allowed across the boundary so that mass will not move backward out of the system. The concentration entering the reach is the concentration determined using the flow weighted mass balance as mentioned above. The boundary condition at the end of the reach is an open boundary where both advection and diffusion are allowed across the boundary. A Neumann condition is used to specify the derivative of the concentration at the downstream boundary (Chapra 1997). The concentration gradient with respect to downstream distance across the boundary at segment $\mathrm{N}$ is assumed to be zero. Therefore, the downstream boundary concentration will be equal to the concentration of the last node, $\mathrm{N}$. These boundary conditions are illustrated in Figure 3.

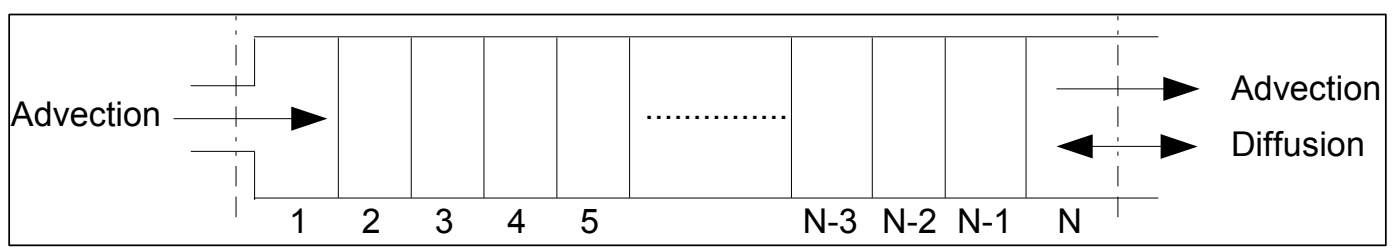

Figure 3. Boundary condition assumptions for the model reach.

The user may specify an upstream boundary concentration or flux at any time update interval. For time steps where a boundary value is not updated, the model will perform a linear interpolation between the previous and next boundary update to determine the value that should be used for each model time step. A boundary condition must be specified for time zero and, if no other concentrations are specified, that value will be used as a steady-state condition for every time step. 


\section{Solution Methods}

An implicit, finite difference, numerical solution scheme is used to solve the partial differential equations for surface water contaminant and suspended sediment concentrations (Equations 6 and 10). A choice between two numerical integration schemes is provided to solve the ordinary differential equation for sediment bed contaminant mass (Equation 9). The details of these solution methods are discussed below.

\section{Finite difference scheme}

A variation of the Crank-Nicolson (CR) method (Chapra 1997) was selected for the implicit, finite difference scheme. The CR scheme is a centered in time and centered-in-space approximation. This method is second-order accurate and is stable even for large time steps. The CR scheme reduces numerical dissipation by approximating the spatial derivatives at both the present and future time steps. These estimates are then averaged to obtain a spatial estimate that corresponds to the midpoint of the time step as illustrated in Figure 4 (Chapra 1997).

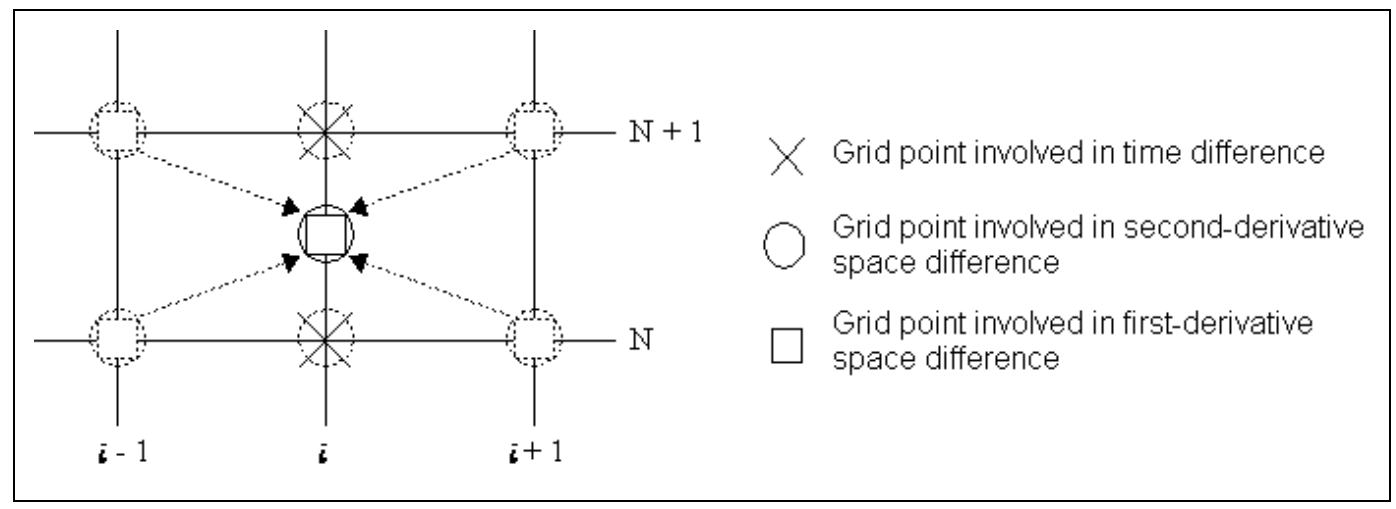

Figure 4. Computational molecule or stencil for the Crank-Nicolson method using a centered difference approximation for the advective term. The dashed lines are meant to show that the spatial derivative estimates at the present $(\mathrm{N})$ and future $(\mathrm{N}+1)$ times are averaged to obtain the estimate at the intermediate time $(\mathrm{N}+1 / 2)$.

The time weighting in the modified CR method is performed using a coefficient of implicity $(\theta)$ as shown below for the transport-reaction equation (Equation 6) where a central difference for advection is used: 


$$
\begin{aligned}
\frac{c_{i}^{n+1}-c_{i}^{n}}{\Delta t}= & -U\left[(1-\theta) \frac{c_{i+1}^{n}-c_{i-1}^{n}}{2 \Delta x}+\theta \frac{c_{i+1}^{n+1}-c_{i-1}^{n+1}}{2 \Delta x}\right] \\
& +D_{x}\left[(1-\theta) \frac{c_{i+1}^{n}-2 c_{i}^{n}+c_{i-1}^{n}}{(\Delta x)^{2}}+\theta \frac{c_{i+1}^{n+1}-2 c_{i}^{n+1}+c_{i-1}^{n+1}}{(\Delta x)^{2}}\right] \\
& -k\left[(1-\theta) c_{i}^{n}+\theta c_{i}^{n+1}\right]+q^{n}
\end{aligned}
$$

where

$$
\begin{aligned}
c= & \text { surface water concentration for contaminant constituent or } \\
& \text { suspended sediment } \\
\Delta t= & \text { time step } \\
\Delta x= & \text { spatial step size }(\mathrm{L}) \\
n= & \text { time level. }
\end{aligned}
$$

Other variables in Equation 15 were defined for Equations 1, 7, and 8. If $\theta$ is set to a value of $O . O$, the equation becomes fully explicit, and the only values included are from the current time step. If a value of 1.0 is used, the equation is fully implicit and only values from the future time step are included. The CR method is a special case where the coefficient of implicity is set to 0.5 to obtain an approximation that is centered in time as well as in space. This scheme is implemented such that the user can set the value for $\theta$.

Collecting terms and rearranging where all of the unknown terms (values at the future time step) are on the left-hand side, and all of the known terms (values at the current time step) are on the right-hand side yields

$$
\begin{aligned}
& -(\gamma+\lambda) \theta c_{i-1}^{n+1}+(1+2 \lambda \theta+k \Delta t \theta) c_{i}^{n+1}+(\gamma-\lambda) \theta c_{i+1}^{n+1} \\
& =(\gamma+\lambda)(1-\theta) c_{i-1}^{n}+(1-2 \lambda(1-\theta)-k \Delta t(1-\theta)) c_{i}^{n} \\
& +(\lambda-\gamma)(1-\theta) c_{i+1}^{n}+q \Delta t
\end{aligned}
$$


where

$$
\begin{gathered}
\lambda=\frac{D_{x} \Delta t}{(\Delta x)^{2}} \\
\gamma=\frac{U \Delta t}{2 \Delta x} .
\end{gathered}
$$

This results in one equation and three unknown values for $c$ at locations $i-1, i$, and $i+1$. However, by constructing a recursive relation for nodes 1 through $\mathrm{N}$, a matrix can be set up for $\mathrm{N}$ equations with $\mathrm{N}$ unknowns as shown in Equation 19 below, thus requiring an iterative and simultaneous solution.

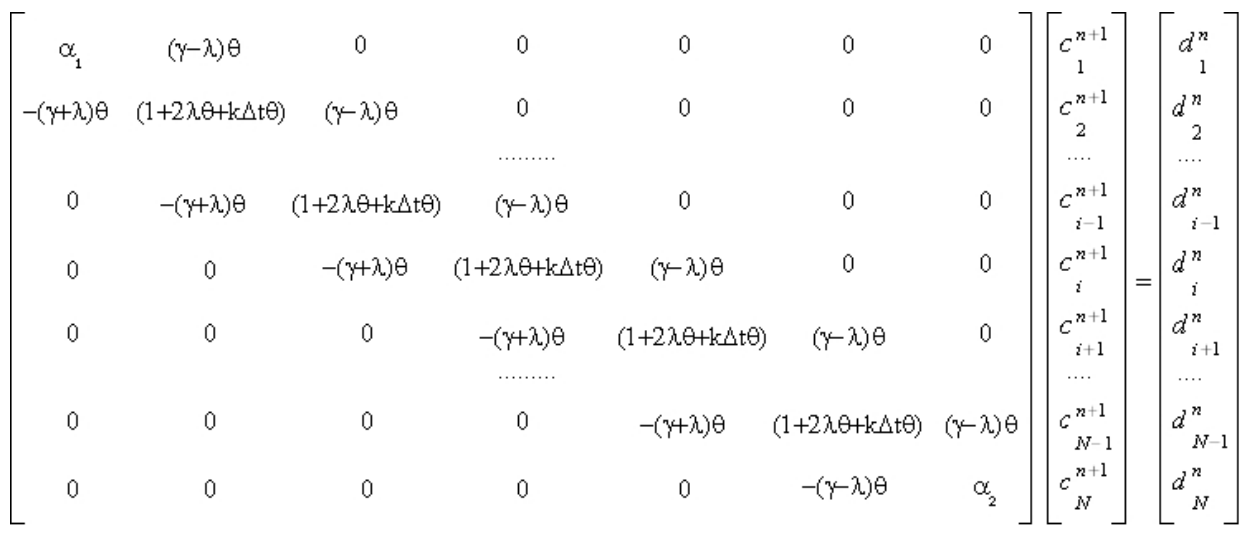

where $d_{i}^{n}$ is the right side of Equation 16. This is defined as follows for the internal segments:

$$
\begin{aligned}
d_{i}^{n}= & (\gamma+\lambda)(1-\theta) c_{i-1}^{n}+(1-2 \lambda(1-\theta)-k \Delta t(1-\theta)) c_{i}^{n} \\
& +(\lambda-\gamma)(1-\theta) c_{i+1}^{n}+q \Delta t .
\end{aligned}
$$

The values of $\alpha_{1}, \alpha_{2}, d_{1}^{n}$, and $d_{N}^{n}$ depend on the numerical solution scheme that is used and the previously discussed boundary conditions that are imposed at the upstream and downstream boundaries. For the secondorder solution method given above, these values are given as

$$
\alpha_{1}=1+\gamma \theta+\lambda \theta+k \Delta t \theta
$$




$$
\begin{gathered}
\alpha_{2}=1+\gamma \theta-\lambda \theta+k \Delta t \theta \\
d_{1}^{n}=(1-\gamma(1-\theta)-\lambda(1-\theta)-k \Delta t(1-\theta)) c_{1}^{n} \\
+(\lambda-\gamma)(1-\theta) c_{2}^{n}+2 \gamma c_{b}^{n}+q \Delta t \\
d_{N}^{n}=(\gamma-\lambda)(1-\theta) c_{N-1}^{n} \\
+(1+\lambda(1-\theta)-\gamma(1-\theta)-k \Delta t(1-\theta)) c_{N}^{n}+q \Delta t
\end{gathered}
$$

where

$$
c_{b}=\text { concentration at the upstream boundary. }
$$

Equation 19 is an $\boldsymbol{N} \boldsymbol{x} \boldsymbol{N}$ tridiagonal matrix, which has zero values in all positions except for the diagonal, sub-diagonal, and super-diagonal. A tridiagonal matrix can be easily solved using a form of Gaussian elimination commonly referred to in engineering disciplines as the "Thomas Algorithm."

Upwind differencing for the advection was added as an additional option. The coefficient of implicity was used to apply the same time weighting as was provided with the central difference scheme discussed above. The spatial derivative for advection, however, is not centered, rather only information at the current and upstream segment are used as follows:

$$
\text { advection term }=U\left[(1-\theta) \frac{c_{i}^{n}-c_{i-1}^{n}}{\Delta x}+\theta \frac{c_{i}^{n+1}-c_{i-1}^{n+1}}{\Delta x}\right]
$$

The main drawback to using the upwind differencing scheme is that it tends to introduce numerical diffusion into the solution, especially at high stream velocities or large spatial steps. However, this scheme introduces less artificial oscillation for sharp gradients than the central difference scheme and was added to the model to allow the user more flexibility and choice in solving a wider range of problems.

Equation 16 must be modified for upwind differencing for advection, resulting in Equations 26 and 27 below. 


$$
\begin{aligned}
& -\left(\gamma_{u}+\lambda\right) \theta c_{i-1}^{n+1}+\left(1+\gamma_{u} \theta+2 \lambda \theta+k \Delta t \theta\right) c_{i}^{n+1}-\lambda \theta c_{i+1}^{n+1} \\
& =\left(\gamma_{u}+\lambda\right)(1-\theta) c_{i-1}^{n}+\left(1-\gamma_{u}-2 \lambda(1-\theta)-k \Delta t(1-\theta)\right) c_{i}^{n} \\
& +\lambda(1-\theta) c_{i+1}^{n}+q \Delta t
\end{aligned}
$$

where

$$
\gamma_{u}=U \frac{\Delta t}{\Delta x}
$$

\section{Ordinary differential equation solution}

The option of using the Euler method or the fourth-order Runge-Kutta method is provided for solving for the contaminant concentration in the sediment bed (i.e., Equation 9). The Euler method is easy to implement, but it is only first-order accurate in time, and it is expressed as

$$
c_{b}^{n+1}=c_{b}^{n}+\frac{d c_{b}}{d t} \Delta t
$$

where the term $d c_{b} / d t$ is Equation 9 evaluated with the most recent updates for $c_{w}$ and with $c_{b}$ taken at time level $n$.

The fourth-order Runge-Kutta method uses estimates of the slope at four points to calculate an improved average slope for the time interval (Chapra 1997). The classical fourth-order Runge-Kutta method is given by the following equation:

$$
c^{n+1}=c^{n}+\left[\frac{1}{6}\left(k_{1}+2 k_{2}+2 k_{3}+k_{4}\right)\right] \Delta t
$$

where the four slope estimates are defined as

$$
\begin{gathered}
k_{1}=f\left(t_{i}, c_{i}\right) \\
k_{2}=f\left(t_{i}+\frac{1}{2} \Delta t, c_{i}+\frac{1}{2} \Delta t k_{1}\right)
\end{gathered}
$$




$$
\begin{gathered}
k_{3}=f\left(t_{i}+\frac{1}{2} \Delta t, c_{i}+\frac{1}{2} \Delta t k_{2}\right) \\
k_{4}=f\left(t_{i}+\Delta t, c_{i}+\Delta t k_{3}\right) .
\end{gathered}
$$

When applied to the constituent mass balance given in Equation 9, this yields the following:

$$
\begin{aligned}
& k_{1}=-\left(k_{d b} F_{d b}+k_{p b} F_{p b}\right) c_{b}+\frac{V_{d}}{h}\left(F_{d w} c_{w}-F_{d b} c_{b}\right) \\
& -\frac{V_{r}}{h} c_{b}+\frac{V_{s}}{h} F_{p w} c_{w}-\frac{V_{b}}{h} c_{b} \\
& k_{2}=-\left(k_{d b} F_{d b}+k_{p b} F_{p b}\right)\left(c_{b}+0.5 k_{1} \Delta t\right)+\frac{V_{d}}{h}\left[F_{d w} c_{w}-F_{d b}\left(c_{b}+0.5 k_{1} \Delta t\right)\right] \\
& -\frac{V_{r}}{h}\left(c_{b}+0.5 k_{1} \Delta t\right)+\frac{V_{s}}{h} F_{p w} c_{w}-\frac{V_{b}}{h}\left(c_{b}+0.5 k_{1} \Delta t\right) \\
& k_{3}=-\left(k_{d b} F_{d b}+k_{p b} F_{p b}\right)\left(c_{b}+0.5 k_{2} \Delta t\right)+\frac{V_{d}}{h}\left[F_{d w} c_{w}-F_{d b}\left(c_{b}+0.5 k_{2} \Delta t\right)\right] \\
& -\frac{V_{r}}{h}\left(c_{b}+0.5 k_{2} \Delta t\right)+\frac{V_{s}}{h} F_{p w} c_{w}-\frac{V_{b}}{h}\left(c_{b}+0.5 k_{2} \Delta t\right) \\
& k_{4}=-\left(k_{d b} F_{d b}+k_{p b} F_{p b}\right)\left(c_{b}+k_{3} \Delta t\right)+\frac{V_{d}}{h}\left[F_{d w} c_{w}-F_{d b}\left(c_{b}+k_{3} \Delta t\right)\right] \\
& -\frac{V_{r}}{h}\left(c_{b}+k_{3} \Delta t\right)+\frac{V_{s}}{h} F_{p w} c_{w}-\frac{V_{b}}{h}\left(c_{b}+k_{3} \Delta t\right) .
\end{aligned}
$$

The final concentration in the sediment bed at the new time step is then determined as

$$
c_{b}^{n+1}=c_{b}^{n}+\left[\frac{1}{6}\left(k_{1}+2 k_{2}+2 k_{3}+k_{4}\right)\right] \Delta t
$$


Although the implicit solution for the water column is unconditionally stable, the solution for the bed is not and can generate oscillating, unrealistic concentrations. An adaptive solution option has been implemented for solving the ordinary differential equation for the bed to ensure stable results. The adaptive scheme starts with a time step, $\Delta t$, that is actually one-tenth of the specified time step. This helps to insure that the initial calculations will meet the convergence criteria. For each time loop, the sediment calculations are first performed using the current time step and a value that is twice as large as the current time step. If the values from these two calculations for all segments meet the convergence criteria, the larger time step will be the new time step and the values from the calculations using this time step will be used for the current time loop. If the convergence criteria are not met, the calculations are performed using the current time step and a value that is half as large as the current time step. If the convergence criteria are met, the current time step will be unchanged. Otherwise, the routine will set the current time step to $0.5 \Delta t$ and continue to iterate, lowering the time step with each iteration, until convergence is reached. 


\section{Model Verification}

Because there was no readily available, long-term constituent concentration data to validate the CMS, the model equations have been verified using two existing contaminant models: RECOVERY (Ruiz and Gerald 2001) and PREWet (Dortch and Gerald 1995). RECOVERY is a numerical, time-varying model of water column and bed contaminant mass where the water column is a single, fully mixed compartment, and the bed is modeled with multiple layers over the depth. PREWet is a 1-D (longitudinal), steady-state model with an analytical solution. RECOVERY assumes a steady-state solids balance for the bed, and suspended solids are input and constant throughout the water column and over time. Although PREWet calculates suspended solids concentration at the end of the reach given the concentration entering the reach and assuming a steady-state solids balance in the bed, the bed solids flux rates (burial, resuspension, deposition) are assumed uniform over the reach, and the unknown flux is computed using the entering solids concentration. Thus, the suspended solids computations are not really coupled with the contaminant computations. The steady-state solids balance in the bed of both models requires entering two of the three rates of settling, resuspension, and burial and solving for the unspecified rate assuming that bed solids mass is constant with respect to time.

One organic and one inorganic constituent were chosen for the model verification tests, and two test sets were run. The first test was a long-term, steady-state loading simulation run for 200 years, long enough for constituent concentrations in both the water column and sediment bed to reach steady-state values. All three models were compared for this test. The second test was a time-varying test case with stepped constituent influx concentrations over a simulation period of 100 years. The constituent flux was increased at 25 and 50 years and then decreased at 75 years. In this simulation, the constituent concentrations in the sediment bed were never allowed to reach steady-state. Only RECOVERY was compared to the CMS for this test because PREWet does not allow a variable flux input. The input data and the results for each test set are described below. 


\section{Input data}

Three general types of data are required as input: (1) chemical-specific parameters/inputs; (2) system or water body inputs; and (3) sediment bed properties. Each of the inputs for these test is described as follows.

\section{Chemical specific inputs}

The constituents used in the test cases were DDT and Chromium III. Both of these constituents are known water contaminants. The data required for each constituent to perform the tests with the aforementioned models is given below. Assumptions were made regarding some inputs to simplify comparisons between the models. Extremely small values were used for some input values in place of entering 0.o, such as Henry's law constant for chromium.

\section{DDT}

- Molecular weight - 354.49 g/g-mole

- Molecular diffusivity $-4.95 \mathrm{E}-6 \mathrm{~cm}^{2} / \mathrm{s}$

- Henry's law constant - 8.3E-6 atm-m3/g-mole

- Octanol-water partition coefficient (Kow) $-8.128 \mathrm{E}+6 \mathrm{~mL} / \mathrm{mL}$

- Partition coefficients

○ Water column - o L/kg

- Sediment bed - o L/kg

- Decay rates in water column

- Dissolved fraction - 0.00388 /day

- Particulate fraction - o /day

- Decay rates in sediment bed

○ Dissolved fraction -0.00388 /day

- Particulate fraction $-\mathrm{o} /$ day

- Volatilization rate from the water column - $0.111 \mathrm{~m} /$ day (calculated)

- Mass transfer velocity between water and sediment - $0.00133 \mathrm{~m} /$ day (calculated)

- Initial concentration in water column - o mg/L

- Initial concentration in sediment bed - o mg/L

\section{Chromium III}

- Molecular weight - $51.996 \mathrm{~g} / \mathrm{g}$-mole

- Molecular diffusivity $-5.94 \mathrm{E}-6 \mathrm{~cm}^{2} / \mathrm{s}$

- Henry's law constant - 9.60E-40 atm-m3/g-mole 
- Octanol-water partition coefficient (Kow) - o mL/mL

- Partition coefficients

○ Water column - 100,000 L/kg

○ Sediment bed $-1,000,000 \mathrm{~L} / \mathrm{kg}$

- Decay rates in water column

- Dissolved fraction - o /day

- Particulate fraction - o /day

- Decay rates in sediment bed

- Dissolved fraction - o /day

- Particulate fraction $-0 /$ day

- Volatilization rate from the water column - o m/day

- Mass transfer velocity between water and sediment - $0.00477 \mathrm{~m} /$ day (calculated)

- Initial concentration in water column - o mg/L

- Initial concentration in sediment bed - o mg/L

\section{Water body parameters}

Since each of the models being used is intended for different types of water bodies, the following general physical characteristics were applied to each model as appropriate to simulate the same conditions.

- Average annual depth of water body $-3 \mathrm{~m}$

- Average annual width of water body $-50 \mathrm{~m}$

- Length of water body $-100 \mathrm{~km}$

- Average annual surface area of water body $-{ }_{5} \mathrm{E} 6 \mathrm{~m}^{2}$

- Average annual volume of water body $-1.5 \mathrm{E} 7 \mathrm{~m}^{3}$

- Average annual flow - 1E9 m3/yr

- Average annual temperature $-20^{\circ} \mathrm{C}$

- Incoming suspended solids concentration $-150 \mathrm{mg} / \mathrm{L}$

- Fraction organic carbon in suspended solids - 0.02

- Longitudinal dispersion coefficient $-16200 \mathrm{~m}^{2} / \mathrm{hr}$ (CMS only)

\section{Sediment bed parameters}

The following parameters were applied to all models for the active sediment layer.

- Average thickness $-10 \mathrm{~cm}$

- Average porosity - 0.35

- Average dry sediment density - 2,650 g/L 
- Fraction organic carbon in sediment bed - 0.02

- Settling velocity - $0.1 \mathrm{~m} /$ day

- Burial velocity $-4.7 \mathrm{E}-6 \mathrm{~m} /$ day

- Resuspension velocity $-4.467 \mathrm{E}-6 \mathrm{~m} /$ day (calculated)

\section{Steady-state test case}

The steady-state test case was run for each model using the information given above and a constant constituent influx of $30 \mathrm{mg} / \mathrm{L}$ for each constituent. The simulation was run for a period of 200 years allowing the water column and sediment bed concentrations for both constituents to reach steady-state. Table 1 shows the results from each of the three models. The results for CMS and PREWet are reported at the end of the modeled reach.

Table 1. Steady-state test results.

\begin{tabular}{|l|l|l|l|}
\hline \multirow{3}{*}{ Model } & Contaminant & Water Conc., $\mathrm{mg} / \mathrm{L}$ & $\begin{array}{l}\text { Sediment Conc. } \\
\mathrm{mg} / \mathrm{kg}\end{array}$ \\
\hline PREWet & DDT & 26.97 & 168600 \\
\cline { 2 - 4 } & Chromium III & 27.34 & 171400 \\
\hline \multirow{2}{*}{ RECOVERY } & DDT & 26.6 & 166000 \\
\cline { 2 - 4 } & Chromium III & 27.4 & 171000 \\
\hline \multirow{2}{*}{ CMS $^{1}$} & DDT & 27.0 & 168000 \\
\cline { 2 - 4 } & Chromium III & 27.3 & 171000 \\
\cline { 2 - 4 } & Solids & 150 & 184000 \\
\hline \multirow{2}{*}{ CMS $^{2}$} & DDT & 26.8 & 187000 \\
\cline { 2 - 4 } & Chromium III & 27.2 & \\
\cline { 2 - 4 } & Solids & 135 & \\
\hline
\end{tabular}

$1 \mathrm{CMS}$ run with steady-state solids balance in water column.

2 CMS run with suspended solids transport.

The results from all three models match well for the water column concentrations for both constituents. This is true for both the steady-state solids balance and with suspended solids transport. However, both the DDT and Chromium III sediment concentrations predicted by the CMS with solids transport are about 9.5 percent higher than all other predictions. The reason for the difference is due to a gradient in the suspended solids concentration created along the stream reach, dropping from the inflow concentration of $150 \mathrm{mg} / \mathrm{L}$ at the upstream boundary to $135 \mathrm{mg} / \mathrm{L}$ at the end of the reach. The calculated resuspension velocities for each cell also decreased along the stream reach, and more constituent mass becomes 
bound in the bed at the low end of the reach. The RECOVERY and PREWet models used a steady solids concentration of $150 \mathrm{mg} / \mathrm{L}$ throughout.

A test was next performed using both the RECOVERY and PREWet models with the suspended solids concentration of $135 \mathrm{mg} / \mathrm{L}$ calculated by the CMS for the end of the stream reach. The results from this test are shown in Table 2.

Table 2. Steady-state solutions for RECOVERY and PREWet using modified suspended solids concentration of $135 \mathrm{mg} / \mathrm{L}$.

\begin{tabular}{|l|l|l|l|}
\hline \multirow{3}{*}{ Model } & Contaminant & $\begin{array}{l}\text { Water Conc. } \\
\mathrm{mg} / \mathrm{L}\end{array}$ & $\begin{array}{l}\text { Sediment Conc. } \\
\mathrm{mg} / \mathrm{kg}\end{array}$ \\
\hline \multirow{3}{*}{ PREWet } & DDT & 26.68 & 184000 \\
\cline { 2 - 4 } & Chromium III & 27.08 & 187400 \\
\hline \multirow{2}{*}{ RECOVERY } & DDT & 26.4 & 181200 \\
\cline { 2 - 4 } & Chromium III & 27.2 & 186900 \\
\hline
\end{tabular}

As can be seen in Table 2, the sediment concentrations computed by RECOVERY and PREWet are about the same as those computed by CMS when using the same suspended solids concentration as the CMS. This test helped to verify that the CMS is working properly, at least for a steadystate loading.

\section{Time-varying test case}

This test case was run for the RECOVERY model and the CMS using the same data as the steadystate case above and stepping the constituent influx at 25-year intervals for each constituent.

Table 3. Constituent inflow concentrations for step function test case.

\begin{tabular}{|l|l|}
\hline Time, yr & Influx concentration, $\mathrm{mg} / \mathrm{L}$ \\
\hline 0 & 30 \\
\hline 25 & 40 \\
\hline 50 & 50 \\
\hline 75 & 15 \\
\hline
\end{tabular}

Table 3 shows the inflow concentrations for the models. 
The simulation was run for a period of 100 years without allowing the sediment bed concentrations for either constituent to fully reach steadystate conditions at any point during the simulation. The inflow concentration after year 75 is assumed to remain at $15 \mathrm{mg} / \mathrm{L}$. Table 4 shows the final results for both models at the end of the simulation and at the downstream end of the reach. The CMS run was made using the suspended solids transport routing option.

Table 4. Final results for RECOVERY and CMS models for the step function test case.

\begin{tabular}{|l|l|l|l|}
\hline \multirow{2}{*}{ Model } & Contaminant & $\begin{array}{l}\text { Water Conc. } \\
\mathrm{mg} / \mathrm{L}\end{array}$ & $\begin{array}{l}\text { Sediment Conc. } \\
\mathrm{mg} / \mathrm{kg}\end{array}$ \\
\hline RECOVERY1 & DDT & 13.36 & 86,621 \\
\cline { 2 - 4 } & Chromium III & 13.77 & 89,298 \\
\hline \multirow{2}{*}{ RECOVERY2 } & DDT & 13.23 & 95,864 \\
\cline { 2 - 4 } & Chromium III & 13.65 & 98,915 \\
\hline \multirow{2}{*}{ CMS } & DDT & 13.4 & 97,400 \\
\cline { 2 - 4 } & Chromium III & 13.6 & 99,100 \\
\cline { 2 - 4 } & Suspended Solids & 135 & \\
\hline
\end{tabular}

1 RECOVERY run with suspended solids concentration of $150 \mathrm{mg} / \mathrm{L}$.

2 RECOVERY run with suspended solids concentration equal to that in the last segment of the CMS, $135 \mathrm{mg} / \mathrm{L}$.

The comparison of CMS and RECOVERY results shows that the water concentrations are close. The sediment concentrations also agree fairly closely when the same suspended solids concentrations are used in the two models. The minor differences between the two results could be due to the fact that RECOVERY treats the entire reach as a single, fully mixed cell of homogeneous concentration, whereas CMS computes a gradient in concentration along the reach. This test verified the CMS for time-varying input data. 


\section{Model Inputs and User Interface}

A user-friendly interface has been created for entering model input data, executing the model, and examining model output. To launch the CMS user interface in stand-alone mode, double click the CMS icon on the desktop (Figure 5).

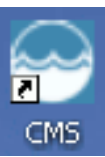

Figure 5. CMS desktop Icon.

The program can also be launched by clicking on the Windows "Start" button and selecting "Programs -> CMS -> CMS." Figure 6 shows all of the entries under the "CMS" menu. The first entry, "CMS," will launch the graphical program interface. The second entry, "CMS Help," will launch the CMS help file. The last entry is used to remove the CMS model from the user's computer.

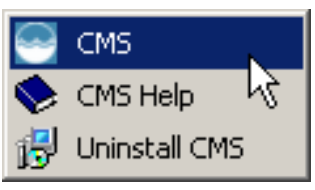

Figure 6. CMS Start Menu Item.

When the CMS model is run from within ARAMS/FRAMES, the standard menu items are used to launch the model, run the model, and launch the results viewer.

After launching the CMS interface, the main screen will appear as shown below in Figure 7. 


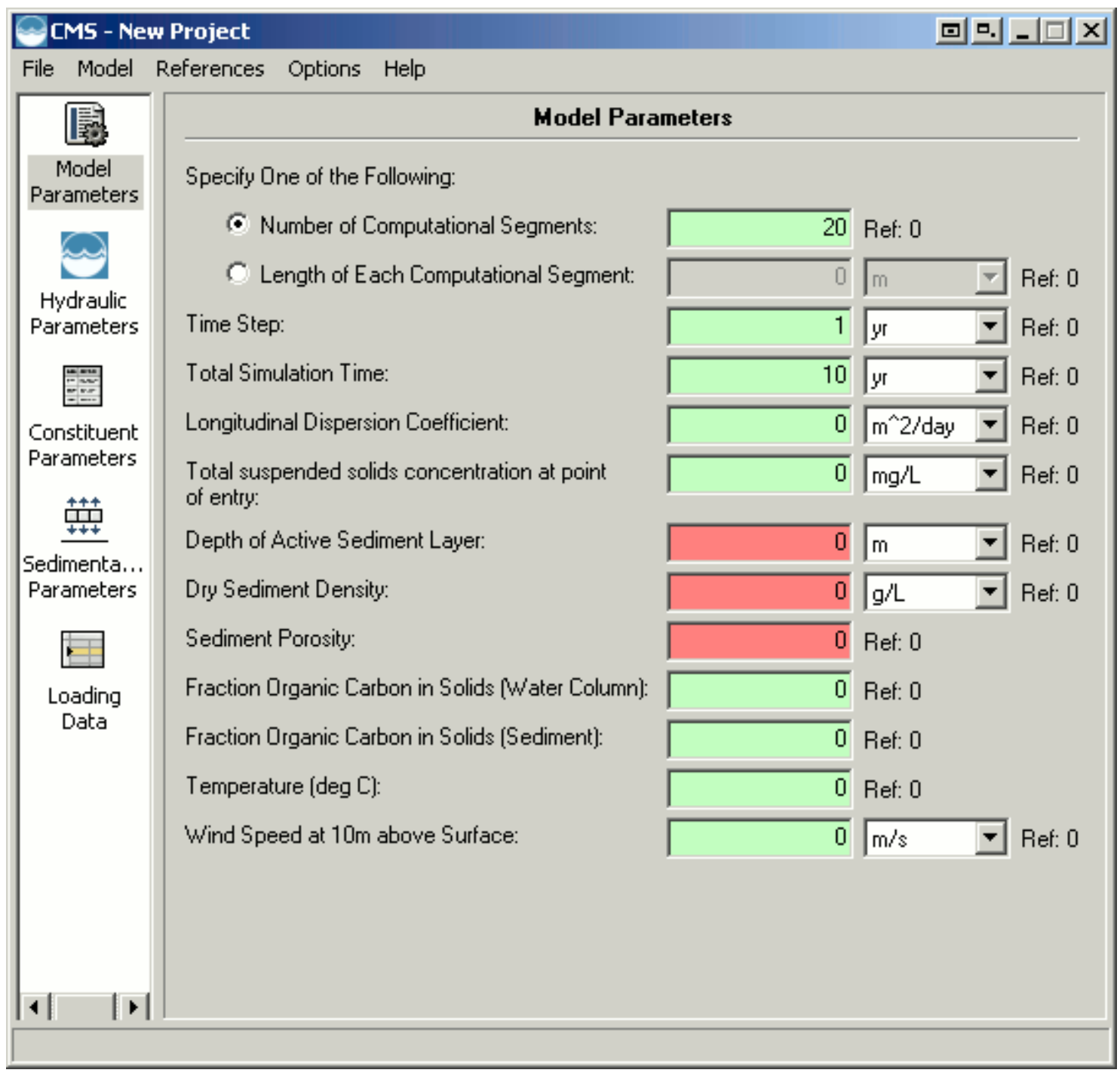

Figure 7. CMS Main Screen.

When the CMS interface is first launched, the default behavior is to create a new data file. However, if at any time the user wishes to start a new project, this can be done by selecting "File -> New" from the main menu as shown in Figure 8 below. 


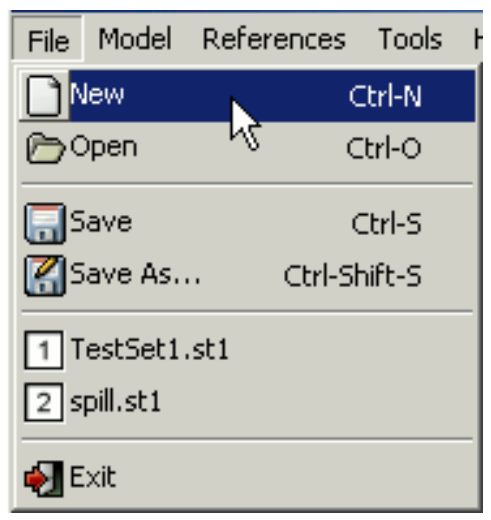

Figure 8. New Data File.

To open an existing data file, select "File -> Open" from the main menu as shown in Figure 9.

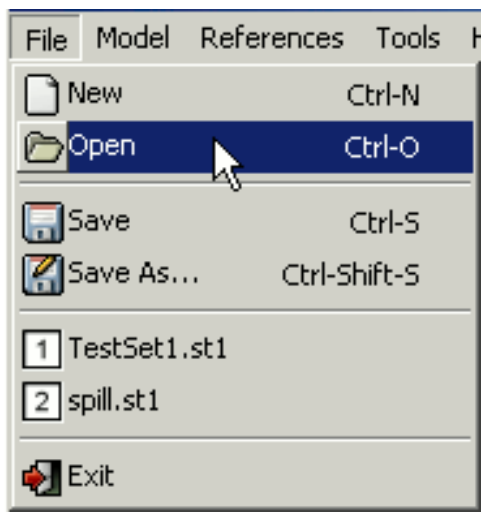

Figure 9. Open Data File.

The open file dialog will then be shown as in Figure 10. Browse to the folder where the desired file is located, select it, and click the button labeled "Open" at the bottom of the dialog. The file can also be opened by double-clicking the left mouse button on the file from the open file dialog or from any Windows Explorer dialog. * Note: an extension of ".st1" is used for all CMS data files. 


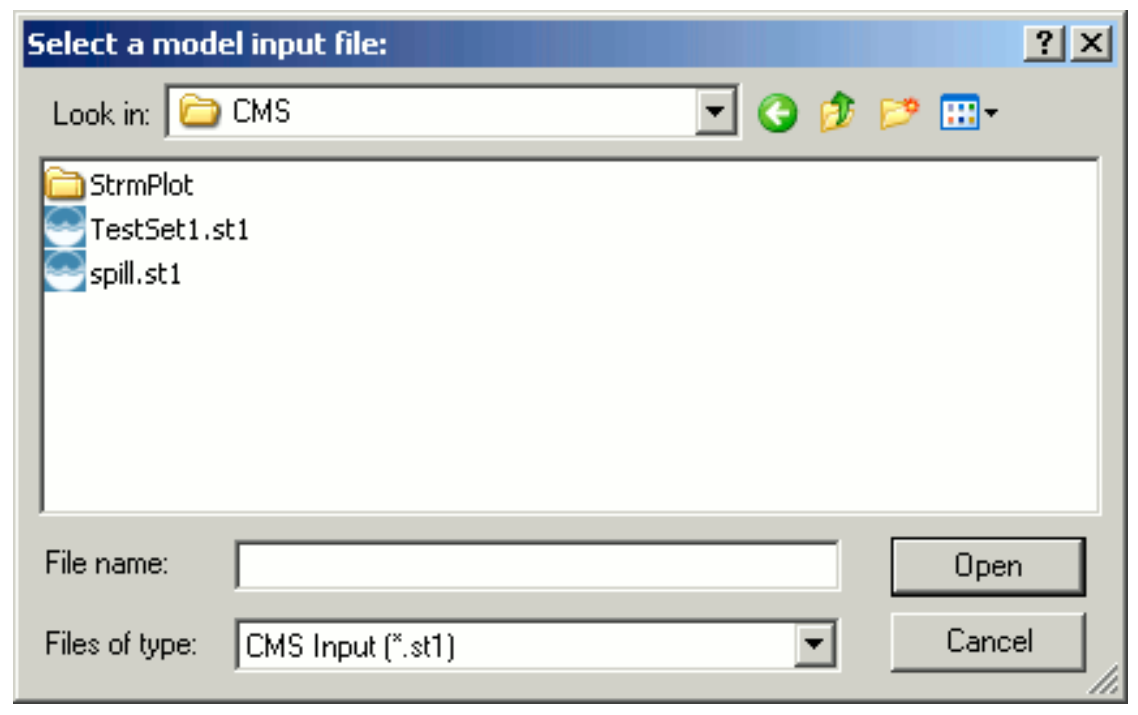

Figure 10. Open File Dialog.

If the data file to be opened was one of the last four files to be opened, it will appear in the recent files list on the file menu. The recently used files will be numbered consecutively from one to a maximum of four and will appear just above the "Exit" option on the file menu as shown in Figures 8 and 9 above. The most recently used data file will appear at the top of the list. Holding the mouse over the file name will cause the full path to the data file to be displayed on the status bar at the bottom of the main application window as shown in Figure 11. To open one of these files simply select the desired item from the menu. 


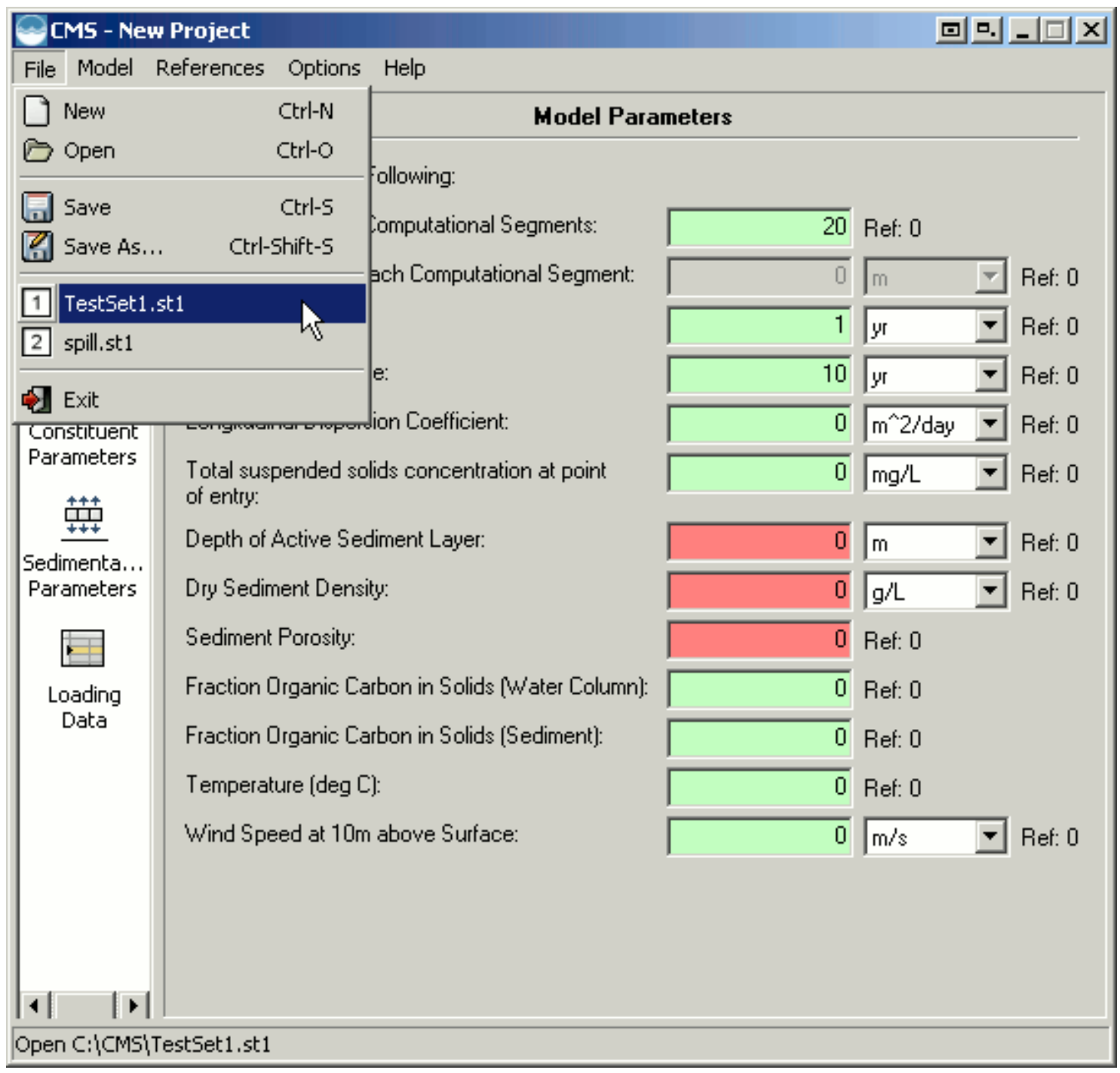

Figure 11. Recent Data Files.

To open a CMS results data file, select "File -> Open" from the main menu as was done for opening an input data file. The open file dialog will then be shown. The default setting when selecting "Open" from the file menu is to open an input data file. To select a results data file, select the "Files of type" combo box at the bottom of the dialog, and change the file type to "CMS Results (*.ac2)" as shown in Figure 12. 


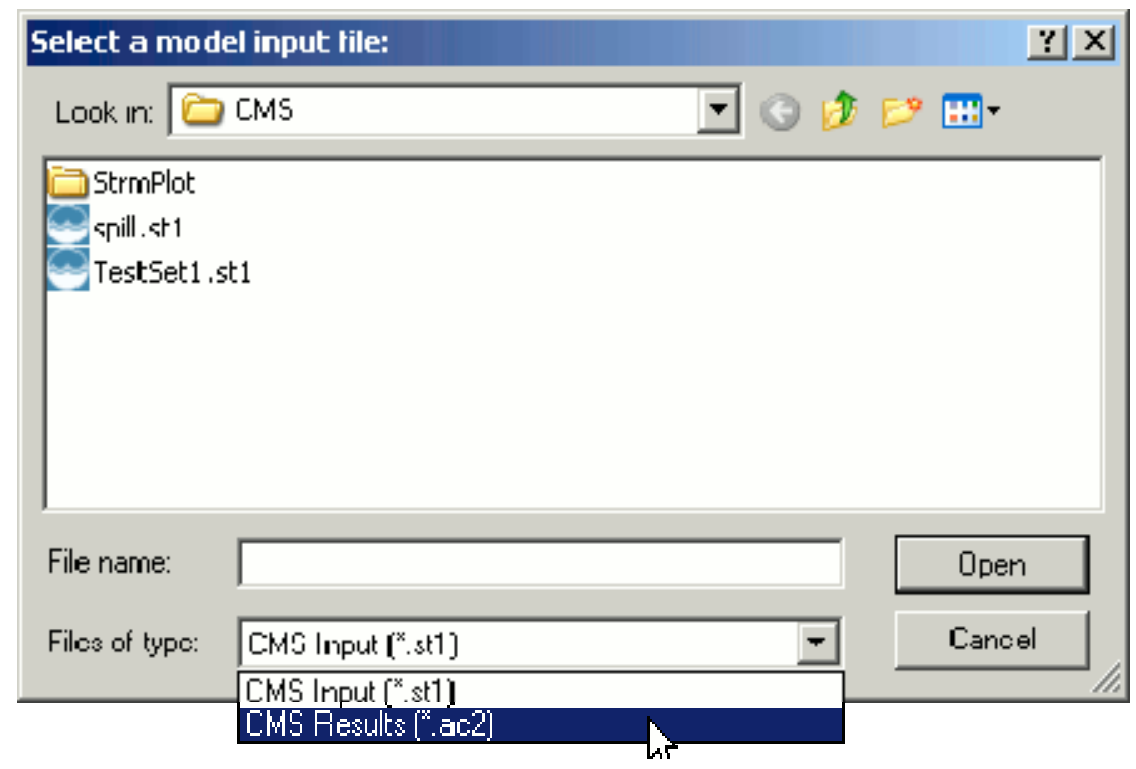

Figure 12. Change File Type.

The files list will now display only CMS results data files (Figure 13). Select the desired file and click the button labeled "Open" to load the results file. As with input data files, the file may also be opened by double-clicking the item in the open file dialog or any Windows Explorer window. * Note: an extension of ".ac23" is used for all CMS results data files.

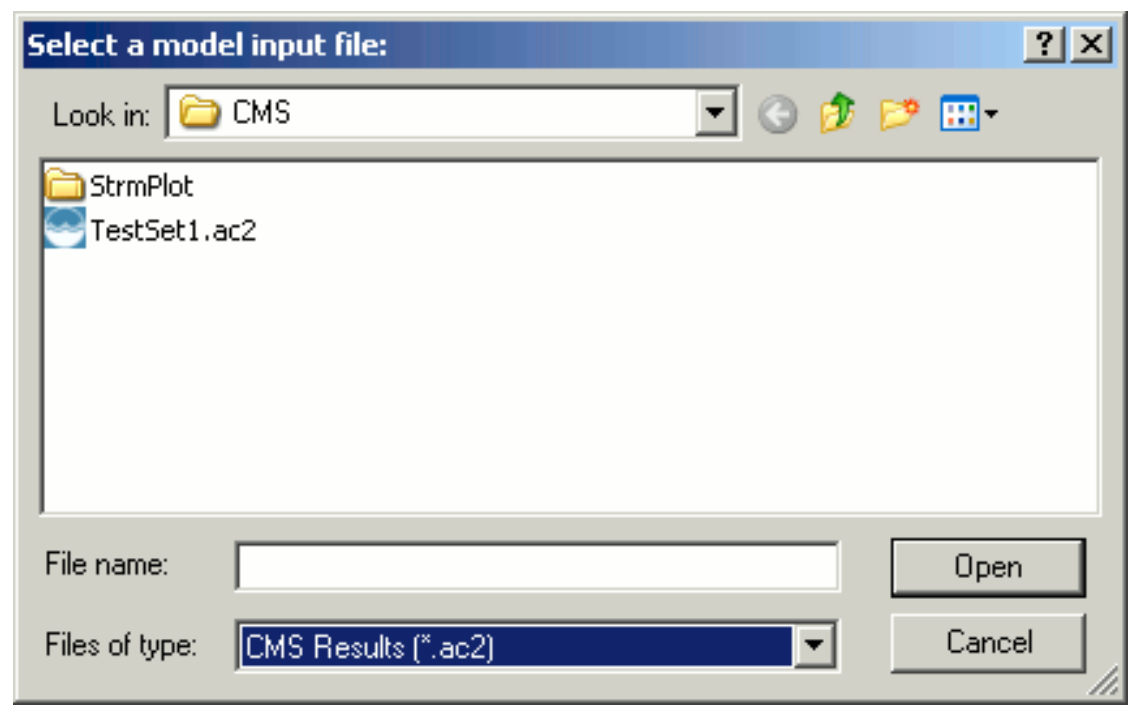

Figure 13. Open Results Dialog.

Data entry is performed through the five main screens of the CMS interface. To access each of these screens, use the toolbox on the left-hand side of the interface as shown in Figure 14. 


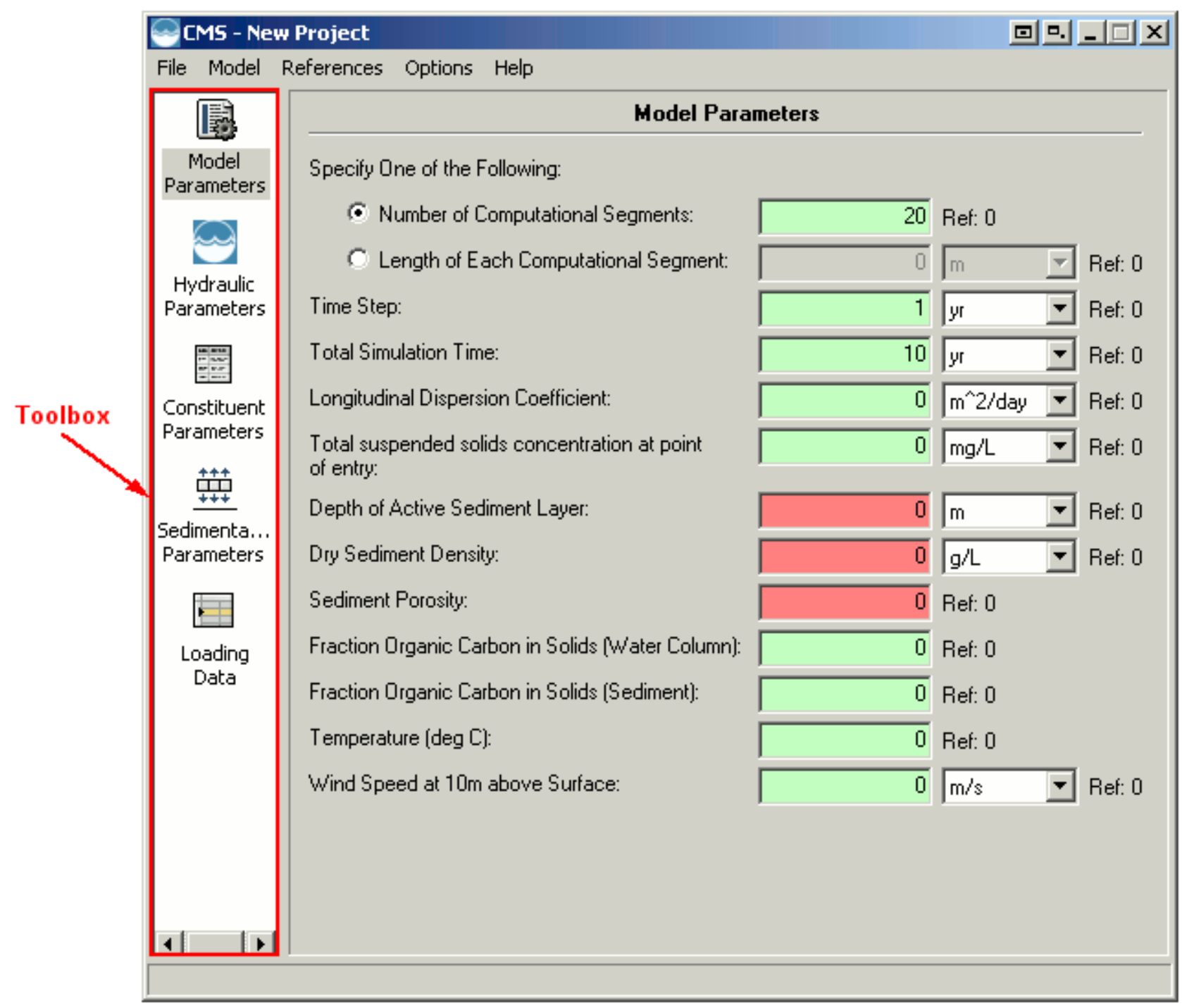

Figure 14. Main Screen Toolbox.

The model parameters screen consists of entry forms for most of the general parameters including time step, spatial step, total simulation time, etc. The model parameters screen is shown in Figure 15, and an explanation of the input fields is given below. 


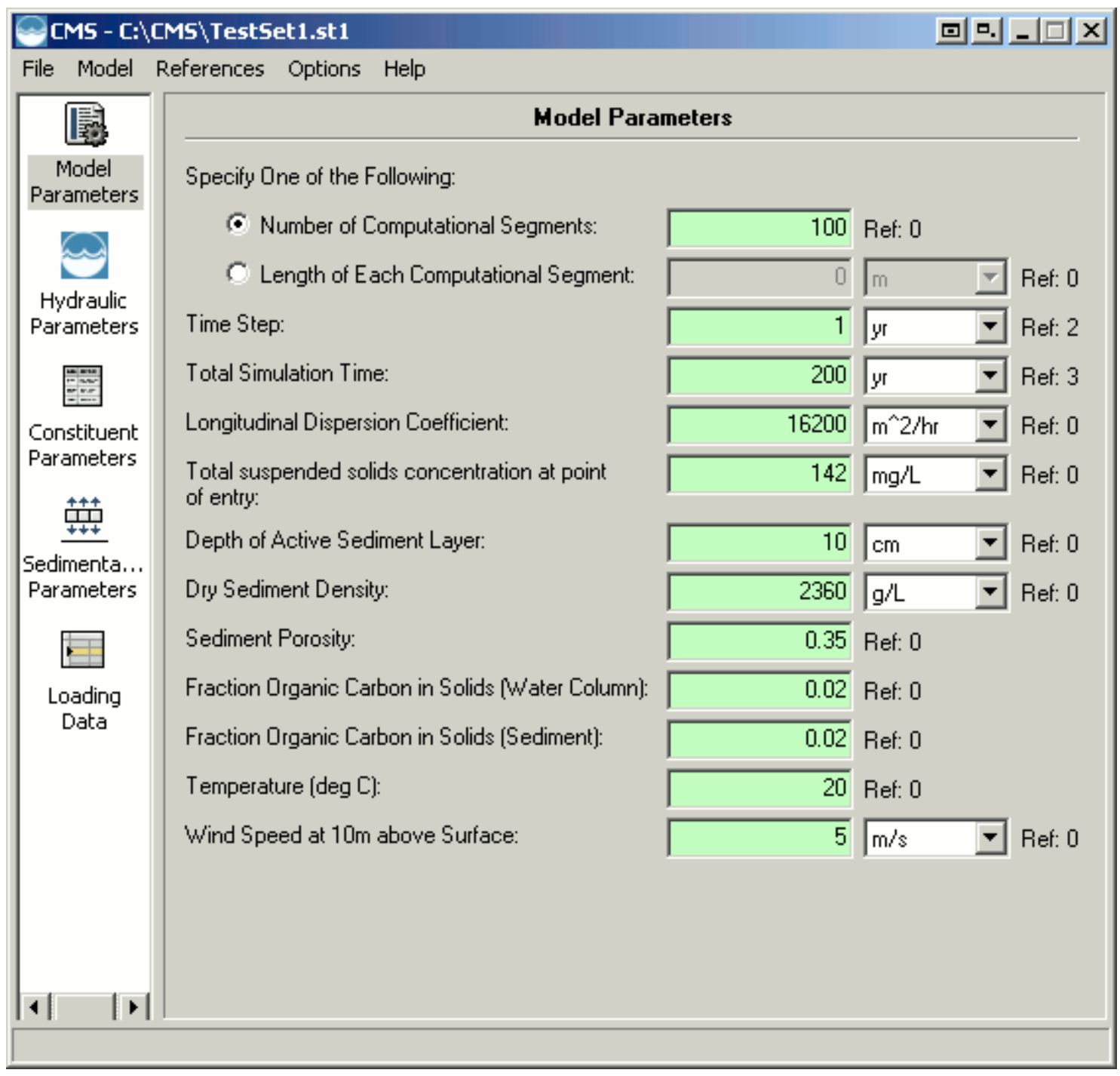

Figure 15. Model Parameters Screen.

\section{Model Parameter Field Descriptions}

- Segment Length Options - One of the following options must be selected.

- Number of Segments - Specifies the number of segments in the stream reach; the segment length will automatically be calculated.

- Length of Segment - Specifies the length of the segments in the stream reach (units may be specified in combo box). The number of segments will automatically be calculated.

- Time Step - Specifies the length of the time step to be used (units may be specified in combo box). 
- Total Simulation Time - Specifies the total length of the simulation (units may be specified in combo box).

- Longitudinal Dispersion Coefficient - Specifies the longitudinal dispersion coefficient to be used (units may be specified in combo box).

- Suspended solids concentration at point of entry - Specifies the concentration of suspended solids in the stream at the point of entry (units may be specified in combo box). Solids concentration loading data will be specified on the Loading Data screen.

- Depth of Active Sediment Layer - Specifies the depth of the active sediment layer (units may be specified in combo box).

- Dry Sediment Density - Specifies the density of the sediment bed in mass per volume dry weight (units may be specified in combo box).

- Sediment Porosity - Specifies the porosity of the sediment bed.

- Fraction Organic Carbon in Solids (Water Column) - Specifies the fraction of organic carbon present in the suspended solids in the water column.

- Fraction Organic Carbon in Solids (Sediment) - Specifies the fraction of organic carbon present in the solids in the sediment bed.

- Temperature (deg C) - Specifies the temperature in degrees Celsius. This is required if the "Calculate" option is specified for the volatilization rate or the mass transfer velocity for any constituent.

- Wind Speed at $10 \mathrm{~m}$ above Surface - Specifies the wind speed at $10 \mathrm{~m}$ above the surface of the stream. This is required if the "Calculate" option is specified for the volatilization rate for any constituent.

The hydraulic parameters screen consists of entry forms for hydraulic parameters including width, depth, cross-sectional area, etc. The hydraulic parameters screen also contains entries for each of the usage locations in the stream reach. A usage location is a point at a given downstream distance and may indicate a withdrawal point, a habitat for a species of interest, or any point where the constituent concentration is of interest. The hydraulic parameters screen is shown in Figure 16, and an explanation of the input fields is given below. 


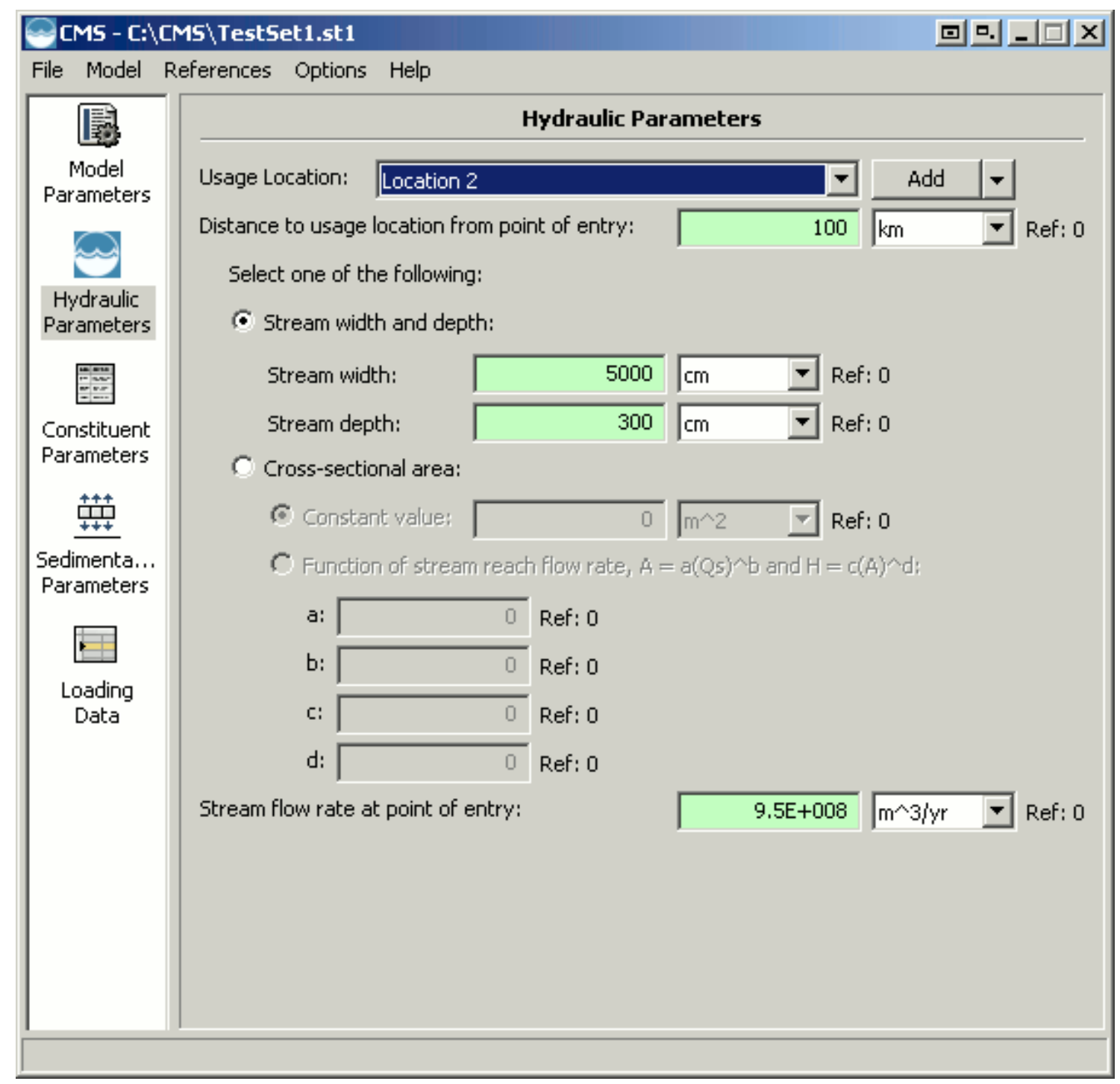

Figure 16. Hydraulic Parameters Screen.

\section{Hydraulic Parameter Field Descriptions}

- Usage Location - Usage locations can be added, edited, or deleted using the button to the right of the usage location combo box. Use the drop-down button at the right to select the appropriate action from the menu as shown in Figure 17, then click on the button to perform the action. 


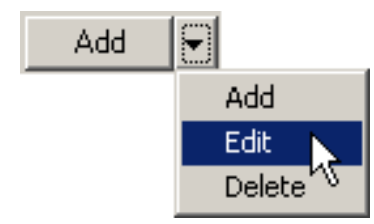

Figure 17. Usage Location Drop-Down Button.

- Distance to usage location from point of entry - Specifies the downstream distance to the currently selected usage location (units may be specified in combo box).

- Cross-sectional area options - One of the following options must be selected.

\section{○ Surface water width and depth}

- Stream width - Specifies the width of the stream for the maximum extent of the reach (units may be specified in combo box).

- Stream depth - Specifies the depth of the stream for the maximum extent of the reach (units may be specified in combo box).

- Cross-sectional area - One of the following options must be selected.

- Constant value - Specifies a constant cross-sectional area of the stream for the maximum extent of the reach (units may be specified in combo box).

- Function of stream reach flow rate, $\boldsymbol{a}(Q s)^{\wedge} \boldsymbol{b}$ - Qs is the stream flow rate including any flows supplied on the loading data screen.

a - Specifies the first coefficient in this function.

b - Specifies the second coefficient in this function.

When using this method, the stream depth can be related to the cross-sectional area by $H=c A^{\wedge} d$ where $H$ is the stream depth, $A$ is the cross-sectional area, and $c$ and $d$ are coefficients supplied by the user.

c - Specifies the first coefficient in this function. d - Specifies the second coefficient in this function.

- Stream flow rate at point of entry - Specifies the flow rate of the stream (units may be specified in combo box). 
The constituent parameters screen consists of entry forms for all of the constituent-specific parameters such as decay rates, partition coefficients, etc. The constituent parameters screen is shown in Figure 18, and an explanation of the input fields is given below.

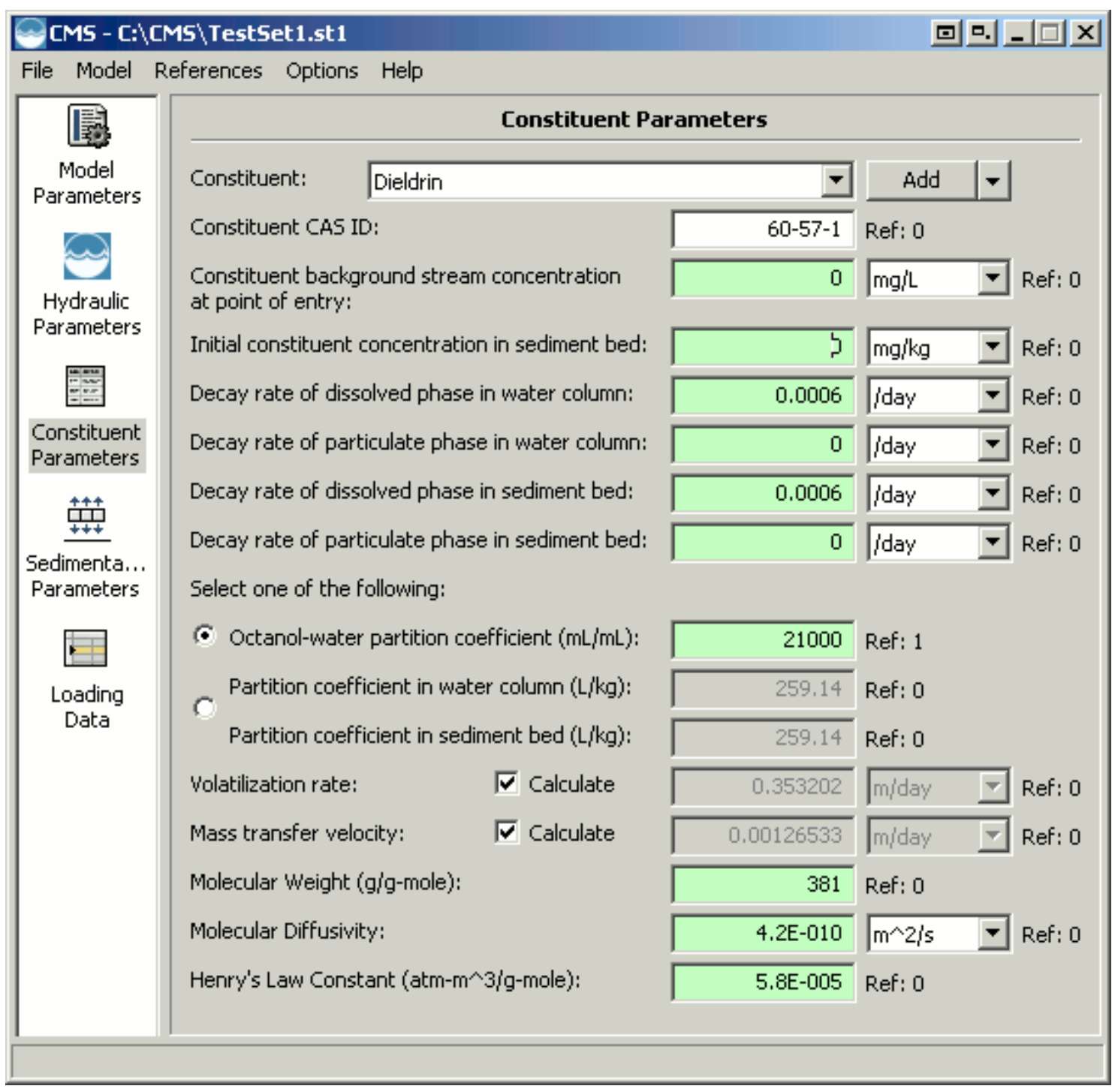

Figure 18. Constituent Parameters Screen. 


\section{Constituent Parameter Field Descriptions}

- Constituent - Constituents can be added, edited, or deleted using the button to the right of the usage constituent combo box. Use the dropdown button at the right to select the appropriate action from the menu as shown in Figure 19. Then click on the button to perform the action.

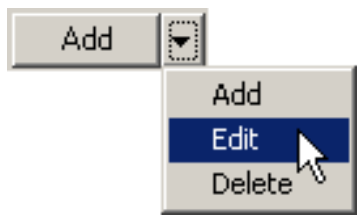

Figure 19. Constituent Drop-Down Button.

- Constituent CAS ID - Specifies the Chemical Abstract Services identification number for the currently selected constituent.

- Constituent background stream concentration at point of entry - Specifies the background concentration of the currently selected constituent in the stream (units may be specified in combo box).

- Initial constituent concentration in sediment bed - Specifies the initial concentration of the currently selected constituent in the sediment bed (units may be specified in combo box).

*Note - The following decay rates do not include physical losses such as volatilization, settling, burial, etc. They are a summation of degradation mechanisms such as biodegradation, hydrolysis, photolysis, etc.

- Decay rate of dissolved phase in water column - Specifies the decay rate of the dissolved phase/fraction of the currently selected constituent in the water column (units may be specified in combo box).

- Decay rate of particulate phase in water column - Specifies the decay rate of the particulate phase/fraction of the currently selected constituent in the water column (units may be specified in combo box).

- Decay rate of dissolved phase in sediment bed - Specifies the decay rate of the dissolved phase/fraction of the currently selected constituent in the sediment bed (units may be specified in combo box).

- Decay rate of particulate phase in sediment bed - Specifies the decay rate of the particulate phase/fraction of the currently selected constituent in the sediment bed (units may be specified in combo box). 
- The user may enter either the octanol-water partition coefficient or partition coefficients in the water column and sediment bed:

o Octanol-water partition coefficient - Specifies the octanolwater partition coefficient for the currently selected constituent in units of $\mathrm{mL}$ octanol $/ \mathrm{mL}$ water. The octanol-water partition coefficient, or KOW, is a measure of the preference of the constituent to bind to organic materials or to remain in the water column. If the KOW is specified, it will be used to calculate the partition coefficients in the water column and sediment bed.

- Partition coefficient in water column - Specifies the partition coefficient of the currently selected constituent in the water column in units of $\mathrm{L} / \mathrm{kg}$. This value will be ignored if the KOW is specified above.

- Partition coefficient in sediment bed - Specifies the partition coefficient of the currently selected constituent in the sediment bed in units of $\mathrm{L} / \mathrm{kg}$. This value will be ignored if the KOW is specified above.

- Volatilization rate - Specifies the rate of volatilization of the currently selected constituent from the water column (units may be specified in combo box). Note* : only the dissolved fraction of the constituent will be considered in the volatilization calculations. Select the "Calculate" option to have this value automatically calculated by the model.

- Mass transfer velocity - Specifies the mass transfer velocity of the currently selected constituent across the sediment-water interface (units may be specified in combo box). Note*: only the dissolved fraction of the constituent will be considered in mass transfer calculations. Select the "Calculate" option to have this value automatically calculated by the model.

- Molecular Weight (g/g-mole) - Specifies the molecular weight of the selected constituent. This value is required if the "Calculate" option is specified for the volatilization rate.

- Molecular Diffusivity - Specifies the molecular diffusivity of the selected constituent. This is required if the "Calculate" option is specified for the mass transfer velocity.

- Henry's Law Constant (atm-m^3/g-mole) - Specifies the Henry's law constant for the selected constituent. This is required if the "Calculate" option is specified for the volatilization rate. 
The sedimentation parameters screen consists of a grid for entering settling, burial, and resuspension velocity data at specified downstream locations. Since velocities can change along the stream reach, the model will accept velocity data at any distance along the reach. A value must be specified for the upstream boundary (downstream distance = zero). If no other velocity data are entered, these values will be used for the entire stream reach. When velocities are entered at multiple distances, the model will perform a linear interpolation to determine the value to use for each segment of the reach. If all velocity values are zero, the model will ignore the water column and sediment bed interactions. In this case the solids will not be modeled, and the constituents will only be modeled in the water column. The sedimentation parameters screen is shown in Figure 20, and an explanation of the input fields is given below.

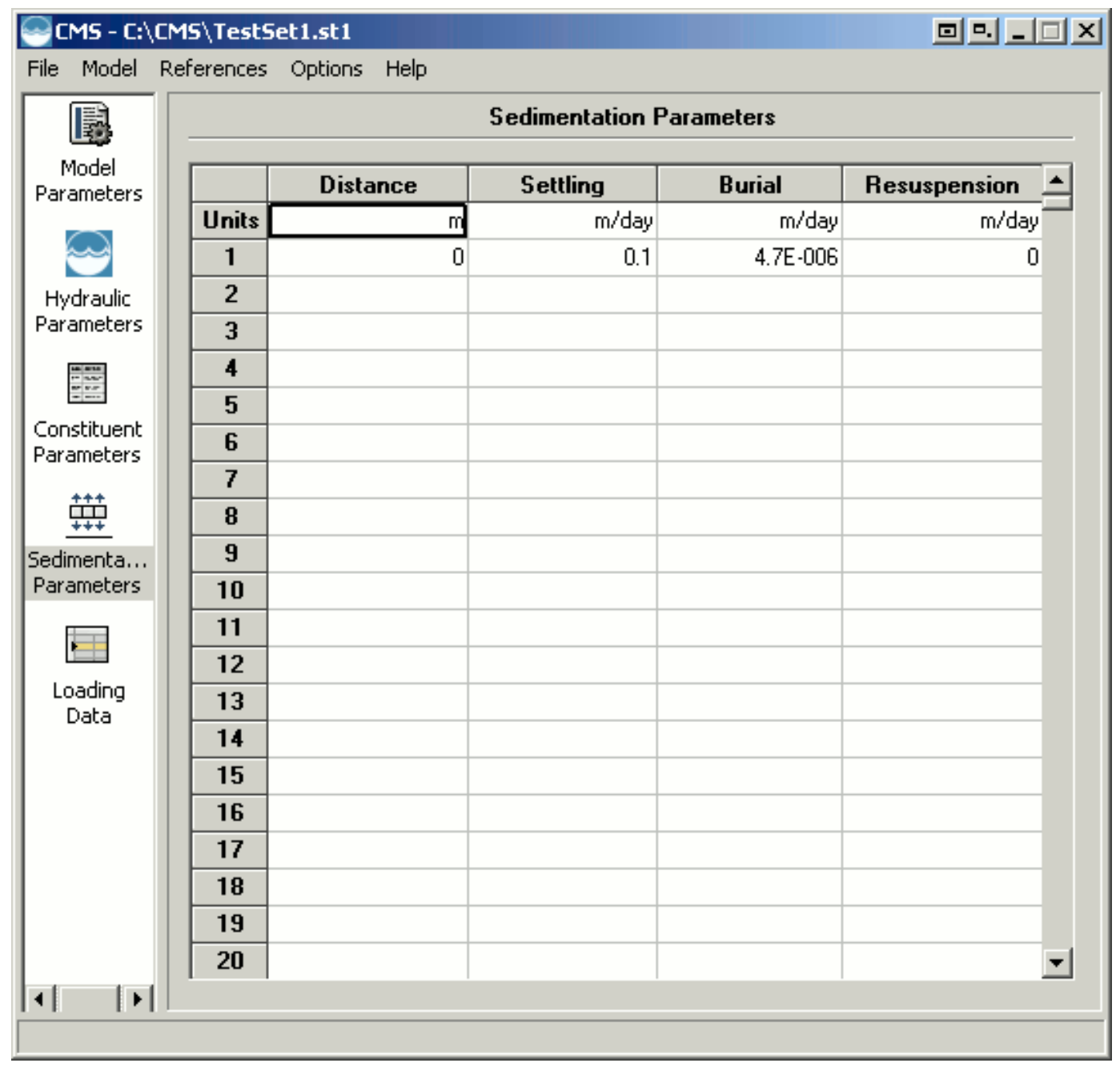

Figure 20. Sedimentation Parameters Screen. 


\section{Sedimentation Parameters Field Descriptions}

- Distance - Downstream distance where the velocities will be specified (units may be specified in combo box). Two of the three velocities must be specified at each distance, and the third should be set to zero to be calculated by the model. Velocities must be specified at the entry point, downstream distance of zero, and these values will be used for all calculations if no other distances are specified.

- Settling Velocity - Specifies the settling velocity at the given distance (units may be specified in combo box).

- Burial Velocity - Specifies the burial velocity at the given distance (units may be specified in combo box).

- Resuspension Velocity - Specifies the resuspension velocity at the given distance (units may be specified in combo box).

All of the grids in the CMS interface operate in the same manner. Data can be copied, cut, pasted, or deleted using shortcut keys or the context menu (Figure 21), which is available by clicking the right mouse button on the grid. The default number of rows in a grid is 100. Rows can be added to the bottom of a grid as necessary by using the "Insert Row(s)" option in the context menu. The shortcut keys for each of these actions can be seen in the context menu where appropriate. 


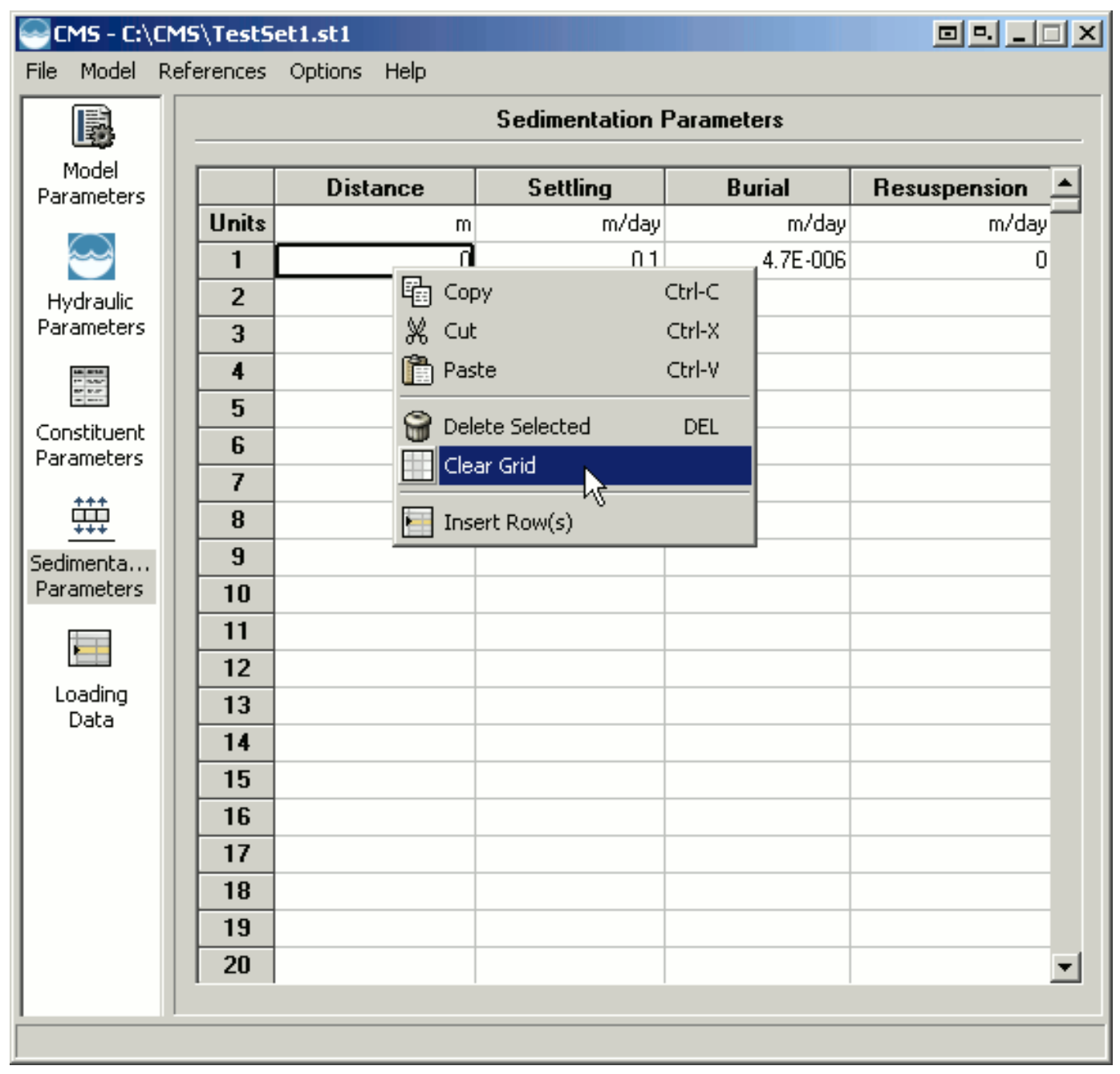

Figure 21. Sedimentation Parameters Grid Context Menu.

The CMS will also allow a steady-state solids concentration to be used. In this case, only one set of velocities is required at the upstream boundary and will be assumed constant along the entire reach. Solids will not be modeled in the water column and no constituent flux entries for solids will be allowed. The suspended solids concentration entered for the upstream boundary will be used as the steady-state concentration throughout the reach. When the model is being run with a steady-state solids balance in the water column, the sedimentation parameters screen will look as shown in Figure 22. The user will input two of the three velocities and the model will calculate the third. * Note - This is currently the only option available when the model is running under ARAMS/FRAMES. The solids transport code is currently under development and will be available in a later release. 


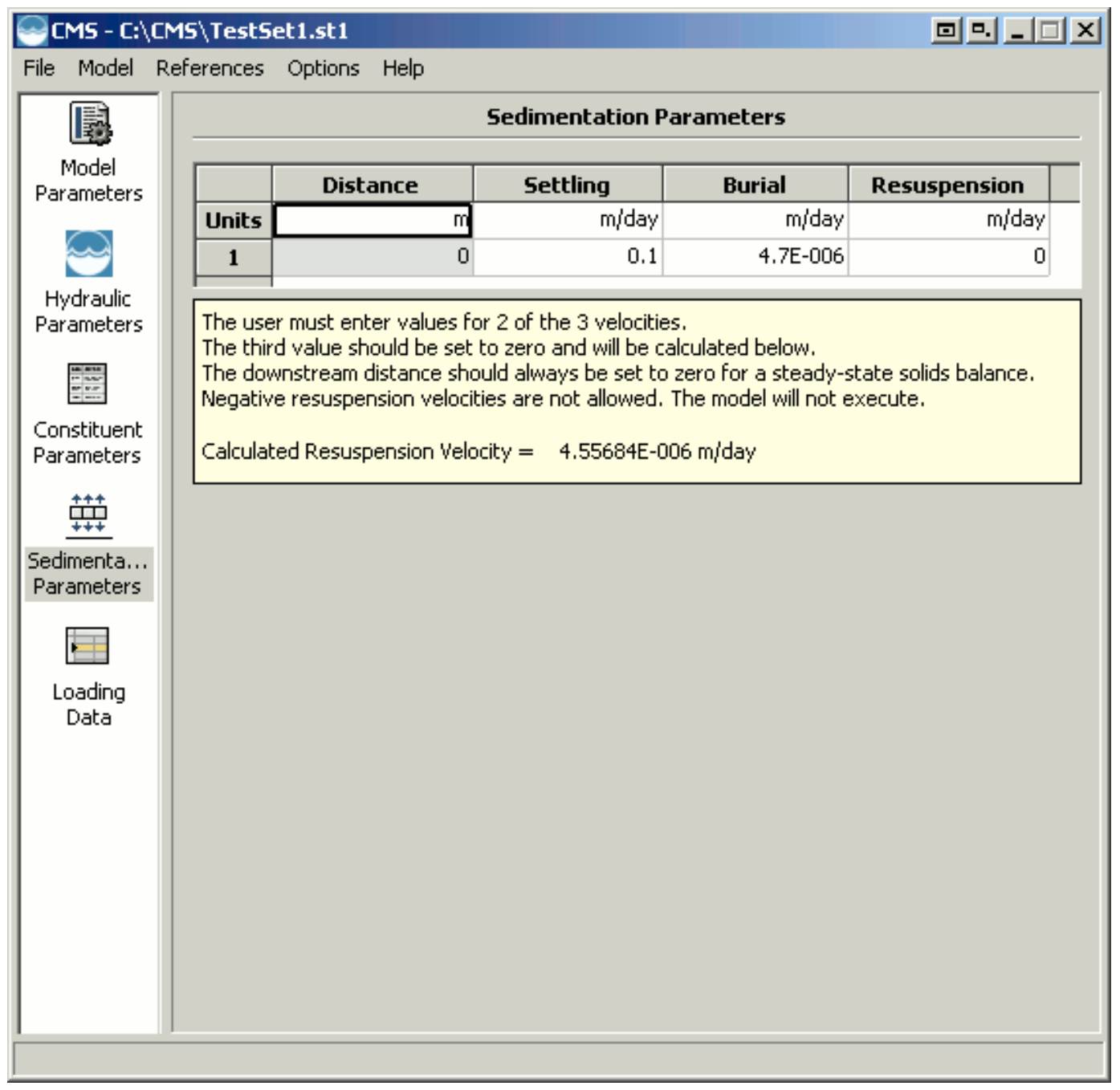

Figure 22. Sedimentation Parameters Screen with Steady-State Solids Balance.

The loading data screen consists of a grid for entering water flow, suspended solids concentration, and constituent fluxes for the upstream loads at specified time periods. The loading data screen and water flow input grid are shown in Figure 23, and an explanation of the input fields is given below. 


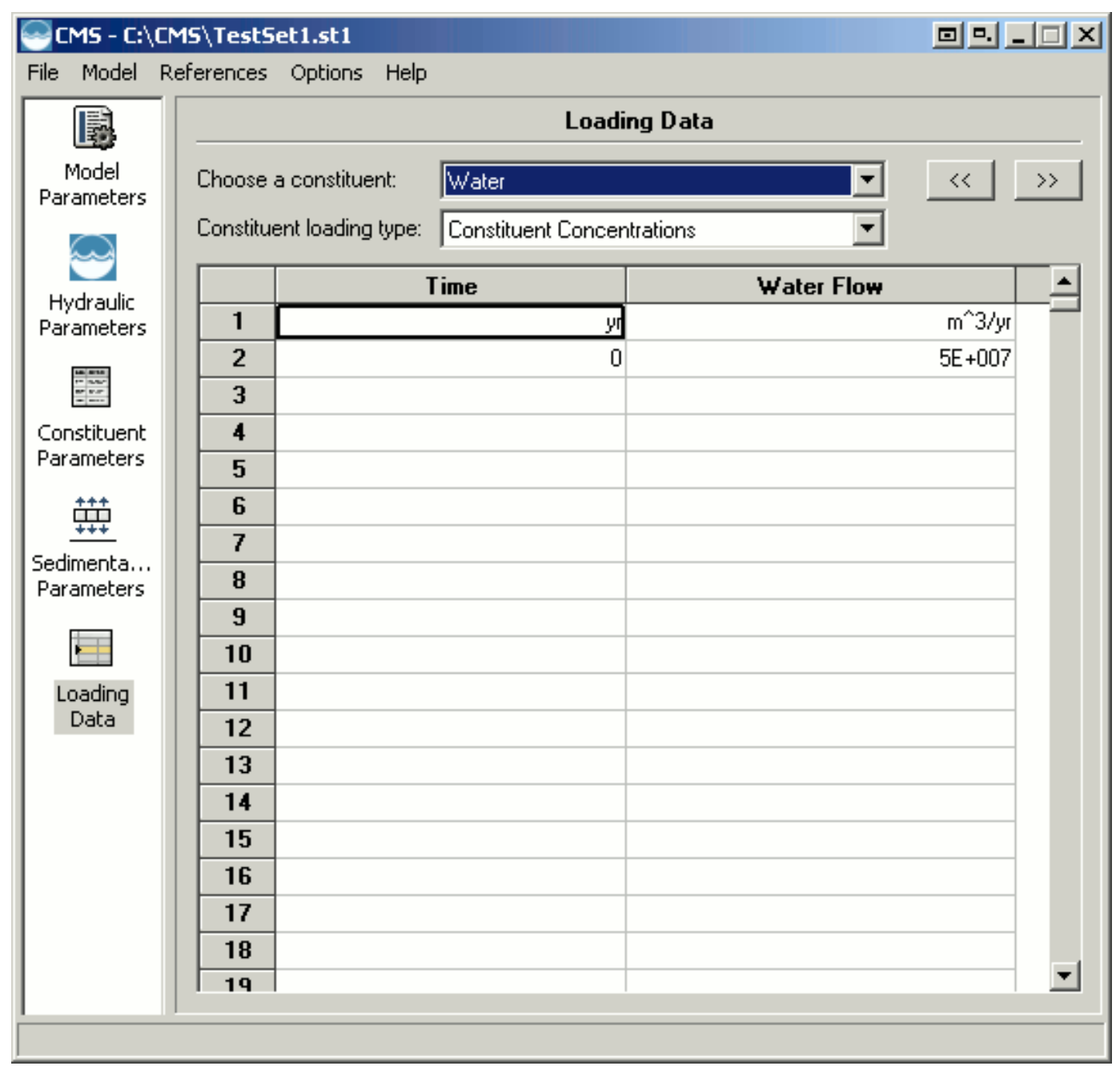

Figure 23. Loading Data Screen (Water Flow Grid).

\section{Water Flow Field Descriptions}

- Time - Specifies a time period for which a water flow value will be specified (units may be specified in combo box). The water flow must be specified at the initial time, a value of zero, and this value will be used for all calculations if no other values are specified.

- Water Flow - Specifies the water flow at the designated time (units may be specified in combo box). 


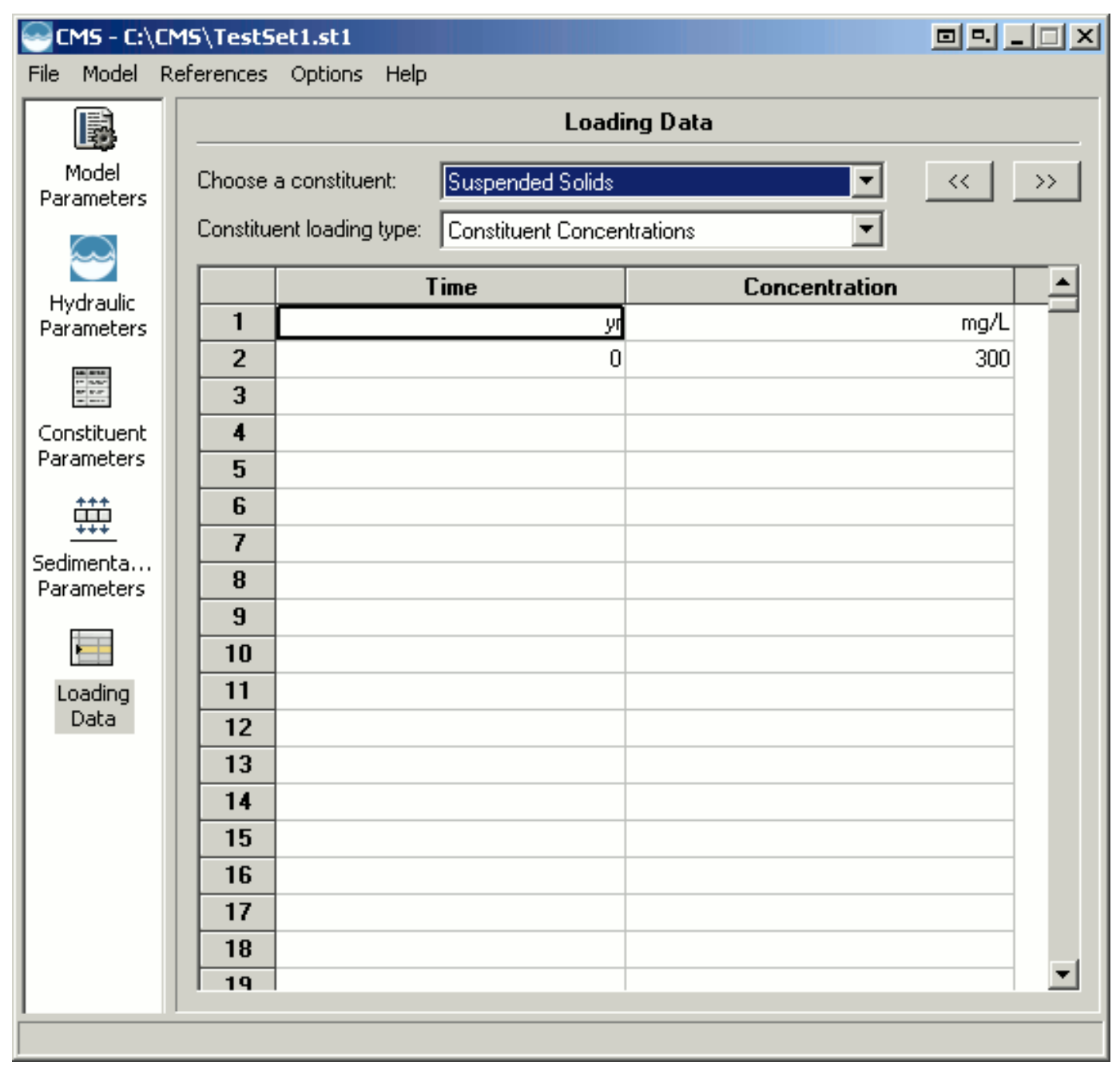

Figure 24. Loading Data Screen (Suspended Solids Concentration Grid).

\section{Suspended Solids Concentration Field Descriptions}

- Time - Specifies a time period for which a suspended solids concentration value will be specified (units may be specified in combo box). The suspended solids concentration must be specified at the initial time, a value of zero, and this value will be used for all calculations if no other values are specified.

- Concentration - Specifies the suspended solids concentration at the designated time (units may be specified in combo box).

- *Note - if the model is being run with a steady-state solids balance, the suspended solids concentration grid will be disabled. In this case, the value entered on the model parameters screen will be used as the steady-state solids concentration. 


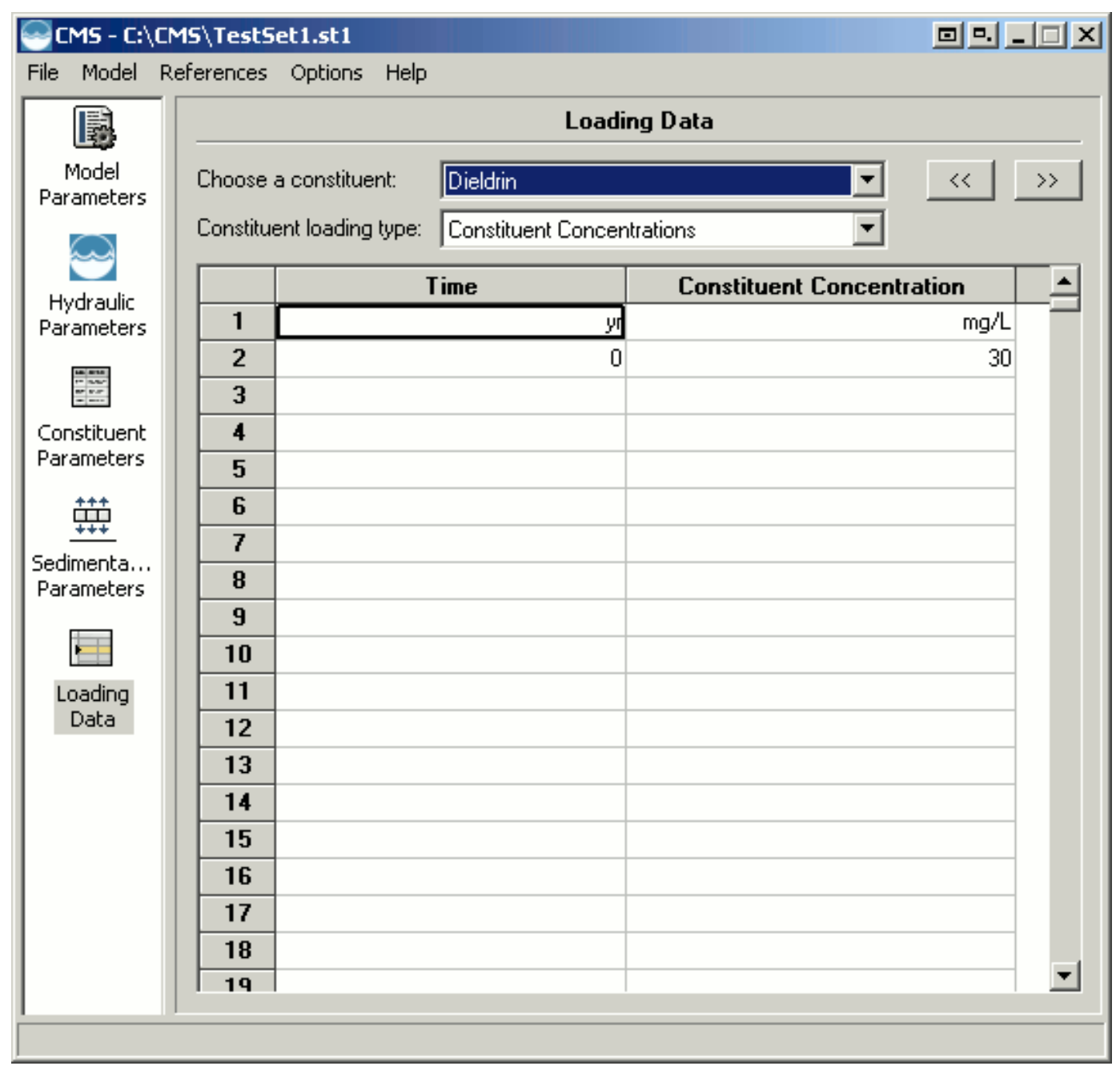

Figure 25. Loading Data Screen (Constituent Flux Grid).

\section{Constituent Concentration Field Descriptions}

- Constituent loading type - Specifies if the constituent data will be entered using fluxes or concentrations. This applies to all constituents and will be the same for each of these.

- Time - Specifies a time period for which a constituent flux value will be specified (units may be specified in combo box). The constituent flux must be specified at the initial time, a value of zero, and this value will be used for all calculations if no other values are specified.

- Constituent Flux - Specifies the constituent flux at the designated time (units may be specified in combo box). 
The model is run by selecting "Model -> Run" from the main menu or pressing the $\mathrm{F}_{5}$ key. When the model is executing, the main window of the program will be hidden. A new dialog will be displayed indicating the progress of the model, the current model time step, and the current simulation time during the execution (Figure 26). The model run can be terminated by clicking the "Cancel" button at any point during the execution process.

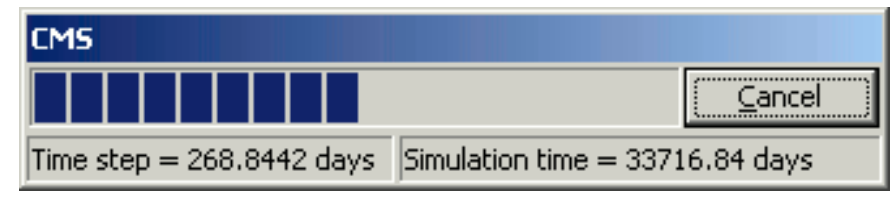

Figure 26. Model Progress Dialog.

The execution options dialog allows the user to specify the action that is to be taken when running the model with data that have been modified. If the current project has been modified and the changes have not been saved, the application can perform one of three tasks:

- Automatically save on run - Specifies that the model will automatically save any changes to the original file before running the model.

- Save to temporary file on run - Specifies that the model will use a temporary file with all of the current project settings and leave the original file unmodified. This is useful to see what effect a certain change will have on the model results without modifying the original file.

- Prompt user for action - Specifies that the model is to prompt the user for an action to take whenever the model is run and there are changes that have not been saved.

The default setting is to use a temporary file if this situation arises, but the user can modify this by using the "Execution Options" dialog. The execution options dialog and all available options are shown in Figure 27. 


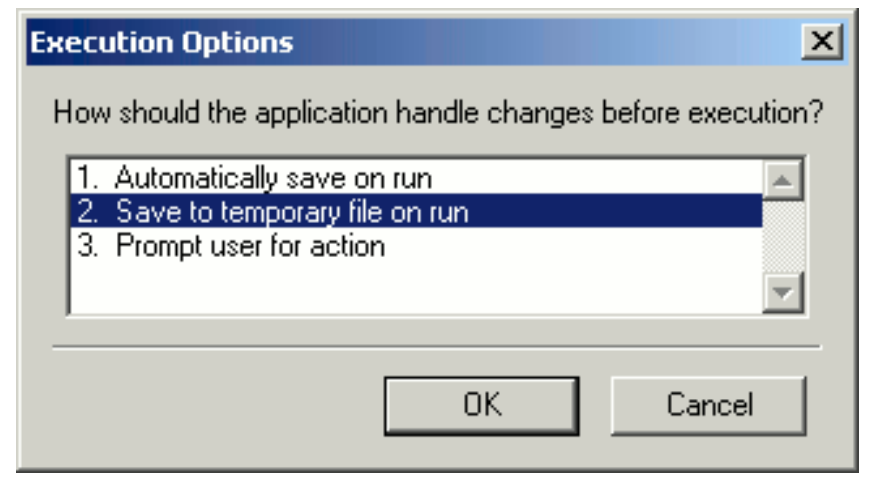

Figure 27. Execution Options Dialog.

Before the model is run, the program checks to ensure that all required data have been entered. This prevents errors from occurring during model execution and informs the user about the data that need to be entered. When a problem is found in the current data set, a dialog such as the one shown in Figure 28 will be displayed. The user should then proceed to correct the problem and try running the model again.

In addition to the message given for input data errors, the input fields on each screen change colors to indicate if the data that have been entered are valid for the current parameter. This can be seen in Figure 28 above where the model time step input field is light red instead of the green color shown for other fields. 


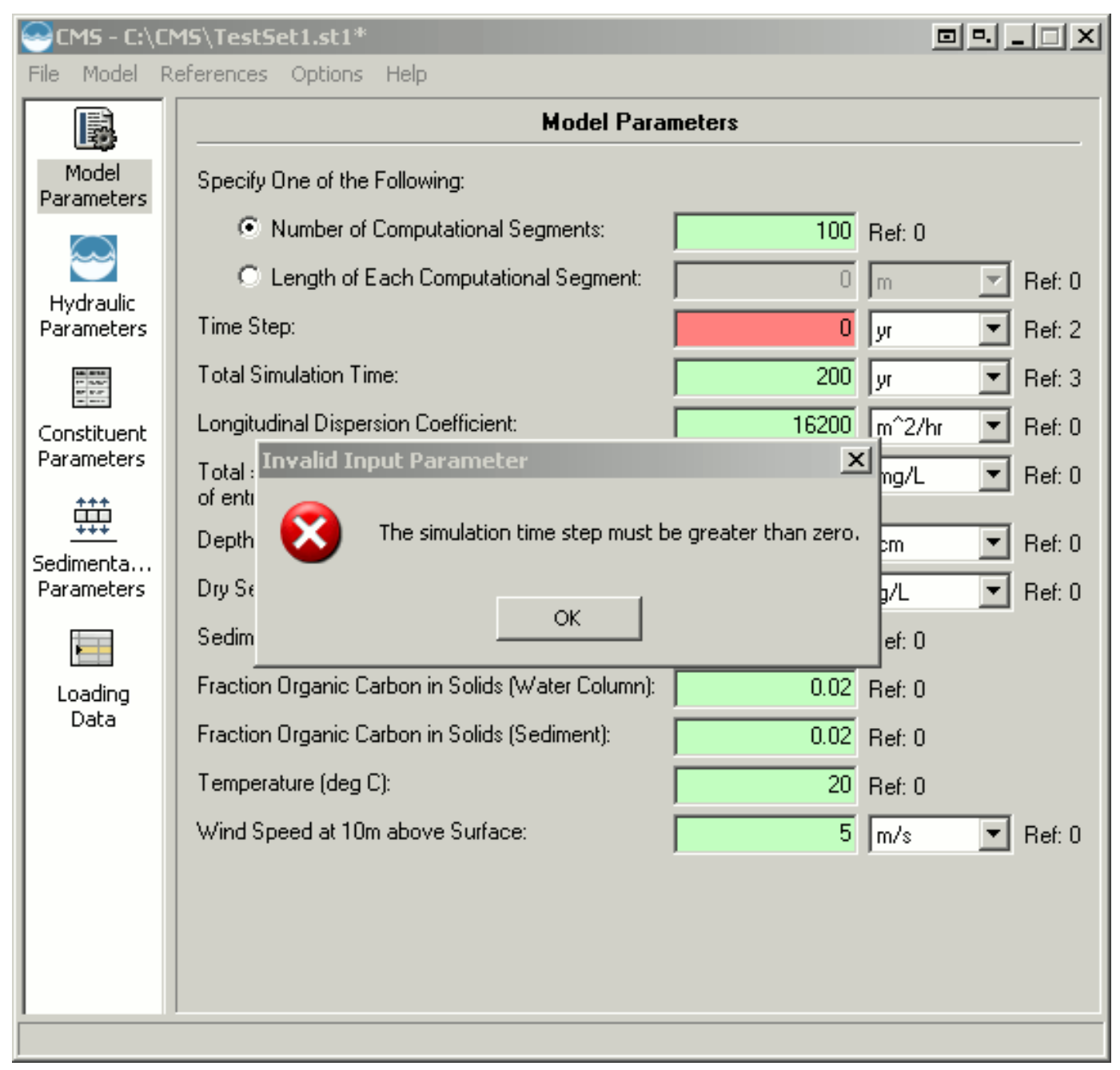

Figure 28. CMS Input Error.

Once model execution has begun, errors may occur as a result of many factors such as an imbalance in the suspended solids, an error reading or writing to a data file, or even because the user presses the "Cancel" button. When an error occurs during model execution, a message dialog will be displayed that indicates what error occurred (Figure 29). The user can then take steps to correct the error and re-run the model. 


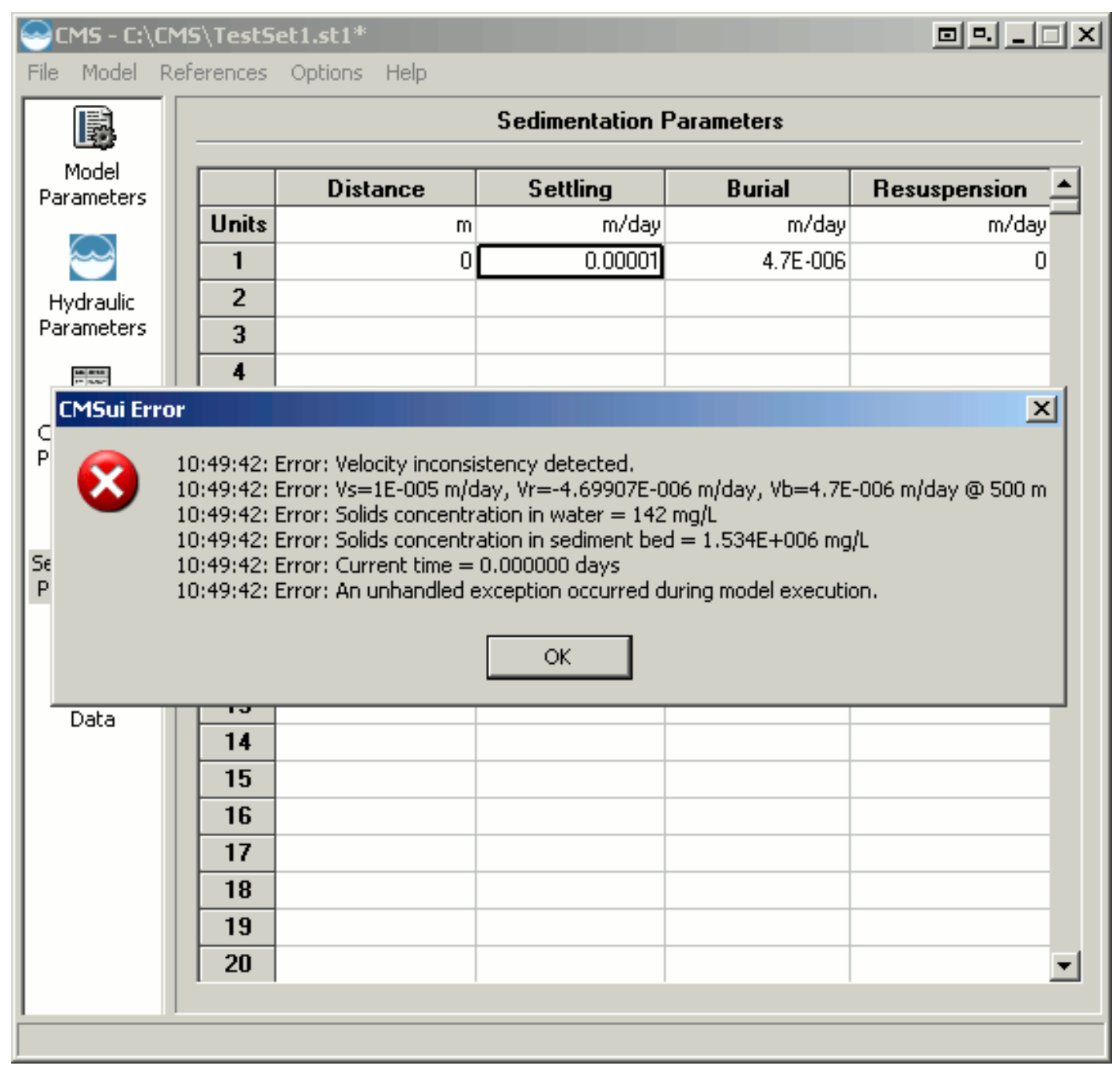

Figure 29. Model Execution Error.

If the error was caused by user intervention, pressing the "Cancel" button, the error message will appear as shown in Figure 30. No action is required by the user since the only error that occurred was an interruption in the model execution process. 


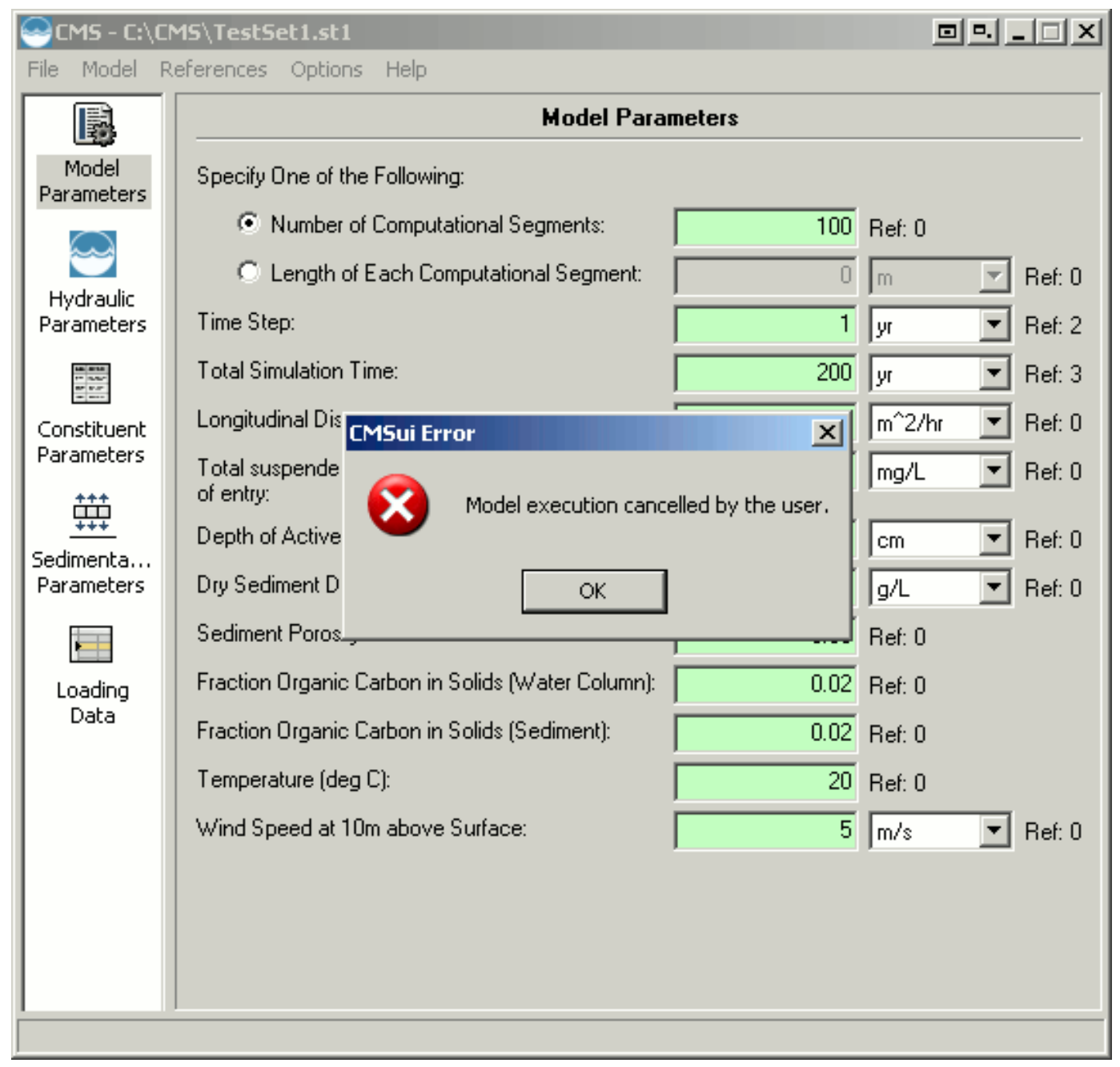

Figure 30. User Intervention Error.

After the model has been run successfully, the "Results" menu item under the "Model" menu will be enabled (Figure 31). This menu item is also enabled when loading an input file that has been run successfully and when loading a results data file. If the model was not run successfully, and no results file was created, the menu item will not be enabled.

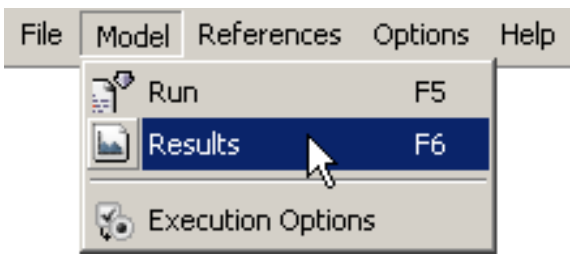

Figure 31. View Results Menu Item. 
To view the model results, select "Model -> Results" from the main menu. The results form shown in Figure 32 will then be loaded. This form will allow the user to view the model results in a variety of ways, both text and graphical. Descriptions of the form fields and the functions they perform are listed below. Once all of the required information has been specified, click the "View Plot" button to load the plot dialog.

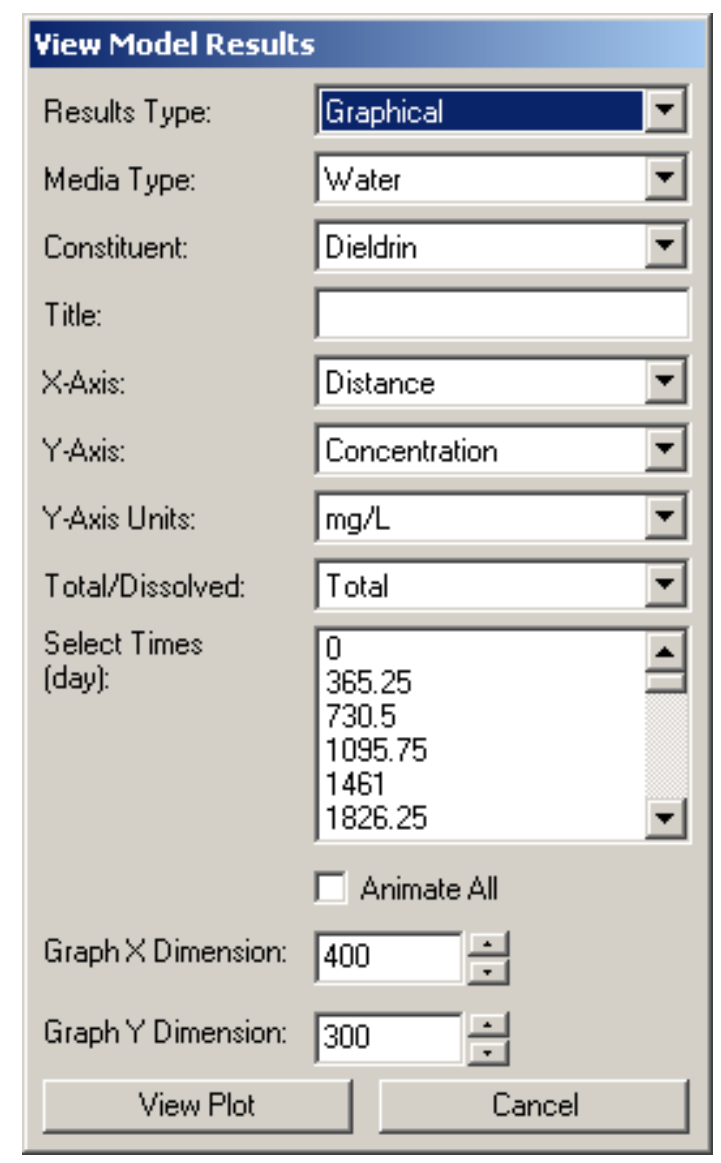

Figure 32. Results Form

\section{Results Form Field Descriptions}

- Results Type - Specifies how the results will be displayed to the user. The two available options are Graphical and Text. The graphical option will display a plot with the user-specified information, and the text option will display the same user-specified information in a tabular view. 
- Media Type - Specifies the values that are to be displayed. The two available options are Water and Sediment. The water option will display the values for the specified constituent in the water column. The sediment option will display the values for the specified constituent in the sediment bed.

- Constituent - Specifies the constituent for which the model results will be displayed. This list contains all of the constituents specified in the model input and also contains a "Suspended Solids" entry when the media type is specified as "water." This allows the user to view the suspended solids concentration in the water column.

- Title - Specifies a title that will be placed at the top of the plot that is produced. This is optional and is present mainly to allow for the option of having a title on images that are exported from the plot dialog.

- $\mathbf{X}$-Axis - Specifies the values for the x-axis on the plot. The two available options are Distance and Time. The distance option will plot concentration values on the $y$-axis versus downstream distance along the $x$-axis. The time option will plot concentration values on the y-axis versus time on the $\mathrm{x}$-axis.

- Y-Axis - Specifies the values for the y-axis on the plot. The only available option at the current time is Concentration. The concentration of the selected constituent will always be plotted on the y-axis.

- Y-Axis Units - Specifies the units for the concentrations plotted on the $y$-axis. The units for the concentration in a water column plot will always be in units of $\mathrm{mg} / \mathrm{L}$. The units of the concentration in a sediment plot can be either $\mathrm{mg} / \mathrm{L}$ or $\mathrm{mg} / \mathrm{kg}$ dry weight. The default for a sediment plot is $\mathrm{mg} / \mathrm{kg}$.

- Total/Dissolved - Specifies if the concentration will be the total concentration for the selected media or only the concentration that is in the dissolved phase. The dissolved phase concentration in the sediment bed refers to the concentration in the pore water. Therefore, the dissolved concentration can only be viewed in units of $\mathrm{mg} / \mathrm{L}$ and refers to the mass dissolved in the pore water per volume of pore water.

- Select Times (Select Distances) - The label for this input option will vary depending upon the value that is chosen for the x-axis. If the $\mathrm{x}$-axis option is specified as "Distance," this list will allow the selection of times for which the concentration vs. distance plots are to be displayed. If the $\mathrm{x}$-axis option is specified as "Time," this list will allow the selection of distances for which the concentration vs. time plots are to be displayed. The user may select a series of values from this list by selecting the first value and holding down the shift key while selecting 
the last value. Multiple values may also be selected individually by holding down the control key while selecting the values.

- Animate All - This option is used to animate the series of plots for concentration vs. time or concentration vs. distance. If this option is selected, the list box containing all of the values will be disabled since all values will be used in the animation.

- Graph X Dimension/Graph Y Dimension - Specify the width and height of the plot that will be produced. The minimum plot size that can be produced is $400 \times 300$, and the maximum plot size that can be produced is $800 \times 600$. All values are in pixels.

The plot dialog will appear as shown in Figure 33 for a single time or distance value. A plot for multiple distance values is shown in Figure 34.

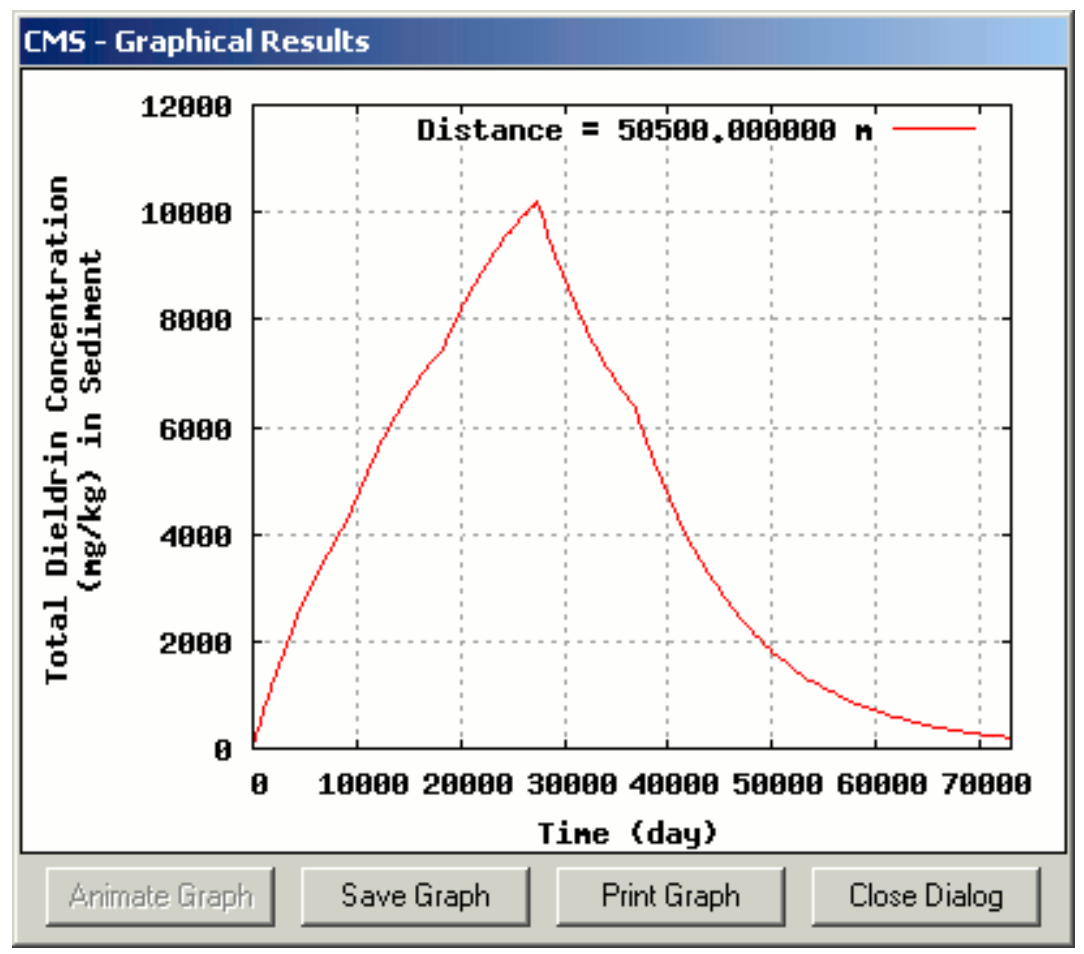

Figure 33. Plot Dialog for a Single Distance. 


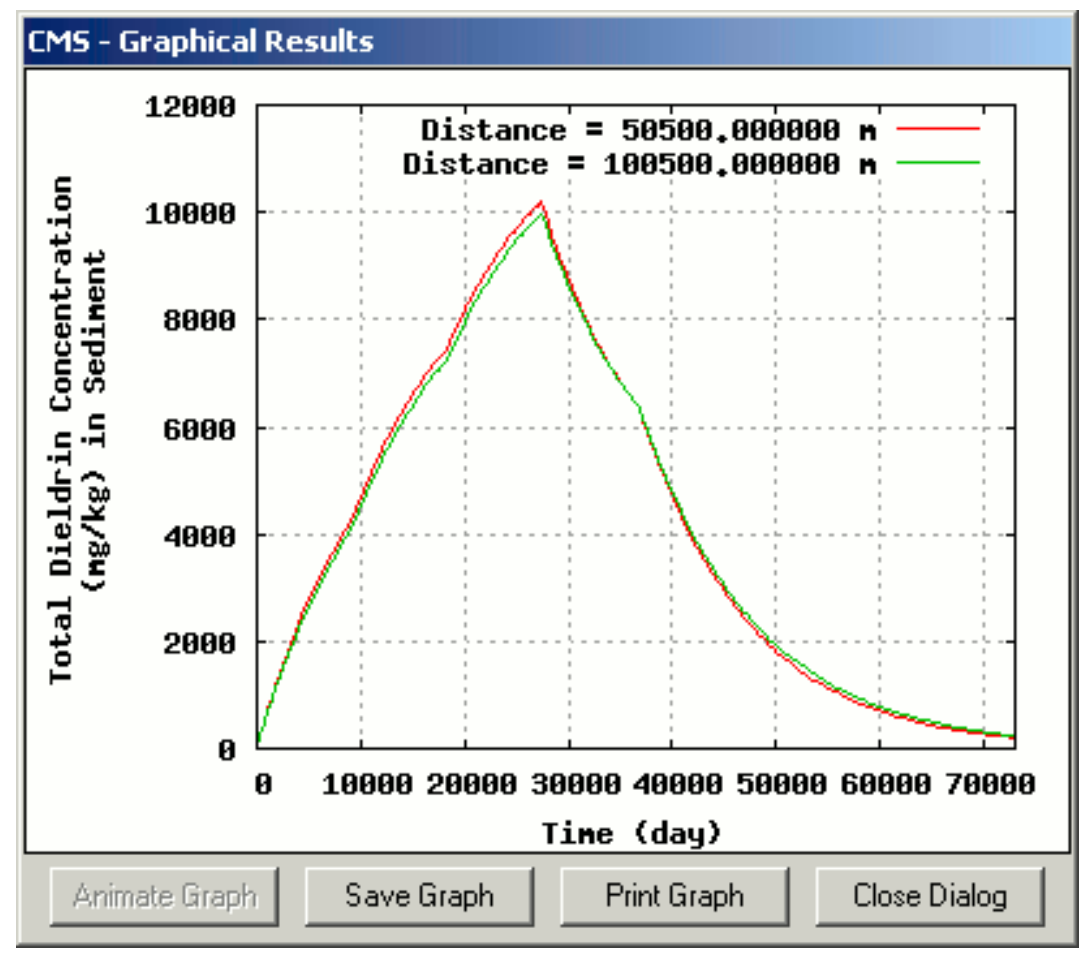

Figure 34. Plot Dialog for Multiple Distance Values.

Time values on the $\mathrm{x}$-axis are always in days and distance values on the $\mathrm{x}$ axis are always in meters. The label for the y-axis indicates the constituent for which the concentration is being plotted as well as the units that were selected. The concentration values always indicate total concentration (dissolved and particulate).

There are buttons at the bottom of the dialog. The "Animate Graph" button is not enabled unless the "Animate All" selection was made on the results form. The "Save Graph" button is used to save the current plot to an image file. The "Print Graph" button is used to print out a hard copy of the current plot. The "Close Dialog" button will close the plot dialog and return the user to the results form.

If the "Animate All" selection is made on the results form, the plot dialog will appear as shown below in Figure 35. 


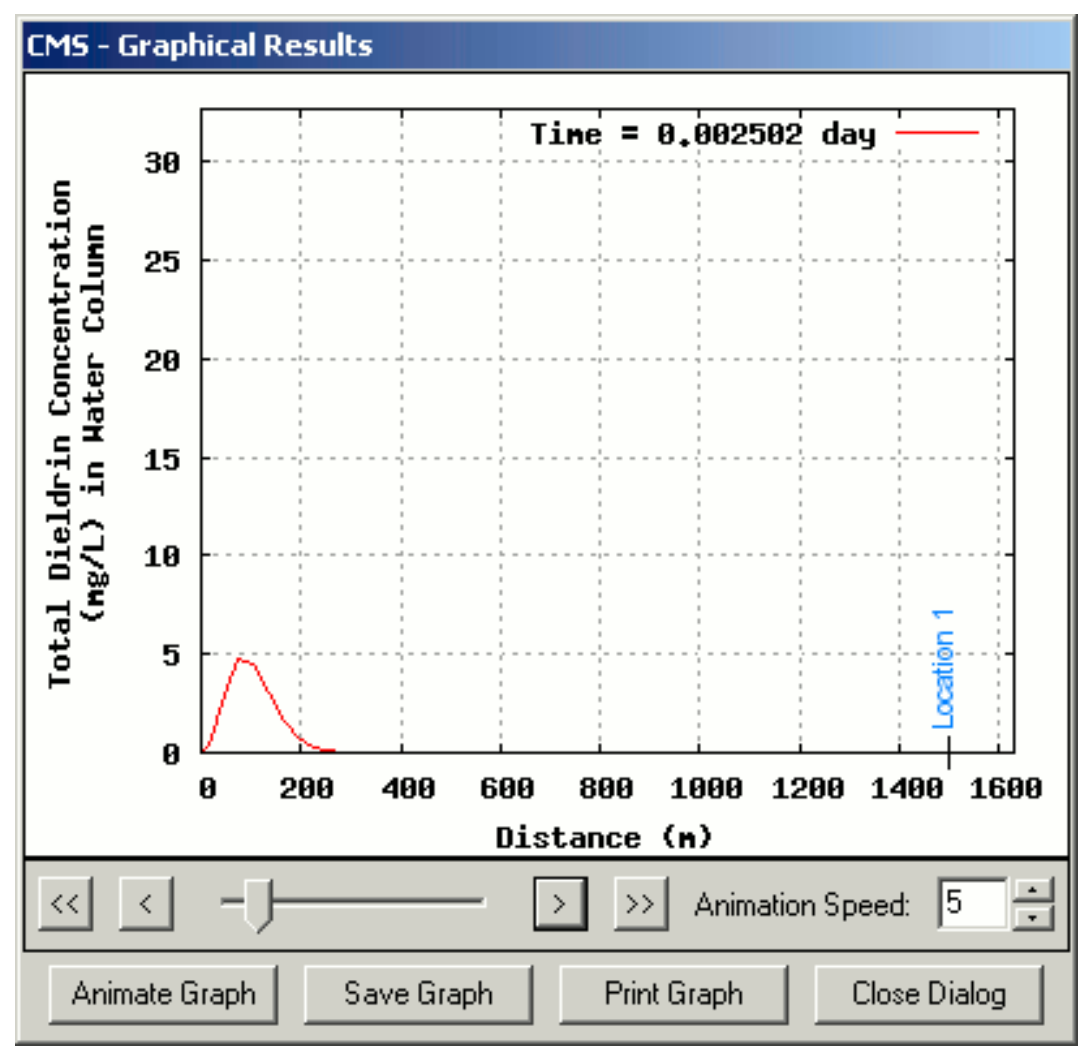

Figure 35. Plot Dialog in Animation Mode.

The "Animate Graph" button is now enabled, and several additional controls appear on the dialog. When the animate button is clicked, the plots will be displayed in order for each time or distance value (depending upon which value was chosen for the $\mathrm{x}$-axis) beginning with the first value. While the animation is playing, the caption of the "Animate Graph" button will change to display "Cancel." This button can be clicked during the animation to cancel playback. The box labeled "Animation Speed" is used to control the speed of the animation. The default value is " 5 " and ranges from a low value (slowest) of 1 to a high value (fastest) of 10 . The slider control is used to move through the plots without actually playing the animation. The two buttons on the left side of the slider control, from left to right, are used to move to the first image in the animation or to the previous image in the animation. The two buttons on the right side of the slider control, from left to right, are used to move to the next image in the animation or to the last image in the animation. If the "Save Graph" button is clicked for an animation, the user has the option to save the current form of the animation or to save the entire animation as an MPEG file. The action that is taken is determined by the type of file chosen in the 
save file dialog (Figure 36). If the *.mpg extension is chosen, the entire animation is saved. Otherwise, the current plot is saved.

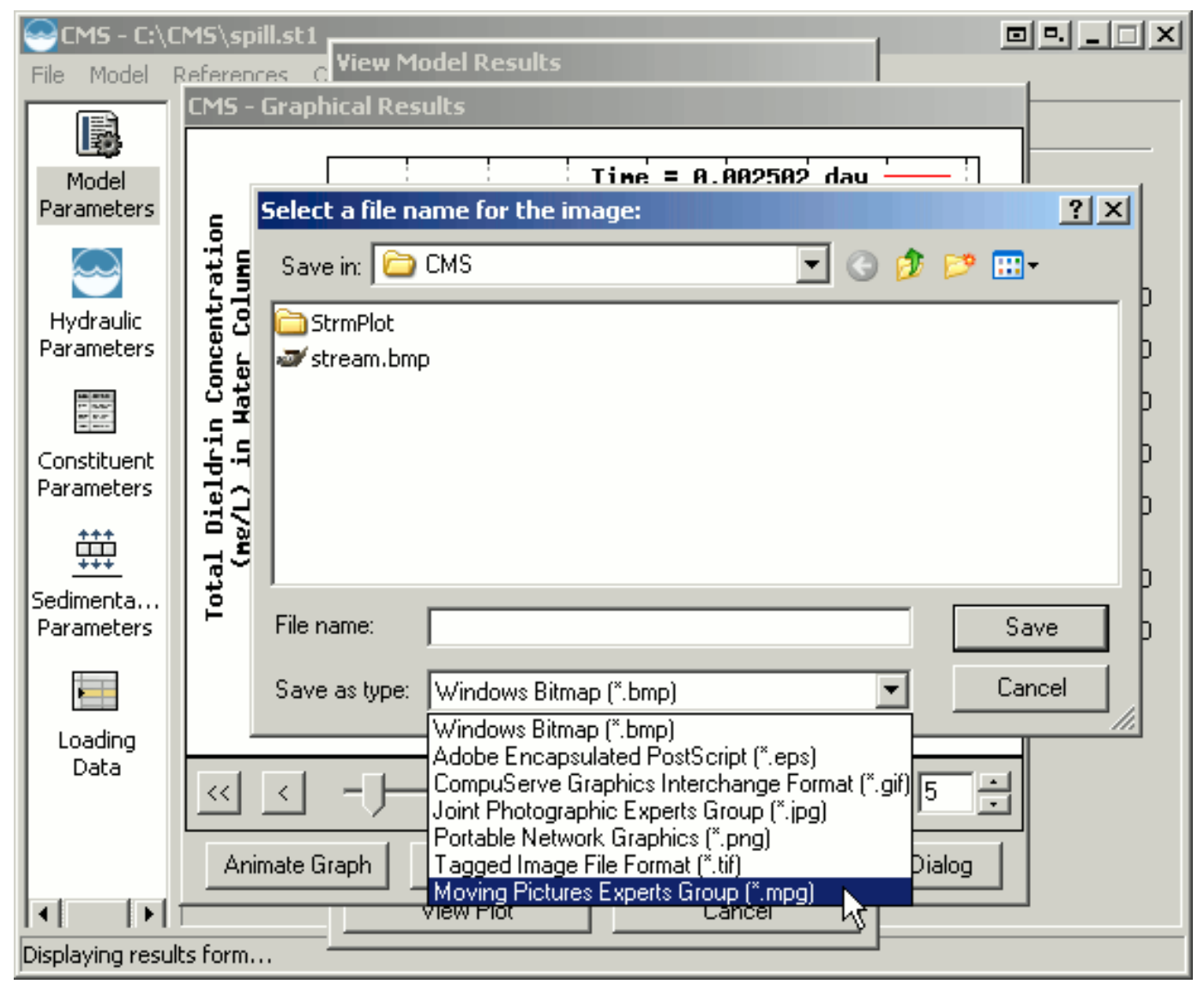

Figure 36. Save File Dialog.

The text viewer displays the concentration data in a tabular format allowing the user to view any point in the data series. When the "Text" option is chosen for the results type on the results form, many of the options available for graphical results are no longer available. This is because all of the data series will be displayed and there is no plot size to define. The results form will appear as shown in Figure 37. 


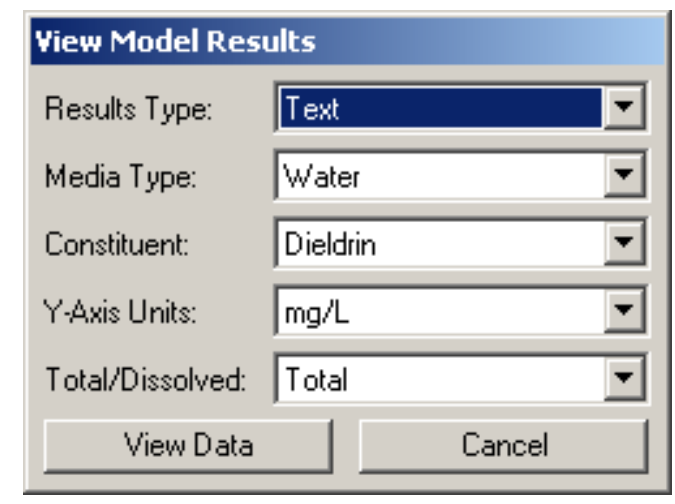

Figure 37. Results Form for Text Results.

The user may select the media type, constituent, and units for the y-axis as was done for the graphical results. The "View Data" button is then used to open the text viewer form (Figure 38). This form displays the downstream distance in meters in the column header (top row) and the time in days in the first column. The user can scroll to any point to view data values. The data can be printed using the "Print Data" button or exported to a commaseparated file using the "Save Data" button.

\begin{tabular}{|c|c|c|c|c|c|c|c|c|}
\hline \multicolumn{9}{|c|}{ CMS - Tabular Results } \\
\hline \multicolumn{9}{|c|}{ Water column values for Dieldrin [mg/L] } \\
\hline & $0.00 E+000$ & $5.00 E+002$ & $1.50 \mathrm{E}+003$ & $2.50 \mathrm{E}+003$ & $3.50 E+003$ & $4.50 E+003$ & $5.50 E+003$ & 6. \\
\hline $0.00 E+000$ & $3.00 \mathrm{E}+001$ & $0.00 E+000$ & $0.00 \mathrm{E}+000$ & $0.00 E+000$ & $0.00 \mathrm{E}+000$ & $0.00 E+000$ & $0.00 E+000$ & \\
\hline $3.65 \mathrm{E}+002$ & $3.00 E+001$ & $3.00 E+001$ & $3.00 \mathrm{E}+001$ & $3.00 \mathrm{E}+001$ & $3.00 \mathrm{E}+001$ & $3.00 \mathrm{E}+001$ & $3.00 E+001$ & \\
\hline $7.31 \mathrm{E}+002$ & $3.00 \mathrm{E}+001$ & $3.00 E+001$ & $3.00 \mathrm{E}+001$ & $3.00 \mathrm{E}+001$ & $3.00 \mathrm{E}+001$ & $3.00 \mathrm{E}+001$ & $3.00 \mathrm{E}+001$ & \\
\hline $1.10 \mathrm{E}+003$ & $3.00 E+001$ & $3.00 E+001$ & $3.00 \mathrm{E}+001$ & $3.00 E+001$ & $3.00 \mathrm{E}+001$ & $3.00 \mathrm{E}+001$ & $3.00 \mathrm{E}+001$ & \\
\hline $1.46 E+003$ & $3.00 E+001$ & $3.00 E+001$ & $3.00 \mathrm{E}+001$ & $3.00 \mathrm{E}+001$ & $3.00 \mathrm{E}+001$ & $3.00 \mathrm{E}+001$ & $3.00 \mathrm{E}+001$ & \\
\hline $1.83 \mathrm{E}+003$ & $3.00 \mathrm{E}+001$ & $3.00 \mathrm{E}+001$ & $3.00 \mathrm{E}+001$ & $3.00 \mathrm{E}+001$ & $3.00 \mathrm{E}+001$ & $3.00 \mathrm{E}+001$ & $3.00 \mathrm{E}+001$ & \\
\hline $2.19 \mathrm{E}+003$ & $3.00 E+001$ & $3.00 E+001$ & $3.00 \mathrm{E}+001$ & $3.00 \mathrm{E}+001$ & 3.00E +001 & $3.00 \mathrm{E}+001$ & $3.00 \mathrm{E}+001$ & \\
\hline $2.56 \mathrm{E}+003$ & $3.00 E+001$ & $3.00 \mathrm{E}+001$ & $3.00 \mathrm{E}+001$ & $3.00 E+001$ & $3.00 \mathrm{E}+001$ & $3.00 \mathrm{E}+001$ & $3.00 E+001$ & \\
\hline $2.92 \mathrm{E}+003$ & $3.00 \mathrm{E}+001$ & $3.00 \mathrm{E}+001$ & $3.00 \mathrm{E}+001$ & $3.00 \mathrm{E}+001$ & $3.00 \mathrm{E}+001$ & $3.00 \mathrm{E}+001$ & $3.00 E+001$ & \\
\hline $3.29 \mathrm{E}+003$ & $3.00 \mathrm{E}+001$ & $3.00 E+001$ & $3.00 \mathrm{E}+001$ & $3.00 \mathrm{E}+001$ & $3.00 \mathrm{E}+001$ & $3.00 \mathrm{E}+001$ & $3.00 \mathrm{E}+001$ & \\
\hline $3.65 E+003$ & $3.00 E+001$ & $3.00 \mathrm{E}+001$ & $3.00 \mathrm{E}+001$ & $3.00 \mathrm{E}+001$ & $3.00 \mathrm{E}+001$ & $3.00 \mathrm{E}+001$ & $3.00 \mathrm{E}+001$ & \\
\hline $4.02 E+003$ & $3.00 \mathrm{E}+001$ & $3.00 E+001$ & $3.00 \mathrm{E}+001$ & $3.00 \mathrm{E}+001$ & $3.00 \mathrm{E}+001$ & $3.00 \mathrm{E}+001$ & $3.00 \mathrm{E}+001$ & \\
\hline $4.38 E+003$ & $3.00 \mathrm{E}+001$ & $3.00 \mathrm{E}+001$ & $3.00 \mathrm{E}+001$ & $3.00 \mathrm{E}+001$ & $3.00 \mathrm{E}+001$ & $3.00 \mathrm{E}+001$ & $3.00 \mathrm{E}+001$ & $\nabla$ \\
\hline \multicolumn{8}{|l|}{ 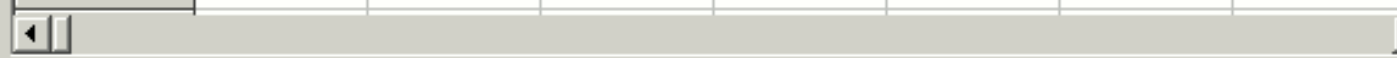 } & - \\
\hline \multicolumn{9}{|c|}{${ }^{x}$ Rows indicate the time step [day] and Columns indicate downstream distance [m] } \\
\hline \multicolumn{3}{|c|}{ Save Data } & \multicolumn{3}{|c|}{ Print Data } & \multicolumn{3}{|c|}{ Close } \\
\hline
\end{tabular}

Figure 38. Text Viewer. 
References can be useful to indicate where or how a certain value in the model input was obtained. References can be added for most fields in the model, and the reference number will be shown to the right of the field as in Figure 39 below for the Octanol-Water Partition Coefficient.

\begin{tabular}{|c|c|c|c|c|c|c|}
\hline \multicolumn{3}{|c|}{ CMS - C:'CMS TestSet1.st1 } & & \multicolumn{3}{|c|}{ 미 ㅁ. $=x$} \\
\hline \multicolumn{7}{|c|}{ File Model References Options Help } \\
\hline \multicolumn{7}{|c|}{ Constituent Parameters } \\
\hline $\begin{array}{c}\text { Model } \\
\text { Parameters }\end{array}$ & Constituent: & & $\nabla$ & Add & 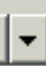 & \multirow[b]{3}{*}{ Ref: 0} \\
\hline \multirow{3}{*}{$\begin{array}{l}\text { Hydraulic } \\
\text { Parameters }\end{array}$} & Constituent CAS ID: & & $60-57-1$ & \multicolumn{2}{|l|}{ Ref: 0} & \\
\hline & \multicolumn{2}{|c|}{$\begin{array}{l}\text { Constituent background stream concentration } \\
\text { at point of entry: }\end{array}$} & $\overline{0}$ & $\mathrm{mg} / \mathrm{L}$ & $\nabla$ & \\
\hline & \multicolumn{2}{|c|}{ Initial constituent concentration in sediment bed: } & $\overline{0}$ & $\mathrm{mg} / \mathrm{L}$ & $\nabla$ & Ref: 0 \\
\hline 登要 & \multicolumn{2}{|c|}{ Decay rate of dissolved phase in water column: } & 0.0006 & /day & $\nabla$ & Ref: 0 \\
\hline $\begin{array}{l}\text { Constituent } \\
\text { Parameters }\end{array}$ & \multicolumn{2}{|c|}{ Decay rate of particulate phase in water column: } & 0 & /day & $\mp$ & Ref: 0 \\
\hline - & \multicolumn{2}{|c|}{ Decay rate of dissolved phase in sediment bed: } & 0.0006 & /day & $\nabla$ & Ref: 0 \\
\hline 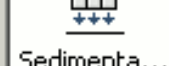 & \multirow{2}{*}{\multicolumn{2}{|c|}{$\begin{array}{l}\text { Decay rate of particulate phase in sediment bed: } \\
\text { Select one of the following: }\end{array}$}} & 0 & /day & $\nabla$ & \multirow[t]{2}{*}{ Ref: 0} \\
\hline Parameters & & & & & & \\
\hline 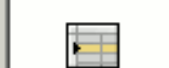 & \multicolumn{2}{|c|}{ (- Octanol-water partition coefficient $(\mathrm{mL} / \mathrm{mL})$ : } & 21000 & Ref: 1 & & \multirow{5}{*}{$\begin{array}{l}\text { Ref: } 0 \\
\text { Ref: } 0\end{array}$} \\
\hline \multirow{7}{*}{$\begin{array}{l}\text { Loading } \\
\text { Data }\end{array}$} & \multicolumn{2}{|c|}{ Partition coefficient in water column $(\mathrm{L} / \mathrm{kg})$ : } & $\overline{259.14}$ & Ref: 0 & & \\
\hline & \multicolumn{2}{|c|}{ Partition coefficient in sediment bed $(\mathrm{L} / \mathrm{kg})$ : } & $\overline{259.14}$ & Ref: 0 & & \\
\hline & \multirow{2}{*}{\multicolumn{2}{|c|}{$\begin{array}{ll}\text { Volatilization rate: } & \sqrt{ } \text { Calculate } \\
\text { Mass transfer velocity: } & \sqrt{\checkmark} \text { Calculate }\end{array}$}} & 0.353202 & $\mathrm{~m} / \mathrm{day}$ & $\nabla$ & \\
\hline & & & $\overline{0.422061}$ & $\mathrm{~m} / \mathrm{day}$ & $\nabla$ & \\
\hline & \multicolumn{2}{|c|}{ Molecular Weight (g/g-mole): } & $\overline{381}$ & \multicolumn{2}{|l|}{ Ref: 0} & \multirow{3}{*}{ Ref: 0} \\
\hline & \multicolumn{2}{|l|}{ Molecular Diffusivity: } & $4.2 \mathrm{E}-010$ & $\mathrm{~m}^{\wedge} 2 / \mathrm{s}$ & $\nabla$ & \\
\hline & \multicolumn{2}{|c|}{ Henry's Law Constant (atm-m^3/g-mole): } & $5.8 \mathrm{E}-005$ & Ref: 0 & & \\
\hline
\end{tabular}

Figure 39. Reference Number Indicator.

To view all references used in the current project, select "References -> View" from the main menu (Figure 40).

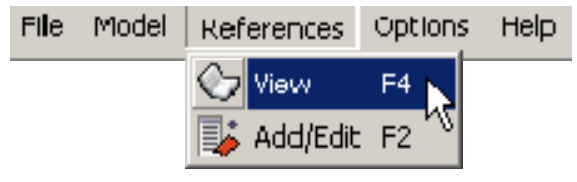

Figure 40. References Menu. 
The references dialog will then be displayed as shown in Figure 41. The user can click on the column labels to sort the references in either ascending or descending order according to any of the columns. This dialog is also used to delete references. To delete a reference, select the appropriate reference in the list and click the "Delete Reference" button at the bottom left corner of the dialog. If multiple fields are using a reference, it will be displayed once for each field with the field name and constituent name (where applicable) listed in the appropriate columns. A reference cannot be deleted if one or more fields are currently using it. Therefore, a reference can be deleted only if the "Field Name" column is empty.

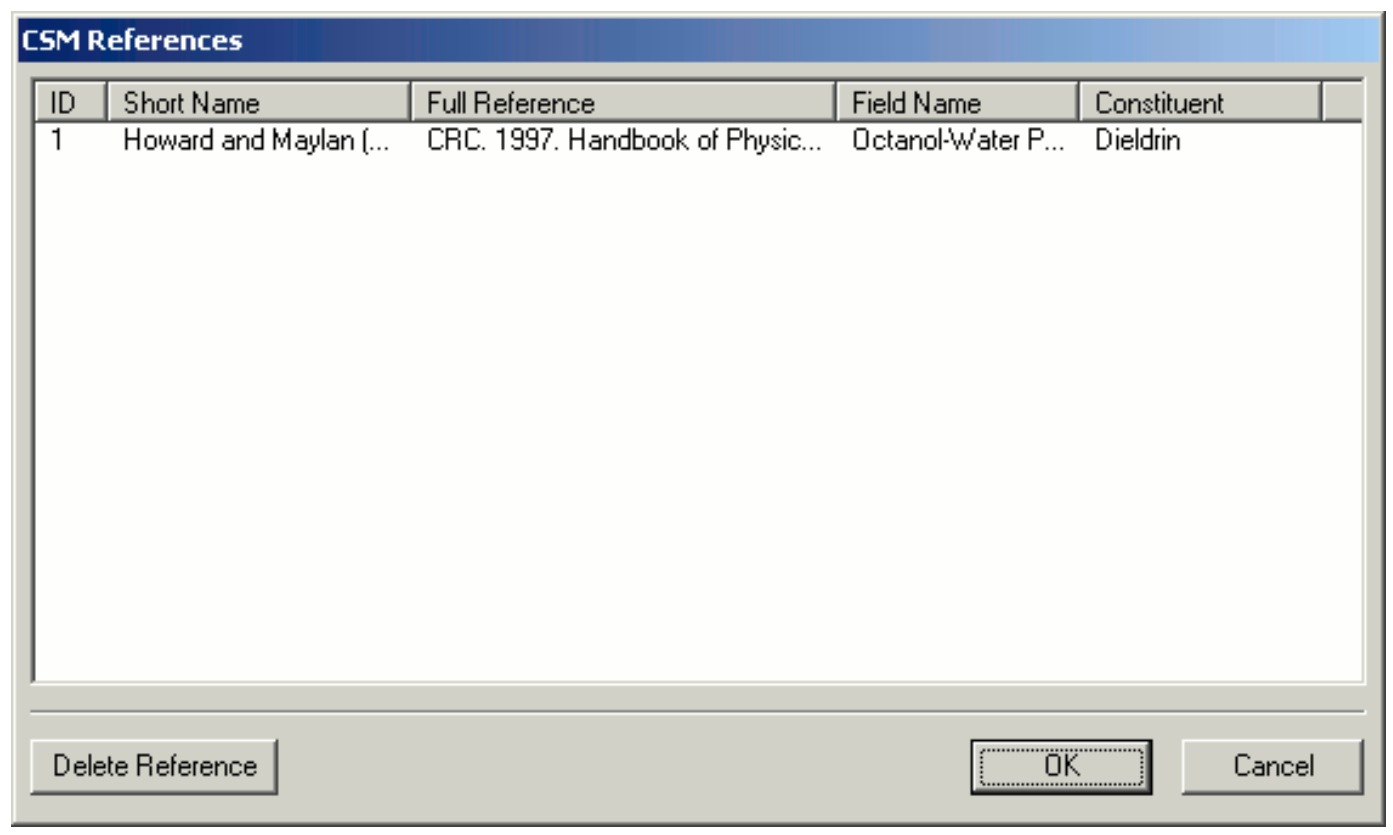

Figure 41. CMS References.

To enter a new reference or edit an existing reference for a field in the current project, make sure that the desired field is selected and choose "References -> Add/Edit" from the main menu. The reference dialog (Figure 42) will then appear as shown below. 


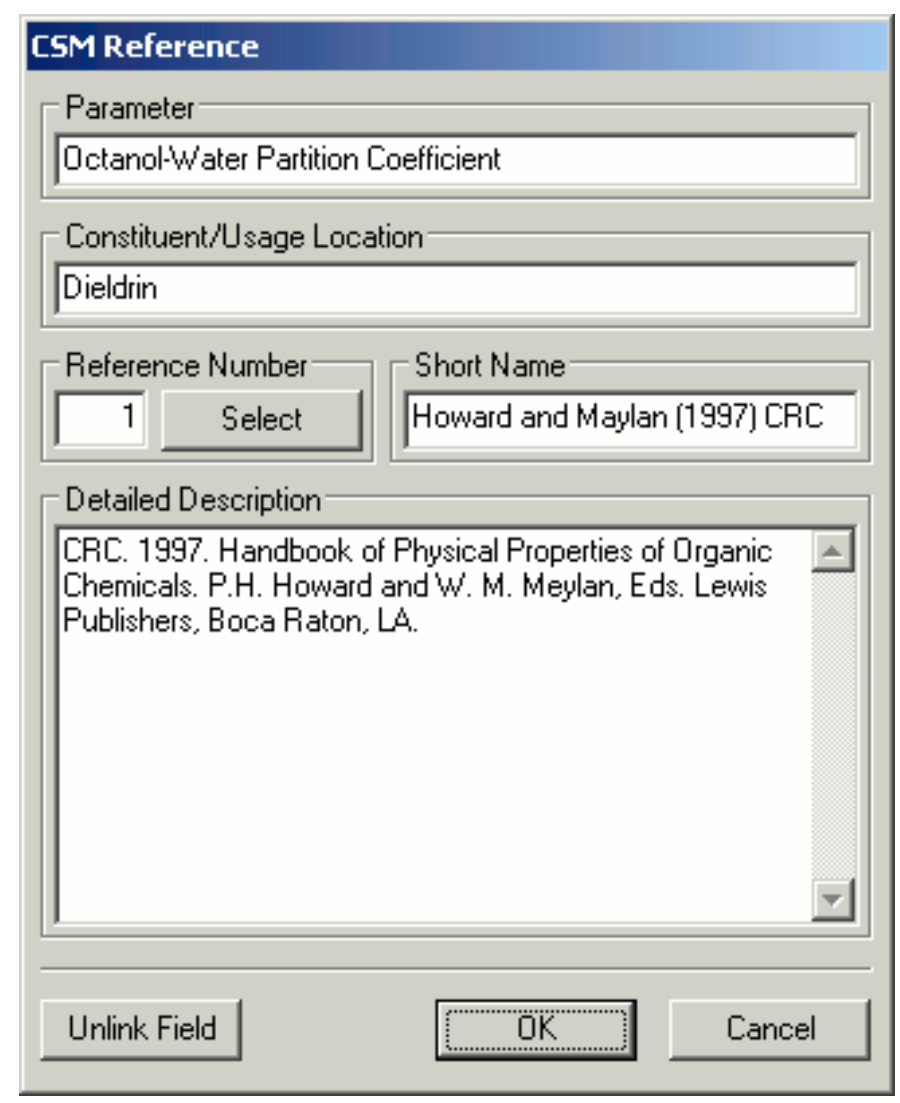

Figure 42. Reference Dialog.

The reference number is automatically generated and can not be modified. An existing reference can be used for the current field by clicking the "Select" button. The dialog shown in Figure 43 will be displayed, allowing the user to select from the list of existing references. 


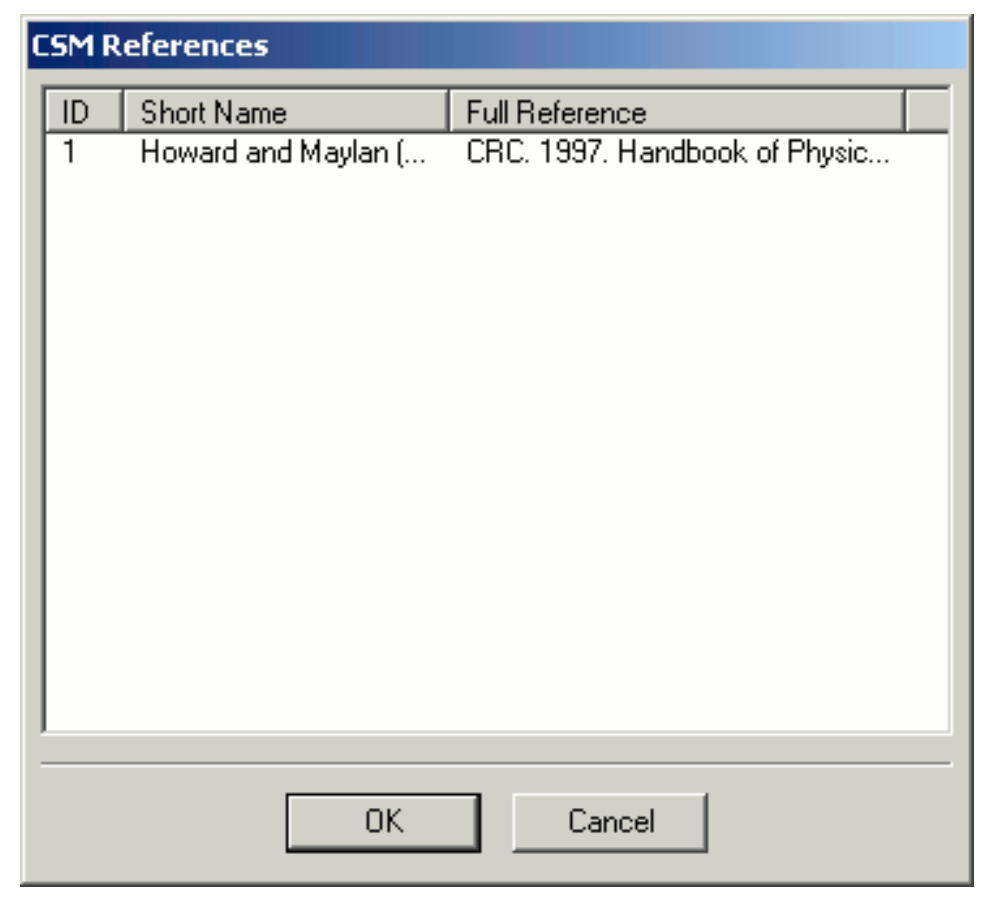

Figure 43. Reference Selection Dialog.

To remove the reference from the current field, click the "Unlink Field" button at the bottom left corner of the reference dialog shown in Figure 42. This will remove the reference number from the field but will not delete the reference information so that it may be used with other fields.

CMS numerical solution options and settings can be modified through the "Options" menu (Figure 44). Through these menu options, users can modify numerical solution scheme settings, solids balance type, and print interval/frequency settings.

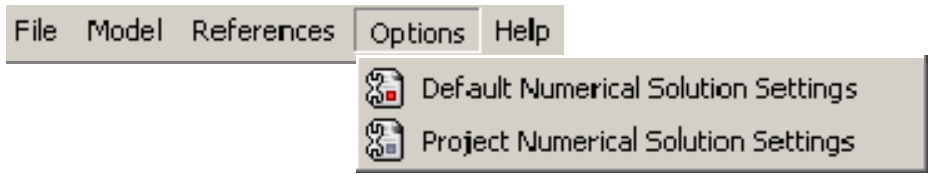

Figure 44. Tools Menu.

The default numerical solution settings dialog allows the user to modify the numerical solution scheme and solids balance settings. These settings will be used for all new projects and all existing projects that have not overridden the default settings. The default numerical solution settings dialog is shown in Figure 45, and the field descriptions are given below. 


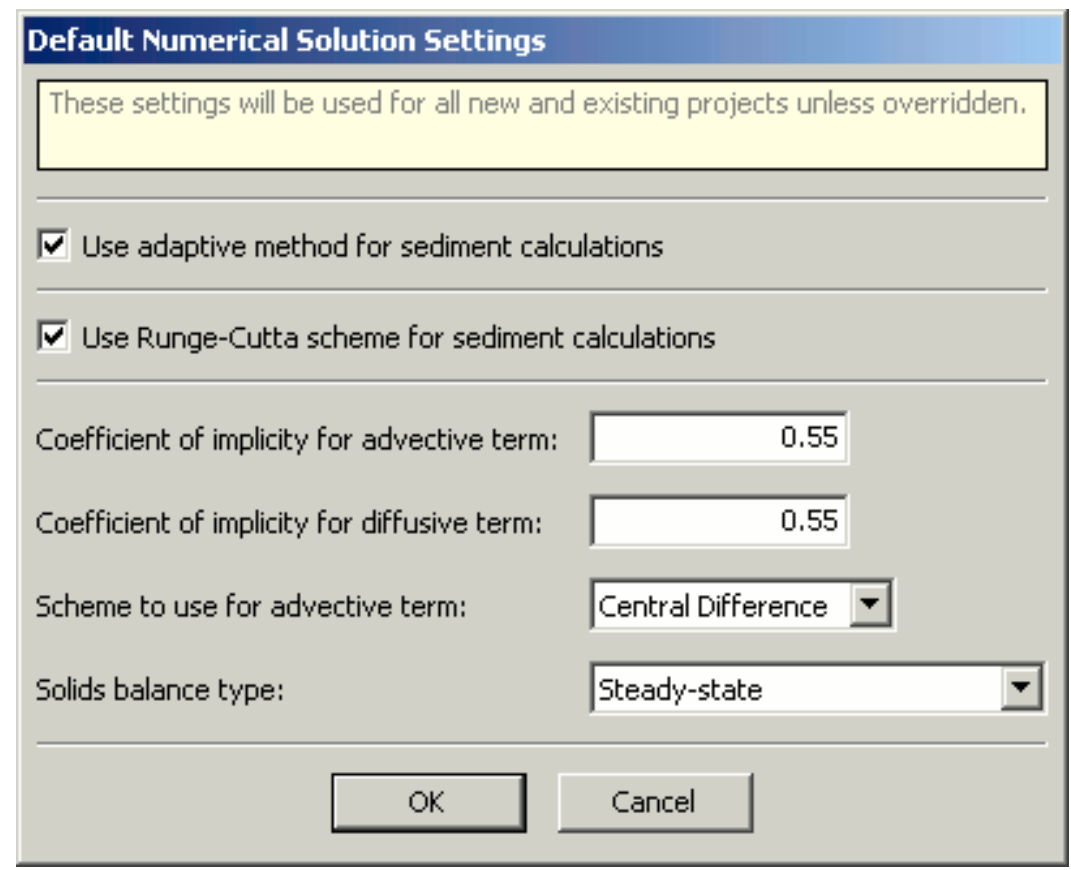

Figure 45. Default Numerical Solution Settings Dialog.

\section{Default Numerical Solution Settings Field Descriptions}

- Use adaptive method for sediment calculations - Specifies that the model should use an adaptive method for performing the sediment bed calculations. This will allow the model to modify the time step in order to maintain the stability of the calculations. This will apply to both the first-order Euler and fourth-order Runge-Kutta schemes.

- Use Runge-Cutta scheme sediment calculations - Specifies that the model should use the fourth-order Runge-Kutta scheme for the sediment calculations instead of the default first-order Euler scheme.

- Coefficient of implicity for advective term - Specifies the division of the advection numerical solution scheme into explicit and implicit parameters. A value of "o" specifies a fully explicit scheme and uses only values from the current time step. A value of " 1 " specifies a fully implicit scheme and uses only values from the future time step.

- Coefficient of implicity for diffusive term - Specifies the division of the diffusion numerical solution scheme into explicit and implicit parameters. A value of "o" specifies a fully explicit scheme and uses only values from the current time step. A value of " 1 " specifies a fully implicit scheme and uses only values from the future time step. 
- Scheme to use for advective term - Specifies the numerical solution scheme to use for the solution of the advective terms. The diffusive terms are always solved using the second-order accurate Crank-Nicolson centered-time, centered-space method. The advective terms can be solved using either the Crank-Nicolson method or the first-order accurate upwind method. The upwind method is not as sensitive to large changes in the concentration gradient, but it induces numerical diffusion.

- Solids balance type - Specifies if the suspended solids in the water column are assumed to be at steady-state or if the solids should be modeled in the same manner as the constituents. The steady-state option will use the value entered for the total solids concentration at the point of entry as the steady-state concentration. The unsteady-state option combines this value with the values entered on the loading data screen to model the solids concentration along the stream reach.

*Note - The only option currently available while the model is running under ARAMS/FRAMES is the steady-state solids balance. The solids transport code is under development and will be available in a later release.

The project numerical solution settings dialog allows the user to modify the numerical solution scheme settings, the solids balance type, and the print interval for the current project. These settings will be used only for the current project and can be reset to use the default system settings at any point by clicking the button labeled "Reset to System." The project numerical solution settings dialog is shown in Figure 46, and the field descriptions are listed below. 


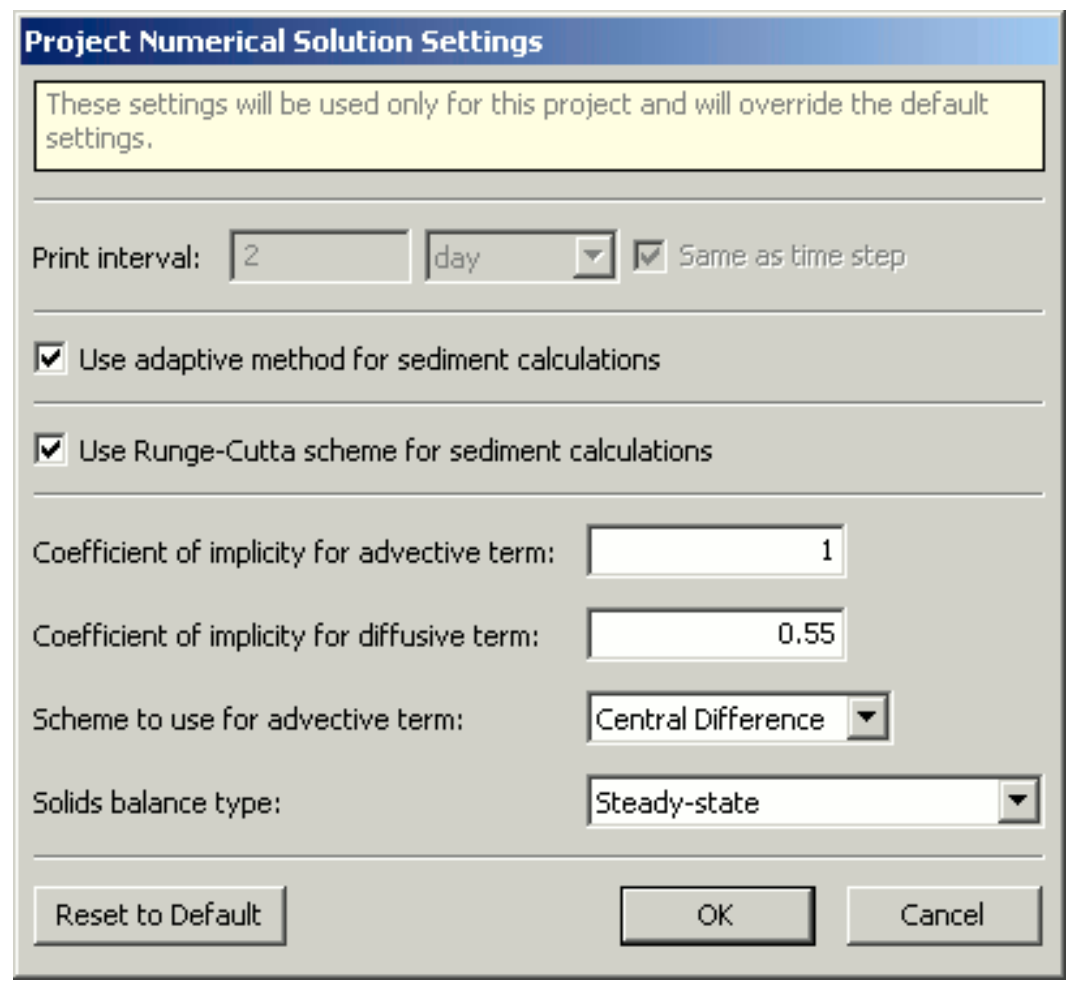

Figure 46. Project Numerical Solution Settings Dialog.

\section{Project Numerical Solution Settings Field Descriptions}

- Print interval - Specifies how frequently data will be written to the output file when running the model. This value is specified in a similar fashion as the time step. By default, the "Same as time step" option is selected. This will print a data point for every time step. If this option is not selected, the data will be output only on the print interval specified here. *Note - this does not apply when the adaptive method is selected. The adaptive method will modify the time step as necessary and may not be able to output data at the exact times specified. In this case, the model will attempt to output data at the time step interval originally specified by the user on the Model Parameters screen.

- Use adaptive method for sediment calculations - Specifies that the model should use an adaptive method for performing the sediment bed calculations. This will allow the model to modify the time step in order to maintain the stability of the calculations. This will apply to both the first-order Euler and fourth-order Runge-Kutta schemes. 
- Use Runge-Kutta scheme sediment calculations - Specifies that the model should use the fourth-order Runge-Kutta scheme for the sediment calculations instead of the default first-order Euler scheme.

- Coefficient of implicity for advective term - Specifies the division of the advection numerical solution scheme into explicit and implicit parameters. A value of "o" specifies a fully explicit scheme and uses only values from the current time step. A value of " 1 " specifies a fully implicit scheme and uses only values from the future time step.

- Coefficient of implicity for diffusive term - Specifies the division of the diffusion numerical solution scheme into explicit and implicit parameters. A value of "o" specifies a fully explicit scheme and uses only values from the current time step. A value of " 1 " specifies a fully implicit scheme and uses only values from the future time step.

- Scheme to use for advective term - Specifies the numerical solution scheme to use for the solution of the advective terms. The diffusive terms are always solved using the second-order accurate CrankNicolson centered-time, centered-space method. The advective terms can be solved using either the Crank-Nicolson method or the firstorder accurate upwind method. The upwind method is not as sensitive to large changes in the concentration gradient, but it induces numerical diffusion.

- Solids balance type - Specifies if the suspended solids in the water column are assumed to be at steady-state or if the solids should be modeled in the same manner as the constituents. The steady-state option will use the value entered for the total solids concentration at the point of entry as the steady-state concentration. The unsteady-state option combines this value with the values entered on the loading data screen to model the solids concentration along the stream reach. *Note - The only option currently available while the model is running under ARAMS/FRAMES is the steady-state solids balance. The solids transport code is under development and will be available in a later release.

The Help menu provides access to information concerning the CMS model. Selecting "Contents" from the help menu or pressing the "F1" key will display this help file. The initial location displayed in the help file will depend upon the current data screen and field that are selected. This allows for help to be displayed for a specific data field simply by clicking into the field and pressing the "F1" key. The Help menu is shown in Figure 47. 


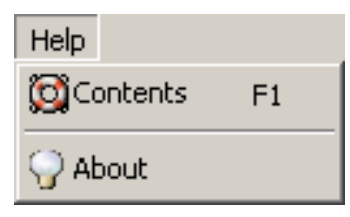

Figure 47. Help Menu.

The "About" item in the Help menu will display an informational dialog containing a brief description of the model, the current version number, and a link to a Web site with more information pertaining to the Stream Model. The About dialog is shown in Figure 48.

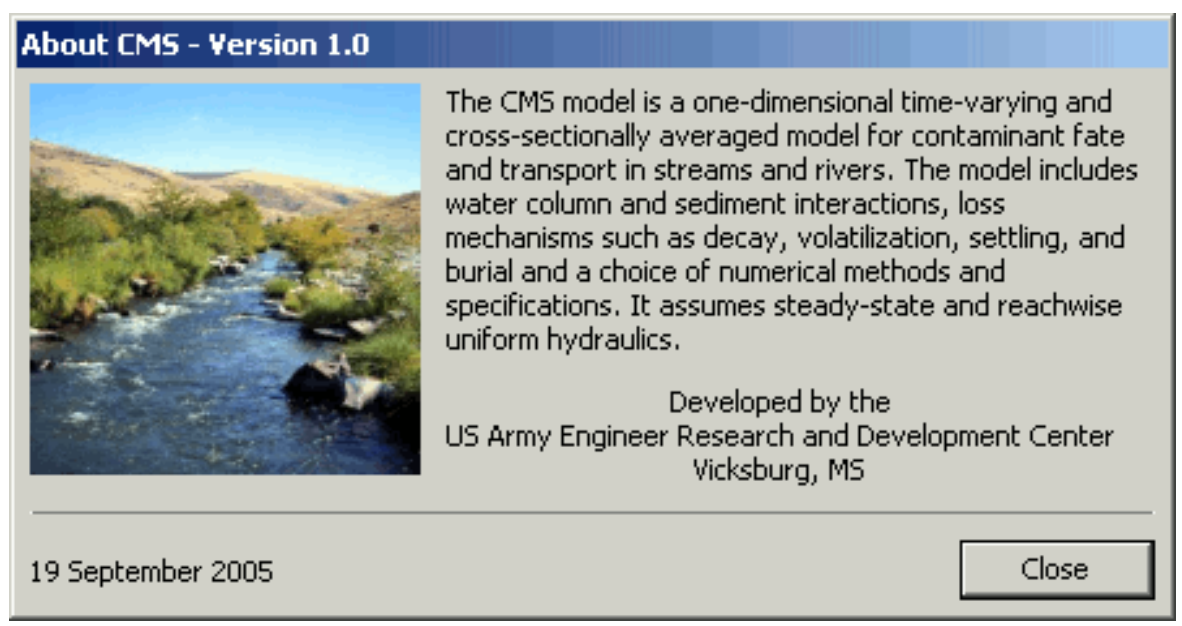

Figure 48. About Dialog. 


\section{References}

Ariathurai, R., R. MacArthur, and R. Krone, R. 1977. Mathematical model of estuarial sediment transport. TR D-77-12. Vicksburg, MS: U.S. Army Engineer Waterways Experiment Station.

Banks, R. B. 1975. Some features of wind action on shallow lakes. J. Environ. Engr. Div. ASCE 101(EE5):813-827.

Banks, R. B. and F. F. Herrera. 1977. Effect of wind and rain on surface reaeration. $J$. Environ. Engr. Div. ASCE 103(EE3):489-504.

Chapra, S. C. 1997. Surface water-quality modeling. New York, NY: McGraw-Hill, 194, 227-228.

Di Toro, D. M., D. J. O'Connor, R.V. Thomann, and J. P. John. 1981. Analysis of fate of chemicals in receiving waters. Phase 1. Washington, DC: Chem. Manufact. Assoc.

Dortch, M. S., and J.A. Gerald. 1995. Screening-level model for estimating pollutant removal by wetlands. Technical Report WRP-CP-9. Vicksburg, MS: U.S. Army Engineer Waterways Experiment Station.

Mills, W. B., et al. 1985. Water quality assessment: A screening procedure for toxic and conventional pollutants, Part I. EPA-600/-82-004a. Athens, GA: Tetra Tech, Inc., Env. Res. Lab., Office of Research and Devel., USEPA.

O'Connor, D. J., and W. E. Dobbins. 1958. Mechanism of reaeration in natural streams., Am. Sot. Civil Eng. Trans. 123: 641-684.

Ruiz, C. E., and T. Gerald. 2001. RECOVERY version 2.o, a mathematical model to predict the temporal response of surface water to contaminated sediments. ERDC/EL TR-01-3. Vicksburg, MS: U.S. Army Engineer Research and Development Center

Schink, D. R., and N. L. Guinasso. 1977. Modelling the influence of bioturbation and other processes on calcium carbonate dissolution at the sea floor. In The fate of fossil fuel Co2 in the oceans, .ed. N. R. Andersen and A. Malahoff, 375-399. New York: Plenum Press.

Wang, P. F., J. L. Martin, T. Wool, and M. S. Dortch (in preparation). CE-QUALICM/TOXI, A three-dimensional contaminant model for surface water: Model theory and user guide. Vicksburg, MS: U.S. Army Engineer Research and Development Center. 
Wool, T. A., R. B. Ambrose, R.B., J. L. Martin, and E. A. Comer. 2001. Water quality analysis simulation program (WASP) version 6.o. Draft user's manual. Atlanta, GA: U.S. Environmental Protection Agency, Region IV. http://www.epa.gov/region4/water/tmdl/tools/wasp.htm 


\section{Appendix A: Calculation of Volatilization Rate}

A modified version of the two-film theory (Chapra 1997) is used to calculate volatilization. Figure A-1 depicts the air-water interface and the two laminar films on either side of the interface.

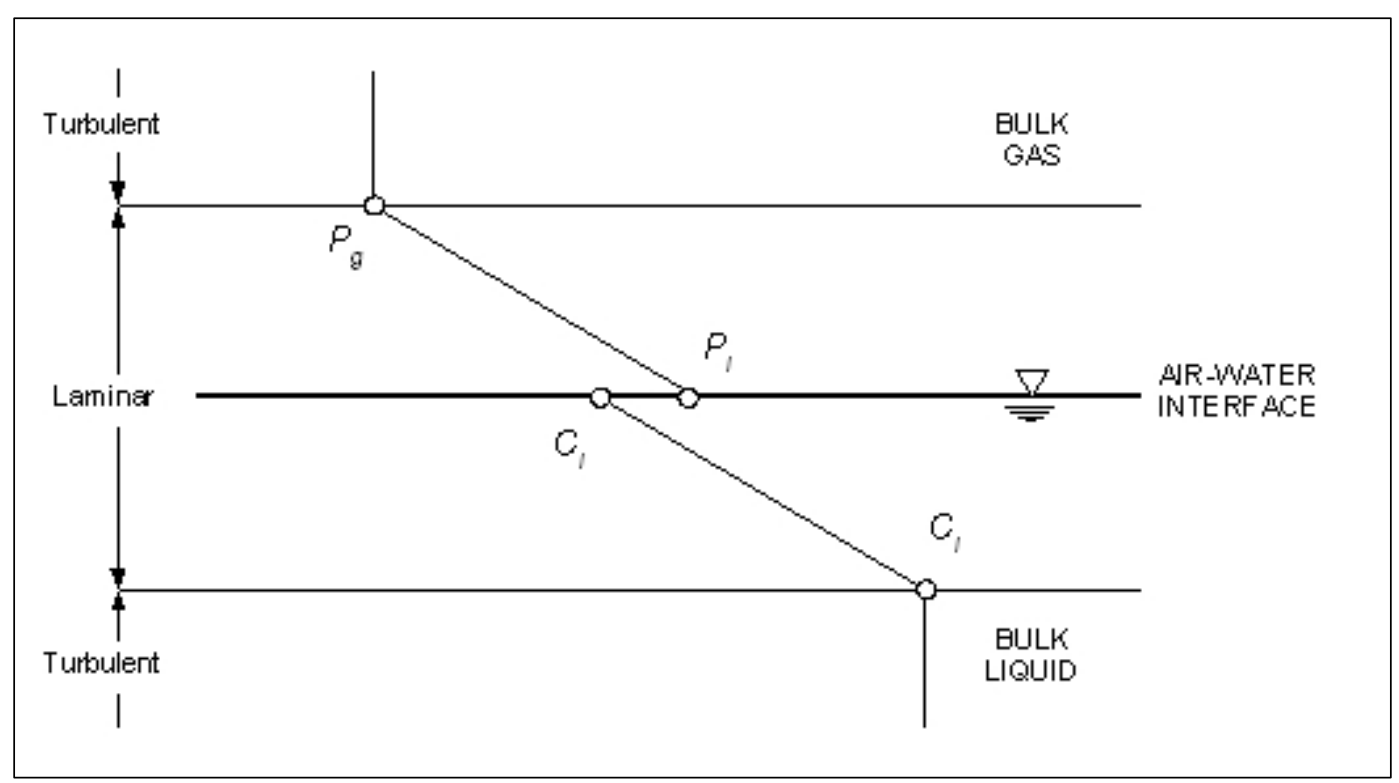

Figure A-1. Representation of Whitman's two-film theory of gas transfer.

The two-film theory implies that the two laminar layers act as a series of resistors for the transfer of gas between the liquid and air. The limiting factor for the transfer rate is the film with the highest resistance or, in turn, the lowest transfer velocity. The equation for the two-film theory is given in Equation A-1.

$$
\frac{1}{V_{v}}=\frac{1}{K_{l}}+\frac{R T_{a}}{H_{e} K_{g}}
$$

where

$V_{v}=$ net transfer velocity across the air-water interface, $\mathrm{m} /$ day

$K_{I}=$ bass transfer velocity in the liquid laminar layer, $\mathrm{m} /$ day

$R=$ ideal Gas constant, 8.206E-5 $\mathrm{m}^{3} \mathrm{~atm}(\mathrm{~mol} \mathrm{~K})^{-1}$

$T_{a}=$ absolute temperature, $\mathrm{K}$ 


$$
\begin{aligned}
& H_{e}=\text { Henry's law constant, atm } \mathrm{m}^{3} \mathrm{~mol}^{-1} \\
& K_{g}=\text { mass transfer velocity in the gaseous laminar layer, m/day. }
\end{aligned}
$$

The liquid mass transfer velocity is calculated using the following formula (Mills et al. 1985) that relates the mass transfer velocity of oxygen to the current constituent using the ratio of the molecular weights.

$$
K_{l}=K_{I, O_{2}}\left(\frac{32}{M}\right)^{0.25}
$$

where

$$
\begin{aligned}
K_{1, O_{2}}= & \text { mass transfer velocity of oxygen in the liquid laminar layer, } \\
& \mathrm{m} / \mathrm{s} \\
M= & \text { molecular weight of the constituent, } \mathrm{g} / \mathrm{mol} \text {. }
\end{aligned}
$$

The mass transfer velocity of oxygen is determined using two formulas; the first relates the transfer velocity to the wind speed above the surface of the water (Equation A-3) (Banks 1975, Banks and Herrera 1977), and the other relates the transfer velocity to the stream velocity (Equation A-4) (O’Connor and Dobbins 1958).

$$
\begin{gathered}
K_{l, O_{2}}=0.728 U_{w}^{0.5}-0.317 U_{w}+0.0372 U_{w}^{2} \\
K_{l, O_{2}}=3.95\left(\frac{U_{w}}{H}\right)^{0.5}
\end{gathered}
$$

where

$$
\begin{aligned}
U_{w} & =\text { wind speed at } 10 \mathrm{~m} \text { above the surface of the water, } \mathrm{m} / \mathrm{s} \\
H & =\text { depth of the stream, } \mathrm{m} .
\end{aligned}
$$

The largest value of the oxygen mass transfer velocity calculated with Equations A-3 and A-4 is then used in equation A-2 since this would represent the highest possible transfer rate. The gas mass transfer velocity is calculated using another formula from Mills et al. (1985), which is similar to Equation A-2 for the liquid transfer velocity. This equation relates the transfer velocity of the constituent in the gaseous phase to that of water vapor. 


$$
K_{g}=K_{g, H_{2} \mathrm{O}}\left(\frac{18}{M}\right)^{0.25}
$$

where

$$
\begin{aligned}
K_{g, H_{2} \mathrm{O}}= & \text { mass transfer velocity of water vapor in the gaseous laminar } \\
& \text { layer, } \mathrm{m} / \mathrm{s} .
\end{aligned}
$$

The mass transfer velocity for water vapor is determined as a function of wind speed using the following equation (Mills et al. 1985).

$$
K_{g, H_{2} \mathrm{O}}=168 U_{w}
$$

As can be seen from the equations above, there is no volatilization in the absence of wind with the two-film theory. However, this is not always the case for swift streams and highly volatile constituents. Therefore, the minimum value for the gas transfer coefficient, $\mathrm{K}_{\mathrm{g}}$, of $100 \mathrm{~m} /$ day will be set to prevent limiting the volatilization rate under these circumstances. This is also the approach used in both WASP (Wool et al. 2001) and ICM/TOXI (Wang et al. in press) for fast-moving streams. 


\section{Appendix B: Calculation of Mass Transfer Rate for Sediment-Water Interface}

It is assumed that the mass transfer across the sediment-water interface acts in a similar manner to the two-film model for volatilization calculations. A two-layer model does not exist for diffusion between the sediment pore water and the water column, but the transfer rate can be calculated based on the properties on each side of the boundary and will be limited by the lowest transfer velocity. The transfer rate can be limited by a low diffusion rate or flow rate in the water column or by a low diffusion rate in the sediments. To capture the influence of each of these factors, the mass transfer velocity will be calculated using formulations derived by Schink and Guinasso (1977) and Di Toro et al. (1981).

The formula given by Schink and Guinasso (1977) is shown below in Equation B-1 and provides a rate based on water column properties such as the molecular diffusivity of the constituent in water, the viscosity of the water, and the flow shear velocity along the bed.

$$
V_{d}=\frac{u_{*}\left(\frac{D_{m}}{v}\right)^{2 / 3}}{24}
$$

where

$$
\begin{aligned}
v_{d}= & \text { mass transfer velocity, } \mathrm{cm} / \text { day } \\
u_{*}= & \text { flow shear velocity along the bed, which is approximately } 10 \\
& \text { percent of the mean velocity of flow, m/s } \\
D_{m}= & \text { molecular diffusivity of dissolved chemical, } \mathrm{m}^{2} / \mathrm{s} \\
v= & \text { kinematic viscosity of water at temperature } T, \mathrm{~m}^{2} / \mathrm{s} .
\end{aligned}
$$

The kinematic viscosity of water can be calculated for a given temperature, $T$, using the following formula.

$$
v=\frac{1.79 \times 10^{-6}}{1.0+0.03368 T+0.000221 T^{2}}
$$


where

$$
T=\text { temperature, }{ }^{\circ} \mathrm{C} \text {. }
$$

In the equation given by Di Toro et al. (1981), the mass transfer is estimated as a function of the molecular weight of the constituent and the porosity of the bed sediments as shown in equation B-3 below.

$$
V_{d}=19 \phi(M)^{-\frac{2}{3}}
$$

where

$$
\begin{aligned}
V_{d} & =\text { mass transfer velocity, } \mathrm{cm} / \text { day } \\
\phi & =\text { porosity of the bed sediments } \\
M & =\text { molecular weight of the constituent, } \mathrm{g} / \mathrm{mol} .
\end{aligned}
$$

After calculation of the mass transfer velocity with each of these methods, the smaller of the two values will then be used for the mass transfer velocity since this will be the limiting rate. 


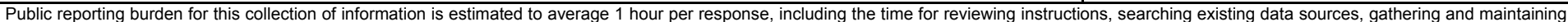

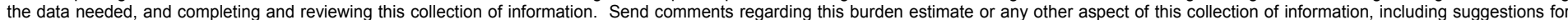

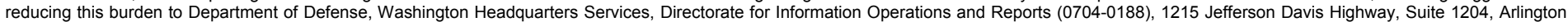

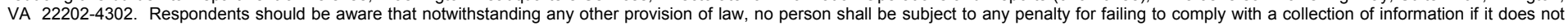
display a currently valid OMB control number. PLEASE DO NOT RETURN YOUR FORM TO THE ABOVE ADDRESS.

\begin{tabular}{l|l}
$\begin{array}{l}\text { 1. REPORT DATE (DD-MM-YYYY) } \\
\text { January } 2007\end{array}$ & $\begin{array}{c}\text { 2. REPORT TYPE } \\
\text { Final report }\end{array}$ \\
\hline
\end{tabular}

\section{TITLE AND SUBTITLE}

Documentation of a One-Dimensional, Time Varying Contaminant Transport and Fate Model for Streams

3. DATES COVERED (From - To)

5a. CONTRACT NUMBER

5b. GRANT NUMBER

5c. PROGRAM ELEMENT NUMBER

5d. PROJECT NUMBER

5e. TASK NUMBER

5f. WORK UNIT NUMBER

8. PERFORMING ORGANIZATION REPORT NUMBER

ERDC/EL TR-07-1

SpecPro, Inc.

122 Apache Court, Clinton, MS 39056-3149;

U.S. Army Engineer Research and Development Center

Environmental Laboratory

3909 Halls Ferry Road, Vicksburg, MS 39180-6199

9. SPONSORING / MONITORING AGENCY NAME(S) AND ADDRESS(ES)

U.S. Army Corps of Engineers

Washington, DC 20314-1000

10. SPONSOR/MONITOR'S ACRONYM(S)

11. SPONSOR/MONITOR'S REPORT NUMBER(S)

\section{DISTRIBUTION / AVAILABILITY STATEMENT}

Approved for public release; distribution is unlimited.

\section{SUPPLEMENTARY NOTES}

\section{ABSTRACT}

The Contaminant Model for Streams (CMS) was developed for studies where data and resources for model application are limited. CMS can be relatively easily and quickly applied, yet it is a versatile model that can be used for a variety of conditions ranging from short-term spill modeling to multi-year simulations of contaminant fate in stream water and bottom sediments. CMS was developed to fill a gap in the Adaptive Risk Assessment Modeling System (ARAMS). Before the addition of CMS, ARAMS did not have a one-dimensional contaminant transport and fate model for streams that could simulate interactions between the water column and sediment bed.

CMS was developed such that it can be applied within the ARAMS framework and also can be run as a stand-alone application outside of ARAMS. The model can be used to simulate a wide range of conditions from spill simulations with time steps in seconds to long-term simulations with time steps of about a year. A variable time step is used with user options. It can be applied for both organic and inorganic contaminants, and the available fate and transport processes include advection and diffusion along the stream reach, settling, resuspension, burial, volatilization, decay or degradation, and diffusion between the water column and the sediment pore water. Suspended solids can be transported or a steady-state concentration may be input.

(Continued)

\section{SUBJECT TERMS}

Contaminant concentration

Long-term fate

16. SECURITY CLASSIFICATION OF:

\section{a. REPORT}

UNCLASSIFIED

b. ABSTRACT
UNCLASSIFIED

Numerical model Sediment bed c. THIS PAGE UNCLASSIFIED
Water column User interface

\begin{tabular}{|c|c|l|}
$\begin{array}{l}\text { 17. LIMITATION } \\
\text { OF ABSTRACT }\end{array}$ & $\begin{array}{l}\text { 18. NUMBER } \\
\text { OF PAGES }\end{array}$ & $\begin{array}{l}\text { 19a. NAME OF RESPONSIBLE } \\
\text { PERSON }\end{array}$ \\
\cline { 3 - 3 } & 82 & $\begin{array}{l}\text { 19b. TELEPHONE NUMBER (include } \\
\text { area code) }\end{array}$ \\
& &
\end{tabular}




\section{4. (Concluded)}

However, the ARAMS version does not currently include solids transport. Steady-state, uniform hydraulic conditions are assumed within the modeled reach. Time-varying upstream loadings and flows can be applied, but flows are updated instantaneously throughout the reach, i.e., there is no hydraulic routing feature, thus greatly reducing model complexity.

The model user interface provides an easy-to-use method for quickly setting up the model and examining results. The interface also allows the user to select the methods and parameters used for the numerical solutions. The solution methods were selected to result in very short computer execution time for most applications. The model was verified against results from two other models developed by ERDC, RECOVERY, and PREWet, the latter of which uses an analytical solution method. This report describes the model and its verification. 